UNIVERSIDADE DE BRASÍLIA

FACULDADE DE EDUCAÇÃO FÍSICA

PROGRAMA DE PÓS-GRADUAÇÃO STRICTO SENSU EM EDUCAÇÃO FÍSICA

\title{
EFEITOS DO TREINAMENTO RESISTIDO COM MÁQUINAS PNEUMÁTICAS E RESISTÊNCIA ELÁSTICA PROGRESSIVA NA FORÇA, CAPACIDADE FUNCIONAL E EQUILÍBRIO EM MULHERES IDOSAS: UM ENSAIO CLÍNICO RANDOMIZADO.
}

KARINA FERREIRA LAGÔA GONÇALVES

BRASÍLIA

2015 


\section{EFEITOS DO TREINAMENTO RESISTIDO COM MÁQUINAS PNEUMÁTICAS E RESISTÊNCIA ELÁSTICA PROGRESSIVA NA FORÇA, CAPACIDADE FUNCIONAL E EQUILÍBRIO EM MULHERES IDOSAS: UM ENSAIO CLÍNICO RANDOMIZADO.}

KARINA FERREIRA LAGÔA GONÇALVES

Dissertação apresentada ao Programa de Mestrado em Educação Física da Universidade de Brasília como requisito para obtenção do grau de Mestre em Educação Física. 


\section{AGRADECIMENTOS}

"No essencial, unidade; no não essencial, flexibilidade; em todas as coisas, o amor." (John Stott).

É chegado o momento em que olho para trás e lembro de todos os passos para chegar até aqui. Impossível não ser grata e partilhar essa explosão de sentimentos. Primeiramente, agradeço a Deus pelo dom da vida, sem Ele nada é possível! Ao longo desses dois anos pude ver o Seu cuidado e sustento nas mais simples situações. Tenho desenvolvido um amor e zelo pelo próximo que é regado em meu coração por meio de muita graça e isso vem do Eterno.

Nesses dois desafiadores anos pude contar com diversas pessoas para que chegasse ao fim com a sensação de dever cumprido. Charles Spurgeon certa vez citou a seguinte frase: "Muitos homens ficam de mãos vazias porque não conhecem a arte de repartir”. Numa esfera ampla é hora de repartir e reconhecer que essa conquista que não ocorreu de forma isolada.

À minha família, que compreendeu os momentos em que me ausentei das confraternizações devido as demandas que o mestrado requer, em especial minha mãe que ao longo da minha vida SEMPRE apoiou minhas decisões nos assuntos relacionados a educação. Seu incentivo e carinho sempre foram combustíveis para me tornar uma pessoa melhor.

Ao meu amado esposo Asafe Silva Gonçalves que tem sido um grande companheiro, amigo, confidente e nesses anos de caminhada tem sido meu suporte e fortaleza. Você me anima e me coloca pra cima quando estou esgotada, sempre paciente, compreensivo e amoroso. Obrigada por ser exemplo de perseverança, humildade e por acreditar em mim. O aprendizado ao seu lado é diário.

Agradeço a minha orientadora Dra. Marisete Peralta Safons por confiar e acreditar nesse projeto. Obrigada pelos ensinamentos e o know how do que realmente funciona ou não numa logística em pesquisa com idosos. Agradeço também ao Grupo de Estudo e Pesquisas sobre Atividade Física para Idosos (GEPAFI) e seus integrantes, além de competência com certeza um pré-requisito é a simpatia, injusto seria citar nomes e esquecer de alguém. 
Um agradecimento a um grande amigo e mentor Wagner Rodrigues Martins que desde a época da graduação tem me incentivado a adentrar no mundo científico. Sem dúvida alguma sou uma profissional melhor pelas suas contribuições e direcionamento.

Aos professores e coordenadores dos laboratórios da FCE por possibilitarem que essa pesquisa fosse concluída com êxito nesses locais. À professora Clarissa Cardoso que nos "47 minutos do $2^{\circ}$ tempo" pacientemente contribuiu com seus conhecimentos e confiou em nossa equipe.

Por falar em equipe, que EQUIPE, juntos fizemos isso acontecer. Olho para trás e lembro da fase de recrutamento e o quanto andamos pela Ceilândia. Dividimos medos quando um terreno incerto da possibilidade de realização dessa pesquisa estava debaixo dos nossos pés. Gerson e Milene, formamos um trio que mesmo com tantas diferenças entre si, porém, com um objetivo em comum, realizou um grande projeto. Não foi fácil! Tito, Anderson e More obrigada pela dedicação e maturidade. Sem vocês a equipe "Sangue nos zói” não estaria completa. Aos demais alunos da educação física e fisioterapia que passaram pelo projeto o meu desejo é que a experiência, mesmo que curta, possa de alguma forma ter contribuído para a formação de cada um.

Aos idosos que se voluntariaram e participaram dessa pesquisa, meus sinceros agradescimentos. Obrigada pelo carinho, pelos beijos e abraços, os mimos, cafés da manhã, quitutes, lições de vida e o aprendizado com a experiência que cada um carrega. Meu desejo é que possamos ter contribuído não somente para a saúde mas também para a história de vida de cada um.

"Você nunca é velho demais para definir outro objetivo ou sonhar um novo sonho." (Clive Staples Lewis) 


\section{SUMÁRIO}

LISTA DE ABREVIAÇÕES........................................................ VII

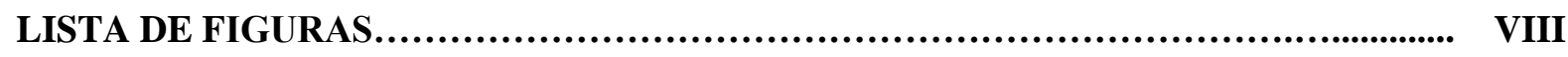

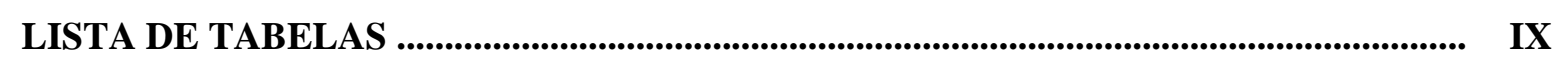

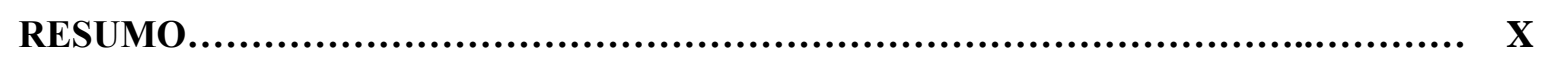

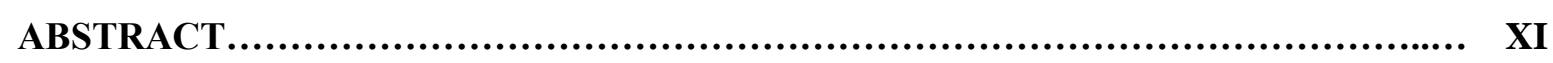

1. INTRODUÇÃ̃

2. OBJETIVOS................................................................... 16

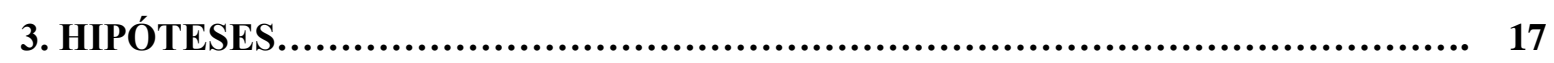

4. REVISÃO DE LITERATURA.................................................. 18

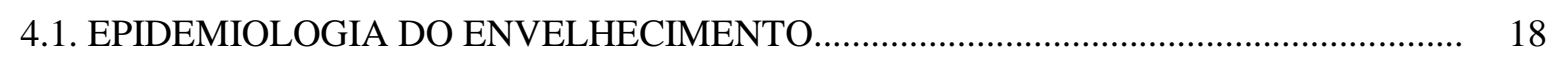

4.2. ALTERAÇÕES MORFOFISIOLÓGICAS NO ENVELHECIMENTO............................... 20

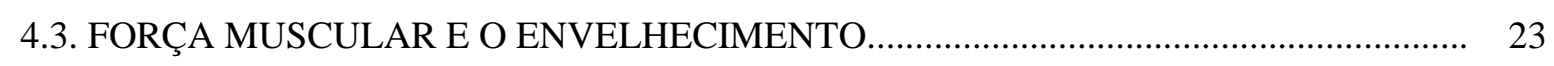

4.4. CAPACIDADE FUNCIONAL, EQUILÍBRIO E O ENVELHECIMENTO......................... 25

4.5. TREINAMENTO RESISTIDO NO ENVELHECIMENTO............................................... 27

4.6. RESISTÊNCIA ELÁSTICA E MÁQUINAS PNEUMÁTICAS......................... 28

5. MATERIAIS E MÉTODOS............................................................ 30

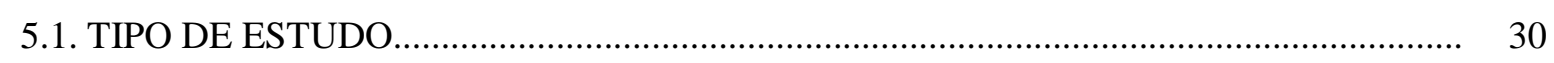

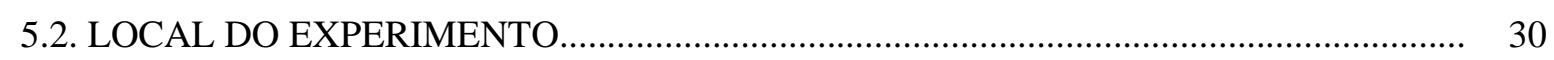

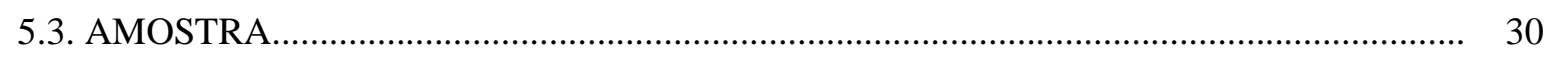

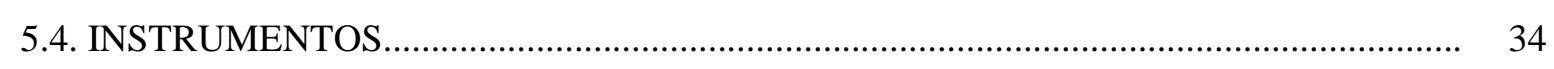

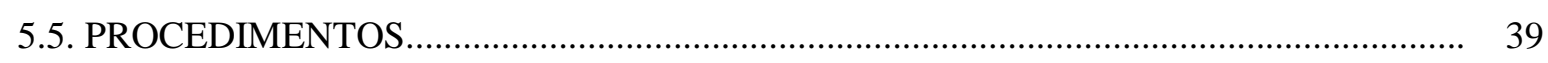

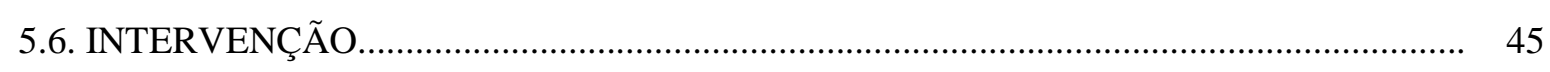

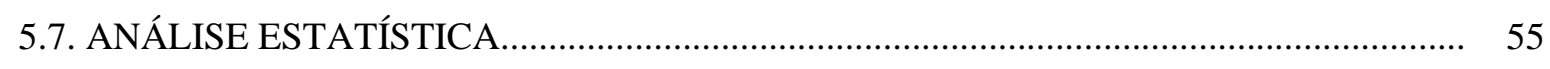

6. RESULTADOS................................................................... 56

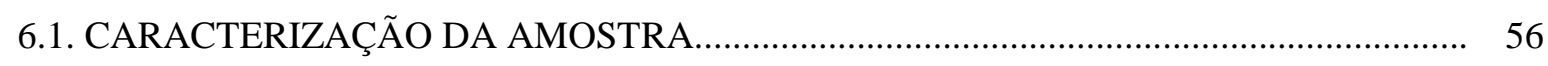

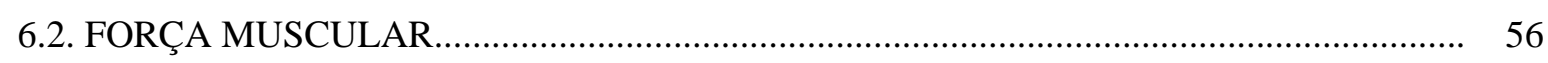

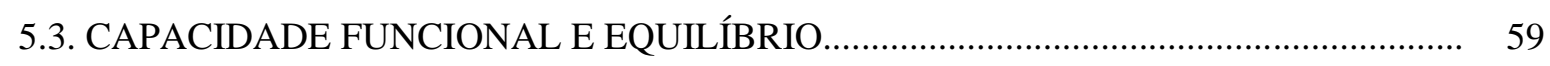

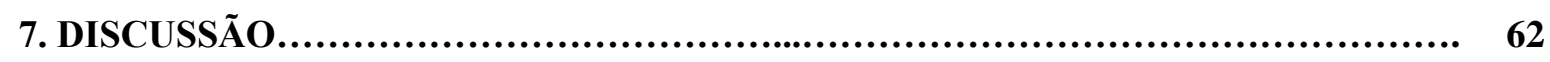

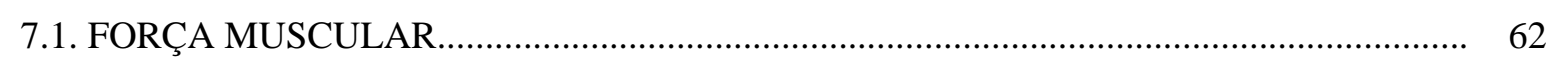

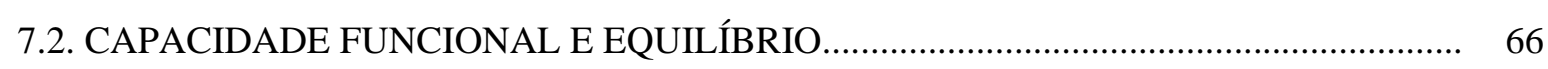

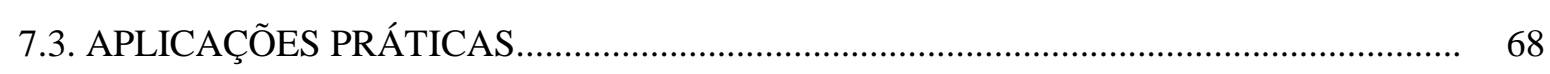

8. CONCLUSÃO .................................................................... 69 
9. REFERÊNCIAS BIBLIOGRÁFICAS

10. ANEXOS E APÊNDICES . 


\section{LISTA DE ABREVIAÇÕES}

ACSM $=$ American College of Sports and Medicine

AHA $=$ American Heart Association

$\mathrm{AVD}=$ Atividades de vida diária

CODEPLAN = Companhia de Planejamento do Distrito Federal

DEXA = Absortometria de Raio- $\mathrm{x}$ de Dupla Energia

EWGSOP $=$ European Working Group on Sarcopenia in Older People

$\mathrm{FCE}=$ Faculdade da Ceilândia

FEF = Faculdade de Educação Física

FPP = Força de Preensão Palmar

GTM = Grupo de Treinamento Máquina

GTRE $=$ Grupo de Treinamento Resistência Elástica

IBGE = Instituto Brasileiro de Geografia e Estatística

MP = Máquinas Pneumáticas

OMS = Organização Mundial da Saúde

PT = Pico de Torque

$\mathrm{RE}=$ Resistência Elástica

REP $=$ Resistência Elástica Progressiva

$\mathrm{RM}=$ Repetições Máximas

TAF $=$ Teste de Alcance Funcional

TAFI $=$ Teste de Aptidão Física para Idosos

TCLE $=$ Termo de Consentimento Livre e Esclarecido

TFC $=$ Teste de Flexão de cotovelo

$\mathrm{TR}=$ Treinamento Resistido

TRP $=$ Treinamento Resistido Progressivo

$\mathrm{TSL}=$ Teste de sentar e levantar

UnB = Universidade de Brasília

$\mathrm{WHO}=$ World Health Association 


\section{LISTA DE FIGURAS}

Figura 1. Projeção do número total da população

Figura 2 - Projeção pirâmide etária da população brasileira .............................................................. 19

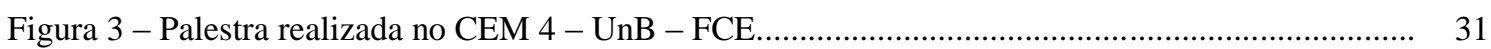

Figura 4 - Fluxo dos indivíduos ao longo da pesquisa............................................................... 33

Figura 5 - Máquina pneumática para exercícios de MMII............................................................... 36

Figura 6 - Máquina pneumática para exercícios de MMSS........................................................ 37

Figura 7 - Sete níveis de resistência elástica e acessórios para fixação........................................... 38

Figura 8 - Acessórios exercitadores para resistência elástica ........................................................... 38

Figura 9 - Acessório e-loop para exercício de deslocamento lateral................................................ 38

Figura 10 - Coeficiente de correlação de Pearson (r) e valor de p .................................................... 39

Figura 11 - Avaliação de PT isocinético para flexão e extensão de joelhos........................................ 41

Figura 12 - Avaliação de PT isocinético para flexão/extensão de cotovelo........................................ 41

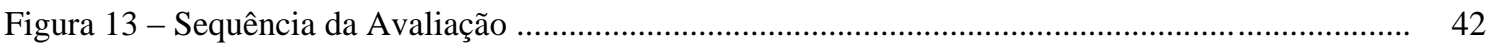

Figura 14 - Teste de Força de Preensão Palmar...........................................................................

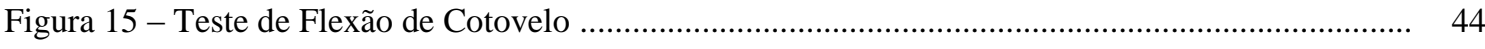

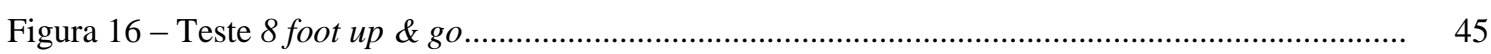

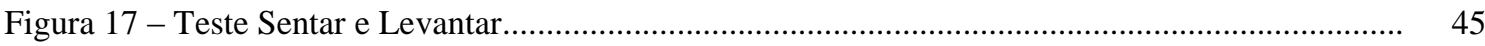

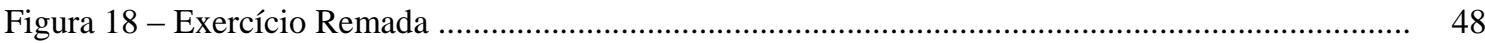

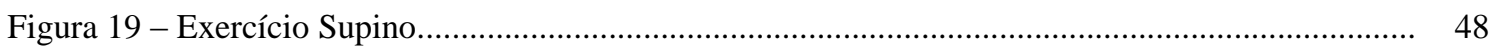

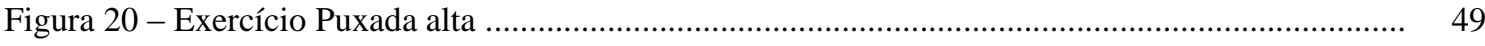

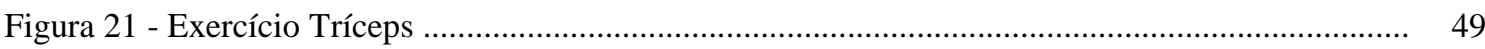

Figura 22 - Exercício Flexão de Joelhos............................................................................. 50

Figura 23 - Exercício Extensão de Joelhos............................................................................ 50

Figura 24 - Exercício Abdução de quadril................................................................................. 51

Figura 25 - Exercício Extensão de quadril............................................................................. 51

Figura 26 - Exercício Deslocamento RE e Abdução de quadril MP............................................... 52

Figura 27 - Sete níveis de intensidade de acordo com cores e corte padronizado do material............... 53

Figura 28 - Display de carga das máquinas pneumáticas........................................................... 54

Figura 29 - Fluxograma dos procedimentos de treinamento resistido............................................... 54

Figura 30 - Comparação PT isocinético para extensão de joelho................................................... 55

Figura 31 - Comparação PT isocinético para flexão de cotovelo.................................................... 55

Figura 32 - Comparação da Força de Preensão palmar.................................................................. 56

Figura 33 - Comparação do Teste Flexão de Cotovelo................................................................. 57

Figura 34 - Comparação do Teste de Sentar e Levantar................................................................... 58

Figura 35 - Comparação do 8-foot up \& go.................................................................................... 58

Figura 36 - Comparação do Teste de Alcance Funcional............................................................. 58 


\section{LISTA DE TABELAS}

Tabela 1 - Valores de força e alongamento em cada níveis de resistência elástica.

Tabela 2 - Exercícios realizados durante o período de treinamento no GTM e GTRE.

Tabela 3 - Divisão dos meso ciclos de treinamento, duração, número de séries e repetições, intervalo de recuperação, ordem de exercício e carga utilizada ao longo de 12 semanas de treinamento.

Tabela 4 - Descrição da amostra por grupos..................................................................................... 56

Tabela 5 - Valores de base para PT de flexores de cotovelo e extensores de joelhos........................ 57

Tabela 6 - Comparação entre as variáveis de força nos momentos pré e pós.................................... 57

Tabela 7 - Valores de base para capacidades funcionais e equilíbrio no momento PRÉ...................... 59

Tabela 8 - Comparação entre as variáveis de capacidade funcional e equilíbrio (Pré e Pós)................ 60 


\section{RESUMO}

INTRODUÇÃO: O envelhecimento populacional é um processo que acarreta diversas mudanças fisiológicas no indivíduo. Um dos principais problemas associados com o avanço da idade é a perda ou a diminuição da força que por sua vez está relacionada com a diminuição da capacidade funcional e independência. Uma das maneiras de intervir nesse processo é por meio do treinamento resistido (TR). O TR pode ser feito utilizando diversos tipos de materiais incluindo entre eles a resistência elástica progressiva (REP) e máquinas pneumáticas (MP). OBJETIVO:O objetivo desse estudo foi verificar e comparar os efeitos de 12 semanas de dois diferentes tipos de TR (MP e REP), na força muscular, equilíbrio e capacidade funcional de mulheres idosas. MÉTODOS: 54 mulheres foram alocadas randomicamente em dois grupos de 27 individuos cada: O Grupo de Treinamento Resistência Elástica (GTRE; $\mathrm{n}=27$; idade $=67.55 \pm 5.20$ anos) e o Grupo Treinamento Máquina $($ GTM; $\mathrm{n}=27$; idade $=$ $69.34 \pm 5.37$ anos). O GTRE $(67.55 \pm 5.20)$ e GTM $(69.34 \pm 5.37)$ participaram do treino duas vezes por semana durante 12 semanas com 9 exercícios para ambos os grupos. O pico de torque(PT) isocinético para extensores de joelhos(PTEJ) e flexores de cotovelo(PTFC) nas velocidades de $60 \%$ $180 \%$, a força de preensão manual(FPP), o teste de sentar e levantar(TSL), o teste de flexão de cotovelo(TFC), o 8-foot up \& go e o teste de alcance funcional(TAF) foram as variáveis dependentes medidas nos momentos pré e pós da intervenção. Todas as avaliações foram realizadas PRÉ e PÓS o período de intervenção. Para análise estatística descritiva verificou-se a normalidade dos dados através do teste de Shapiro-Wilk. Para comparar as variáveis dependentes entre os grupos e entre os momentos pré e pós-intervenção a análise de variância mista $2 \mathrm{X} 2$, testes t pareado e independente, Wilcoxon e U-Mann-Whitney foram aplicados. Os cálculos foram realizados no programa SPSS, para um índice de significância de $p \leq 0,05$. RESULTADOS: Os dois tipos de treinamento promoveram aumento estatisticamente significativo $(\mathrm{p}<0.001)$ para as variáveis dependentes de PTEJ60 \% PTEJ $180 \%$, PTFC60 \% , TFC, TSL e 8 foot up\&go em ambos os grupos. Para o TAF e FPP nos dois grupos e no PT isocinético para flexores de cotovelo na velocidade angular de 180 \% no GTRE não foram observadas diferenças estatisticamente significativas. CONCLUSÃO: Com base nos resultados apresentados, conclui-se que o TR com MP ou REP duas vezes por semana, durante doze semanas, resultam em melhorias na força e capacidade funcional de mulheres idosas.

Palavras-Chaves: Envelhecimento, Treinamento Resistido, Força Muscular, Capacidade Funcional e Equilíbrio. 


\begin{abstract}
INTRODUCTION: Natural population aging is a process that brings about several physiological transformations in an individual. One of the main issues associated with the advance in age is the loss or lowering in strength that, at the same time, is related to the diminishing in the labouring capacity and independence. One of the manners to intervene in that process the resistive training (RT). RT can be made by using several types of materials, including, among others, the elastic progressive resistance (EPR) and pneumatic machines (PM). OBJECTIVE: The purpose of this study was to verify and compare the the effects of 12-week of two different types of RT (PD and EPR), in muscle strength, balance and functional capacity of untrained elderly women. METHODS: 54 women were randomly allocated in 2 groups of 27 individuals each: The Elastic Resistance Training Group (ERTG; n=27; age $=67.55+5.20$ years $)$ and the Machine Training Group $(M T G ; n=27 ;$ age $=69.34+5.37$ years $)$. The ERTG and the MTG participated on the training twice a week during 12 weeks with nine exercises for both groups. The isokinetic Peak Torque (PT) for knee extensors(PTKE) and elbow flexors(PTEF) at the speed of $60 \%$ and $180 \%$, Handgrip Strength (HS), the 30' chair sit to stand(CST), the 30 arm curl test(ACT), the 8-foot up \& go agility test and the Functional Reach Test(FRT) were the dependent variable measures in the moments of pre and post intervention. All evaluations were performed before and after the intervention period. We used descriptive statistics and verified the data normality by the Shapiro-Wilk test. To compare the dependent variables between groups and between pre- and post-intervention a mixed model $2 X 2$ of analysis of variance (ANOVA) and paired t tests and independent, Wilcoxon and U-Mann-Whitney was used. The calculations were performed using SPSS for a $p \leq 0,05$ significance index RESULTS: Both types of training promoted statistically significant increase $(p<0.001)$ for PTKE at $180 \%$ and $60 \%$; PTEF at $60 \%$, CST, ACT and 8 foot up\&go test in both groups. For the FRT and the HS in both groups and the isokinetic PT to elbow flexor in angular speed of $180 \%$ on ERTG no difference statistically significant was found. CONCLUSION: Based on the presented results, it is concluded that the RT with PM or EPR twice a week, for twelve weeks, result in improvements in strength and functional capacity in elderly women.
\end{abstract}

Key words: Aging, Resistance Training, Muscular Strength, Functional Capability and balance. 


\section{INTRODUÇÃO}

O envelhecimento populacional é o principal fenômeno demográfico ocorrido no século XX e o presente século testemunhará de forma acelerada esse fenômeno. Considerado como um desafio para a sociedade, ele é um processo dinâmico que ocorre em larga escala tanto no Brasil quanto no mundo. Diversas frentes de trabalho e pesquisa têm como objetivo garantir que o idoso envelheça de forma digna e segura, além de mantê-lo ativo na sociedade e assegurado quanto aos seus direitos como cidadãos. Por isso, o indivíduo idoso não deve ser observado apenas em seus aspectos biológicos, todavia, deve também ser compreendido em suas esferas psicológicas, ideológicas, sociais e políticas (Closs e Schwanke, 2012; Who, 2012).

Embora o envelhecimento seja um processo complexo e associado a diversas mudanças fisiológicas, neuromusculares e morfológicas, ele não deve ser marcado apenas por doenças e pelos efeitos deletérios que ocorrem com o passar dos anos. Ações que promovam a saúde nesse processo são importantes para que os idosos desempenhem tarefas cotidianas de maneira autônoma e seja apresentado à sociedade como um indivíduo ativo (Garcia, 2002; Spirduso, 2005; Farinatti, 2008).

Uma importante alteração fisiológica no envelhecimento é a diminuição de massa muscular, ou sarcopenia, que apesar de não existir um consenso internacionalmente aceito, é um termo que define, em geral, um processo degenerativo que reduz massa muscular, força e capacidade funcional em idosos. O processo de declínio de massa muscular e força implicam em um aumento de risco de quedas e consequentemente incapacidades funcionais, diminuição das atividades de vida diárias (AVD), redução da qualidade de vida e até mesmo morte (Christmas e Andersen, 2000; Cruz-Jentoft, Baeyens Jp Fau - Bauer et al., 2010; Rosenberg, 2011; Scott, Blizzard et al., 2011).

A perda de massa magra pode estar intimamente ligada com o tipo e a frequência de atividade física. Foram demonstrados que treinamentos resistidos (TR) em intensidades moderadas e altas podem evitar cerca de $25 \%$ da perda de massa magra ao longo do processo de envelhecimento. Esse fato contribui para que intervenções visando a manutenção e prevenção desse acontecimento sejam implementadas e promovam a saúde no idoso (Frontera e Bigard, 2002; Holviala, Sallinen et al., 2006; Rolland, Czerwinski et al., 2008). 
Na literatura, é descrito também que após a quinta década de vida, observa-se um declínio de $1 \%$ a 1,5\% ao ano na força muscular em indivíduos saudáveis e após os 65 anos de idade, esse decréscimo chega a 3\% ao ano (Larsson, Grimby et al., 1979; Macaluso e De Vito, 2004; Von Haehling, Morley et al., 2010). Há indícios de que antes mesmo da perda de força muscular ocorra uma diminuição da potência muscular e a mesma está relacionada com a habilidade de gerar força rapidamente, contribuindo assim, para realização das AVDs. Outros autores afirmam que este fator contribui diretamente para a diminuição da mobilidade e das capacidades funcionais (Lanza, Towse et al., 2003; Hruda, 2006; Raj, Bird et al., 2010).

De acordo com Skelton (1994), a funcionalidade é determinada pela capacidade de realizar as atividades de vida diária (AVD) de maneira independente. Estas capacidades também são reduzidas com o avanço da idade e podem ser modificadas com o TR quando feitos de forma frequente e sistematizada. Revisões sobre o tema têm relatado a eficácia dos exercícios resistidos na melhora de variáveis como força, potência, massa muscular, capacidade funcional e composição corporal de idosos devendo os mesmos serem adotados como práticas comuns para diminuir os efeitos deletérios dos processo de envelhecimento (Matsudo, Matsudo et al., 2001; Frontera e Bigard, 2002; Barnett, Smith et al., 2003; Camara, Gerez et al., 2008; Liu e Latham, 2009; Steib, Schoene et al., 2010; Peterson, Sen et al., 2011).

Embora largamente difundido entre jovens e adultos, o TR com o uso de equipamentos tradicionais de musculação e os ambientes para tais práticas são na maioria das vezes pouco frequentados pela população de idosos. Além disso, o custo inicial para montar e equipar um local para a prática com máquinas tradicionais é elevado e demanda grandes espaços. Outra característica é o abandono do programa de treinamento no primeiro ano. Essas questões são relevantes, pois, faz com que novas estratégias sejam necessárias para que esse público possa aderir a essa prática de treinamento e possam ser beneficiados por ela.

O TR para idosos são recomendados com o objetivo de prevenir e melhorar a perda da funcionalidade decorrente da diminuição da massa e força muscular ao longo dos anos, além de, promover uma manutenção da saúde motora e consequente melhora na qualidade de vida. Essa modalidade tem sido descrita por revisões e consensos como uma das maneiras mais efetivas e populares para os ganhos de força, potência, resistência e hipertrofia. A sobrecarga externa do treinamento pode ser feita por meio de aparelhos de musculação, pesos livres(halteres e anilhas),molas, máquinas de resistência pneumáticas e resistência elástica 
(Frontera e Bigard, 2002; Kraemer, Adams et al., 2002; Bottaro, Machado et al., 2007; Chodzko-Zajko, Proctor et al., 2009; Granacher, Gruber et al., 2009).

Existem vários modos de resistência para que adaptações musculares sejam induzidas com o TR e dentre eles destacam-se: resistência externa constante, resistência externa acomodativa/confortável e resistência variável. A primeira é definida como carga externa que não muda durante toda a amplitude do movimento e é a forma mais popular. $\mathrm{O}$ segundo modo, acomodativo, é realizado com equipamentos que proporcionem velocidades controladas em todo o arco de movimento, ou seja, com uma resistência isocinética ao longo da execussão do exercício. Equipamentos com resistência variável são aqueles que a resistência externa varia de acordo com a aplitude de movimento, são eles realizados com faixas ou tubos elásticos, correntes e molas. Existe ainda uma outra maneira de oferecer resistência que não é totalmente definida e que corresponte tanto à resistência de acomodação quanto à resistência variável e é definida como resistência fluídica promovida por equipamentos hidráulicos ou pneumáticos (Harman, 1994; Stone, Plisk et al., 2002; Mcmaster, Cronin et al.).

Máquinas pneumáticas oferecem cargas semelhantes àquelas ofertadas por bandas elásticas pelo fato de não dependerem de um objeto com massa para gerar carga, pois, esses equipamentos fornecem carga pelo uso de ar. Como resultado, cargas pneumáticas exibem uma menor variação na força muscular exigida para que um exercício seja finalizado. Pelo fato de cargas pneumáticas utilizar menor massa, menos força será requerida para produzir maiores velocidades, ou seja, uma determinada força produzirá maiores forças e acelerações e isso representa um importante fator em treinamentos de potência ou de gestos esportivos. Alguns autores tem optado por esse tipo de dispositivo para trabalhos com idosos, uma vez que, esse tipo de equipamento permite uma menor variação na força necessária para completar um exercício e isso reduz inclusive o rico de lesão daqueles que utilizam esse tipo de dispositivos para o TR. Uma disvantagem para o uso desse tipo de equipamento é o alto custo das máquinas, dificultando à acessibilidade ao TR com o uso de resistência pneumática(Jozsi, Campbell et al., 1999; Fielding, Lebrasseur et al., 2002; Paulus, Reiser et al., 2004; De Vos, Singh et al., 2005; Orr, De Vos et al., 2006; Frost, Cronin et al., 2010).

Por outro lado, equipamentos de resistência elástica tem conquistado espaço no que tange a prescrição de treinamento resistido para jovens, adultos, atletas e idosos e além de possuirem um baixo custo, permitem a possibilidade de trabalhar com padrões de movimentos 
mais funcionais que as máquinas de musculação tradicionais. Esse tipo de material promove resistência variável, ou seja, sua resistência varia de acordo com a amplitude de movimento ao longo do exercício, essa é uma importante característica da resistência elástica, pois, a carga máxima é obtida ao final do movimento. Os dispositivos elásticos são portáteis e permitem o uso em diversos ambientes além de apresentar custo menor que outros equipamentos facilitando o acesso aos mesmos que podem ser encontrados na forma de tubos ou faixas elásticas (Hostler, Schwirian et al., 2001; Sakanoue e Katayama, 2007; Colado, Garcia-Masso et al., 2010; Wilson e Kritz, 2014).

Embora o TR seja recomendado por organizações mundiais como American College of Sports and Medicine (ACSM), American Heart Association (AHA), World Health Organization (WHO) e estejam bem estabelecidos, ainda há uma lacuna na literatura no que diz respeito à comparação de utilização de máquinas pneumáticas(MP) e resistência elástica progressiva(REP) como forma de TR. 


\section{OBJETIVOS}

\subsection{GERAL}

Verificar e comparar os efeitos de 12 semanas de dois diferentes tipos de treinamento resistido (Máquinas Pneumáticas e Resistência Elástica Progressiva) sobre a força muscular, o equilíbrio e as capacidades funcionais de mulheres idosas.

\subsection{ESPECÍFICOS}

1) Verificar os efeitos de 12 semanas de TR com máquinas pneumáticas(MP) e treinamento com resistência elástica progressiva(RPE) sobre a força de preensão manual em mulheres idosas;

2) Verificar os efeitos de 12 semanas de TR com máquinas pneumáticas(MP) e treinamento com resistência elástica progressiva(RPE) no pico de torque (PT) isocinético para extensores de joelhoes e flexores de cotovelo nas velocidades angulares de $60^{\circ} / \mathrm{s}$ e $180^{\circ} \% \mathrm{~s}$ em mulheres idosas;

3) Verificar os efeitos de 12 semanas de TR com máquinas pneumáticas(MP) e treinamento com resistência elástica progressiva(RPE) sobre as capacidades funcionais e equilíbrio dinâmico em mulheres idosas destreinadas por meio dos testes de sentar e levantar 30',(TSL), flexão de cotovelo 30',(TFC); 8 Foot Up and Go e teste de alcance funcional (TAF) em mulheres idosas destreinadas;

4) Comparar os efeitos de 12 semanas de TR entre o GTRE e GTM na força, capacidade funcional e equilíbrio em mulheres idosas. 


\section{HIPÓTESES}

$\mathrm{H}_{1}$ : Haverá diferença estatisticamente significativa na força, capacidade funcional e equilíbrio intra-grupo após o TR.

$\mathrm{H}_{2}$ : Não haverá diferença estatisticamente significativa na força, capacidade funcional e equilíbrio inter-grupo após o TR. 


\section{REVISÃO DA LITERATURA}

\subsection{EPIDEMIOLOGIA DO ENVELHECIMENTO}

O processo de envelhecimento é uma realidade tanto na população mundial quanto na nacional e de acordo com dados da Organização Mundial de Saúde (OMS) é esperado que entre 2000 e 2050 o número de pessoas acima de 60 anos passe de 605 milhões para 2 bilhões de pessoas idosas. Nesse mesmo período, a taxa de idosos com idade de 80 anos ou mais crescerá para aproximadamente 400 milhões quadruplicando o número existente em 2000 (Who, 2012). A figura abaixo ilustra o número de pessoas com 60 anos ou mais em 1950 e a projeção mundial desses números para 2050 nos países desenvolvidos e em desenvolvimento.

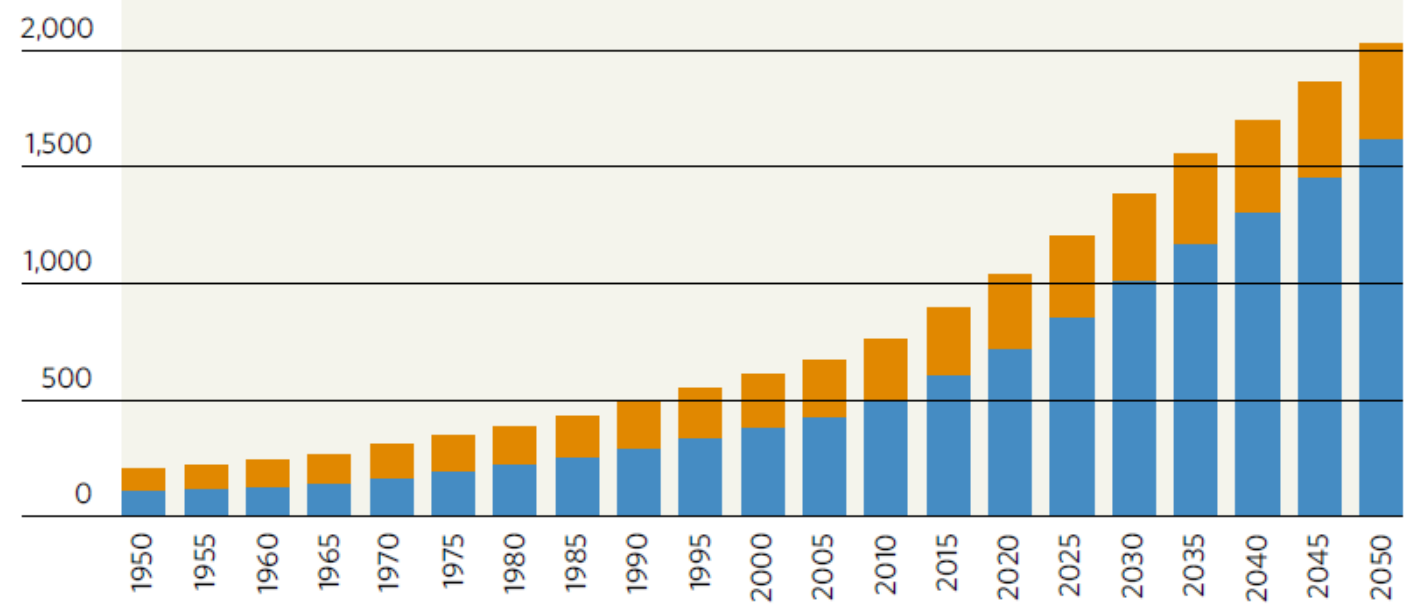

Figura 1. Projeção do número total da população mundial com idade de 60 anos ou mais entre 1950-2050. Fonte: DESA - Departamento de Assuntos Econômicos e Sociais das Nações Unidas, 2012. 
No Brasil, segundo dados do Instituto Brasileiro de Geografia e Estatística (IBGE), a população de idosos representa mais de 24 milhões de indivíduos e a estimativa é de que até 2060 esse número chegue a 73 milhões o que representará 32,9\% da população brasileira. Com essas projeções, pode ser observadas mudanças na forma da pirâmide demográfica demonstrada na Figura 2, com estreitamento da base e alargamento do ápice.
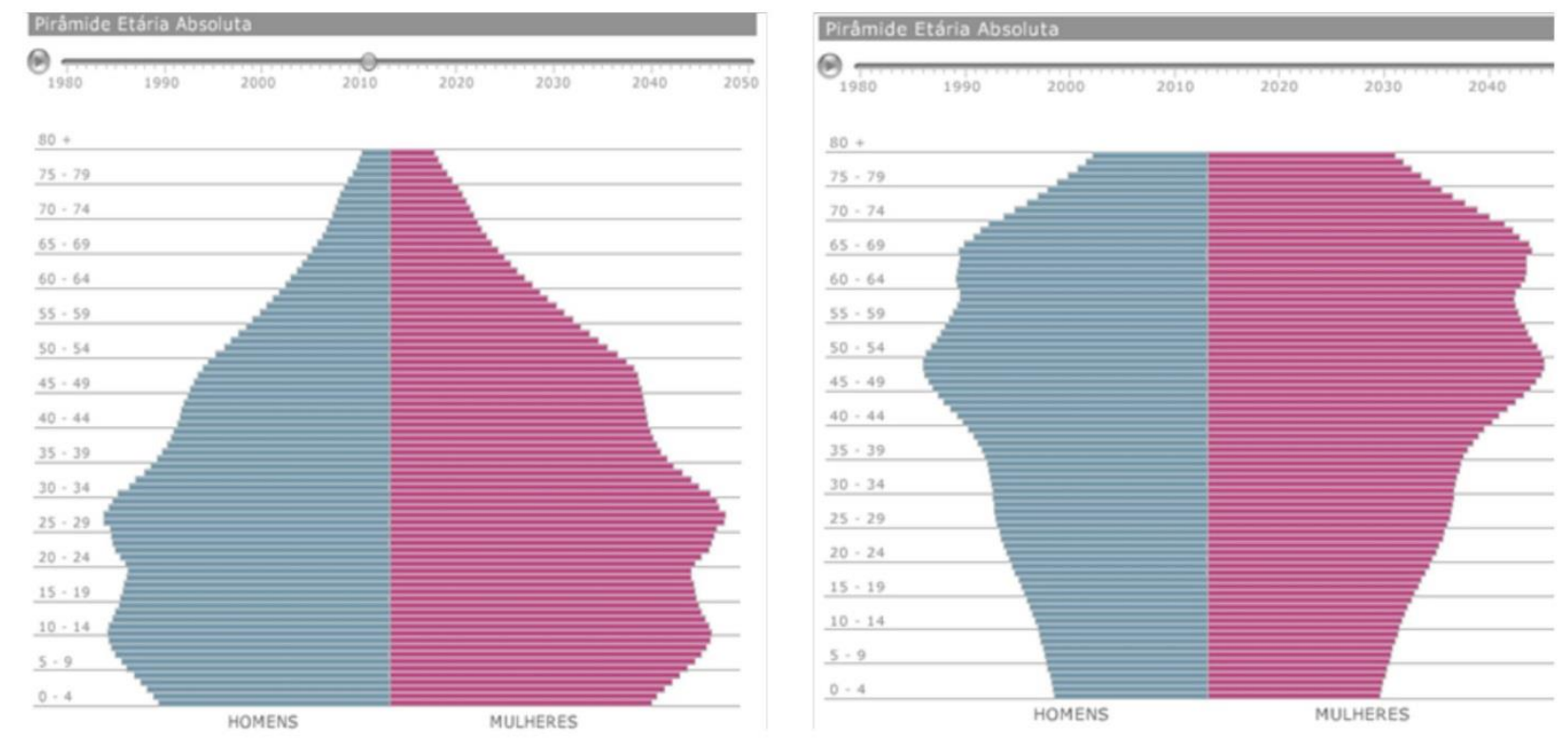

Figura 2 - Projeção da modificação da pirâmide etária da população brasileira entre 2010-2050. Fonte: IBGE Instituto Brasileiro de Geografia e Estatística.

Esse fenômeno ocorre de maneira semelhante no Distrito Federal e de acordo com dados da Companhia de Planejamento do Distrito Federal (CODEPLAN) o número de idosos terá um aumento de $143 \%$ até 2030. Habitantes com mais de 65 anos de idade que em 2010 representavam $4,8 \%$ da população passarão a representar $11,7 \%$ da população do Distrito Federal (Miragaya, Peixoto et al., 2013).

Além do aumento do número de idosos, a expectativa de vida tem também aumentado progressivamente e passou a ser em média 74,6 anos em 2012. Este fato por sua vez, é importante para que intervenções sejam promovidas para melhora na qualidade de vida desses idosos e para que ações diante desse processo de reestruturação demográfica sejam propostos no que tange uma adequação de serviços básicos de saúde para essa população. Segundo Lebrão (2007), um outro fenômeno que ocorre no processo de envelhecimento na população brasileira é a feminilização da velhice. De acordo com o Censo de 2010, para cada 82 homens 
havia 100 mulheres na mesma faixa etária. Essa é uma característica mundial e além disso a expectativa de vida da população feminina mundial é maior do que a dos homens, sendo que para homens é de 66 anos e de 71 anos para mulheres. São diversas as possíveis explicações para esse processo e dentre eles destacam-se as diferenças biológicas entre homens e mulheres, menor consumo de álcool e tabaco por mulheres, diferenças da exposição às causas de risco de trabalho e também pelo fato de mulheres estarem mais atentas ao aparecimento de sinais e sintomas descobrindo doenças precocemente e fazendo com que tomem atitudes em relação às doenças (Veras, Ramos et al., 1987; Lebrão, 2007; Kowal, Chatterji et al., 2012).

Fica explícito que esse é um contingente populacional expressivo e em ascensão, por esse motivo, o indivíduo idoso deve ter como objetivo a manutenção da sua independência e autonomia, e não ser marcado por doenças, declínios de suas capacidades funcionais, isolamento social e dependência. Diante disso é importante a implementação de condutas preventivas e intervenções terapêuticas que proporcionem um envelhecimento digno e saudável (Spirduso, 2005; Farinatti, 2008; Toscano e Oliveira, 2009).

\subsection{ALTERAÇÕES MORFOFISIOLÓGICAS NO ENVELHECIMENTO}

Dentre as alterações fisiológicas no envelhecimento destaca-se a sarcopenia que embora não haja atualmente um consenso internacional bem definido, em geral é descrita como um processo degenerativo contínuo que reduz força e massa muscular, acarretando assim diminuição de equilíbrio, força, funcionalidade e em um estágio avançado a perda da independência nos idosos (Burton e Sumukadas, 2010; Cederholm, Bauer et al., 2011; Rosenberg, 2011; Scott, Blizzard et al., 2011).

Rosenberg foi o primeiro autor a utilizar o termo em 1989 e referia-se apenas como sendo a perda de massa magra com o avanço da idade. A proposta do nome Sarcopenia derivava-se do grego, Sarx = carne e penia= perda e passou a descrever essa importante mudança de composição corporal do idoso. Ao decorrer dos anos, ela deixou de descrever apenas a perda de massa magra e incorporou outros fenômenos que ocorriam concomitantemente (Rosenberg, 1989; Toscano e Oliveira, 2009).

Embora não exista um consenso, alguns índices e cálculos feitos a partir de avaliações clínicas tentam caracterizar o fenômeno. O European Working Group on Sarcopenia in Older Persons (EWGSOP), sugeriu que para critério de diagnóstico o indivíduo deveria apresentar: 
1) diminuição de força muscular, avaliada por meio de teste de força de preensão manual; 2) baixo índice de massa livre de gordura determinado por meio da bioimpedância ou do Dualenergy X-ray Absorptiometry DEXA; 3) lentificação da marcha demonstrando um comprometimento da performance. Considerando outros aspectos o termo "Sarcopenia" deixou de descrever apenas a perda de massa muscular e passa a considerar outros elementos como diminuição da força e capacidade funcional (Studenski, Peters et al., 2014; Miljkovic, Lim et al., 2015).

A fim de promover e validar uma definição clínica para o termo Sarcopenia, em 2009 foi criado um projeto intitulado de "The FNIH Sarcopenia Project" em parceria com diversas instituições acadêmicas, companhias farmacêuticas e institutos relacionados ao envelhecimento. Em março de 2010 pesquisadores de nove instituições distintas acordaram que os critérios para classificação seriam definidos a partir de: 1) diminuição da mobilidade avaliada a partir de testes de performances físicas como critério para avaliação clínica da capacidade funcional e que apresentassem relevante associação muscular; 2) definição de limiares para diminuição de mobilidade nesses testes clínicos como, por exemplo, incapacidade para levantar-se da cadeira e redução da velocidade de marcha; 3) aplicação clínica dessas estratégias e formas de classifica-las.

Em maio de (2014), Studenski e colaboradores, publicaram um manuscrito com os resultados desse projeto que fora previamente apresentados em uma conferência no ano de 2012 reportando dados com características dos estudos, critérios de inclusão, tamanho da amostra, indicadores de base para função física, força e composição corporal, além de indicadores de saúde e doença.

Tendo como objetivo a quantificação de dados que expressassem a sarcopenia, alguns cálculos baseados na composição corporal e dados antropométricos possibilitaram a identificação da mesma. Baumgartner e colaboradores (1998) já haviam proposto um índice para sarcopenia que dividia a massa livre de gordura do esqueleto apendicular, medida por meio de equipamentos de dual-energy X-ray absormetry (DEXA), pela estatura elevada ao quadrado. Outros estudos também avaliaram essa relação e propuseram pontos de corte para classificar o indivíduo, porém, mesmo reconhecido trata-se de um método sofisticado e de alto custo para avaliação devido ao equipamento utilizado para avaliação da composição corporal e sua relação com a sarcopenia 
A partir de seis estudos de coorte contendo uma amostra total de 4.411 homens e 1.869 mulheres, McLean e colaboradores (2014) identificaram a partir da analise de composição corporal critérios para pontos de corte relacionados à massa magra. Essa variável foi analisada por meio do DEXA, equipamento considerado como padrão ouro para esse tipo de análise. Ficou definido que homens que apresentassem a taxa de massa magra apendicular menor que $19,75 \mathrm{~kg}$ e as mulheres abaixo de $15,02 \mathrm{~kg}$ possuíam um índice de massa magra baixo. De maneira secundária, outro índice descrevia essa massa magra abaixo do desejável, e considerava a relação entre massa magra apendicular/índice de massa corporal. No estudo de McLean ficaram definidos que os pontos de corte em valores menores que 0.789 e 0.512 para homens e mulheres respectivamente, eram considerados como baixo índice de massa magra.

De forma semelhante, porém, direcionando para a diminuição de força um estudo transversal com 9.897 homens e 10.950 mulheres foi conduzido por Alley e colaboradores (2014). Nesse estudo ficaram definidos os pontos de corte para força de preensão palmar (FPP) para homens e mulheres idosas a partir de dados contidos no The FNIH Sarcopenia Project e sua associação com a diminuição de mobilidade. A FPP é um dado registrado com um dinamômetro e é um equipamento de custo baixo quando comparado à outros, sendo assim, torna-se um equipamento acessível para avaliações clínicas. Em homens, os resultados para força entre $26-32 \mathrm{kgf}$ foram classificados como intermediários e abaixo de $26 \mathrm{kgf}$ como fracos, $11 \%$ da amostra apresentaram força intermediária e $5 \%$ foram classificados como fracos. Já para as mulheres essa classificação considerou força intermediária aquelas obtiveram resultados entre 16-20kgf e fracas aquelas abaixo de 16kgf, $25 \%$ da amostra foram consideradas com força intermediária e $18 \%$ fracas. Esses resultados diferem-se da classificação do EWGSOP que classificavam como fracos aqueles indivíduos homens que apresentassem força <30kgf e mulheres que apresentassem força <20kgf. Outra questão levantada acerca do assunto é que embora a perda de massa e a diminuição da força não ocorram de forma simultânea, acredita-se que a diminuição de força muscular é um indicador superior para o declínio funcional (Pendergast, Fisher et al., 1993; Doherty, 2003; Alley, Shardell et al., 2014).

Com base nos resultados dos estudos epidemiológicos citados acima e realizados em grandes amostras de homens e mulheres idosas, fica evidente que o comportamento físico de diminuição de massa muscular desencadeia déficits na vida do idoso. Um dos principais é a diminuição de força muscular, que por sua vez aumenta o risco de declínio funcional, 
consequentemente, quedas e até mesmo a morte. Todos esses acontecimentos, são dados relevantes para que estratégias de prevenção do declínio de força muscular sejam implementadas. Dentre as possíveis estratégias, o TR tem sido apontado como importante ferramenta para modificar essa realidade.

\subsection{FORÇA MUSCULAR E ENVELHECIMENTO}

A força muscular pode ser definida como a capacidade máxima que o músculo tem de produz tensão. Diversos fatores contribuem para a diminuição da força muscular, sejam eles de origem morfofisiológicos mencionados anteriormente ou até mesmo uma dieta inapropriada com baixa ingestão de proteínas e também um estilo de vida sedentário adotado ao longo da vida.Um dos principais problemas associados com o avanço da idade é a perda ou a diminuição da força que por sua vez está relacionada com a diminuição da capacidade funcional e independência. Essa relação "força X capacidade funcional" faz com que atitudes sejam adotadas para manter o nível de força em limiares adequados mesmo com o envelhecimento (Liu-Ambrose, Khan et al., 2004).

A maturação plena do sistema muscular do ser humano ocorre por volta da segunda e terceira década de vida. Entre 30 e 40 anos as reduções são pouco significativas prevalecendo ainda força máxima nesse período da vida, dos 40 aos 50 anos a contração passa a ser mais lenta sem, no entanto, sem gerar mudanças absolutas na força muscular. Após os 50 anos de idade o declínio pode chegar a 15\% a cada década e as perdas são mais rápidas dos 65 anos em diante (Viitasalo, Era et al., 1985; Vandervoort e Mccomas, 1986; Porter, Vandervoort et al., 1995; Nóbrega, Freitas et al., 1999).

Com o processo natural de envelhecimento, os sistemas fisiológicos do individuo apresentam declínios tanto em aspectos estruturais como também nas funções possibilitando o aparecimento de doenças crônico-degenerativas e aumentando as incapacidades. Essa realidade faz com que a habilidade e o desempenho físico para realizar tarefas do dia a dia tornem-se limitadas. Tarefas que são consideradas simples e desempenhadas sem grande dispêndio de energia por jovens e adultos, como por exemplo, sentar e levantar de uma cadeira ou subir um lance de escadas são consideradas uma tarefa de desgaste máximo para um idoso (Rikli e Edwards, 1991; Rantanen, Guralnik et al., 1998; Frontera e Bigard, 2002; Burton e Sumukadas, 2010). 
Se levarmos em consideração a repercussão que a força muscular tem sobre a vida do indivíduo idoso, fica evidente a relação que ela tem com a autonomia, mobilidade e até mesmo mortalidade dessa população. Estudos demostram haver correlação entre a diminuição de força e o número de quedas. As quedas por sua vez, são um dos acidentes mais comuns aos idosos e desencadeiam graves consequências sendo responsável por $12 \%$ de óbitos na população geriátrica mundial e a sexta causa de óbito dessa população. No Brasil, em um estudo transversal com 4.003 idosos, a prevalência de quedas entre eles foi de $34,8 \%$ e 12,1\% daqueles que sofreram queda tiveram alguma fratura como consequência. A compreensão da importância da força muscular para o idoso se faz necessária para que profissionais da saúde conduzam práticas de atividades que intervenha nessa condição (Guimarães, Galdino et al., 2004; Siqueira, Facchini et al., 2007; Merom, Pye et al., 2012).

Uma das maneiras de avaliar a força muscular na prática clínica é através da força de preensão manual. Essa avaliação gera informações importantes acerca da perda de massa muscular, além de ser também um método preditivo para o risco de quedas e diminuição da qualidade de vida (Sayer, Syddall et al., 2006; Bohannon, Bear-Lehman et al., 2007). Essa mensuração da força é feita por meio de um dinamômetro de mão, considerado um instrumentos padrão ouro para avaliação de força muscular (Roberts, Denison et al., 2011).

Em um estudo transversal sobre o tema em homens e mulheres com idades entre $45 \mathrm{e}$ 78 anos, foi verificada uma redução de PT isocinético em extensores e flexores de joelho e cotovelo de 15,5-26,7\% em idosos com idades entre 65-78 anos quando comparados com adultos com idades entre 45-54 anos. Esse método é considerado o padrão ouro para avaliação de força muscular. Após 10 anos, 64\% dos sujeitos participantes desse estudo transversal foram novamente aliados, sendo um total de 54 homens e 78 mulheres, foram constatadas perdas do PT isocinético em flexores e extensores de joelhos e cotovelos tanto para mulheres quanto para homens com o passar desses 10 anos entre a primeira avaliação e a reavaliação (Frontera, Hughes et al., 1991; Hughes, Frontera et al., 2001).

Ademais, também é de conhecimento que mulheres tendem a começar a diminuir força muscular mais cedo do que os homens. Uma consequência disso é que elas e chegam ao limiar mínimo de força para manter a independência antes que os homens, carecendo assim, de uma maior atenção no que diz respeito a essa condição(Capodaglio, Capodaglio et al., 2005). 


\subsection{CAPACIDADE FUNCIONAL, EQUILÍbRIO E O PROCESSO DE ENVELHECIMENTO}

A capacidade funcional é um fator importante para a manutenção da saúde, independência e bem estar no idoso. Pode ser definida como a capacidade que um indivíduo tem de realizar suas atividades de vida diárias (AVD) de forma independente, sejam elas, ocupacionais, autocuidado, deslocamento ou lazer (Matsudo, Matsudo et al., 2001).

A preservação da capacidade funcional é um parâmetro que pode indicar a qualidade de vida do idoso, e assim, assegurar que o aumento da expectativa de vida no idoso seja acompanhado pela manutenção dessa qualidade de vida e das AVD desempenhadas por ele. Avaliar se o idoso encontra-se no nível desejado de funcionalidade aparenta ser um aspecto de fundamental importância para prevenir um risco de dependência futura, de complicações por doenças crônicas, episódios quedas, índices de morbidade e mortalidade (Ensrud, Nevitt et al., 1994; Camara, Gerez et al., 2008).

O declínio funcional nessa população distribui-se entre questões sociais, demográficas, alterações clínicas e comprometimentos físicos. Pelo fato da capacidade funcional depender de diversos componentes, se faz necessário, uma bateria de testes que englobe a avaliação clínica para variáveis de força, equilíbrio e agilidade para esse público. Em 1999, Rikli e Jones, propuseram uma série de testes que avaliassem essas capacidades no idoso. O Teste de Aptidão Física para Idosos (TAFI) foi primeiramente associado ao desempenho físico, porém, em virtude de sua avaliação preconizar características relacionadas à mobilidade funcional, o TAFI é considerado um teste de aptidão/capacidade funcional (Da Costa Rosaa, Beníciob et al., 2003; Bertoldo Benedetti, Mazo et al., 2007; Rikli, 2008).

Os parâmetros físicos dos testes englobam força muscular, resistência aeróbica, flexibilidade, agilidade e equilíbrio e são parâmetros básicos para funções necessárias no dia à dia como caminhadas, subir e descer lances de escadas, sentar e levantar de uma cadeira, carregar compras, agachar-se, entre outras tarefas cotidianas (Rikli e Jones, 1999).

Alguns estudos evidenciaram que existe uma correlação entre a capacidade funcional e o risco de quedas em idosos. Sabendo que a queda tem sido um dos principais fatores relacionados à dependência e mortalidade dessa população, condutas para que haja uma diminuição nesse risco quedas e uma melhora das capacidades funcionais são necessárias para 
que a prevalência de quedas seja, de fato, evitada na vida de idosos (King, Whipple et al., 2002; Barnett, Smith et al., 2003; Toraman e Yildirim, 2010; Villareal, Smith et al., 2011).

Segundo Visser e colaboradores (2005), a redução da força nos músculos extensores de joelho pode estar associada com a diminuição da mobilidade e consequentemente ser um fator limitante para o desempenho das AVD. Outro componente importante para desenvolver tarefas no dia a dia é o equilíbrio. O equilibrio é uma habilidade fundamental para a autonomia funcional, necessário para atividades cotidianas como andar, subir escadas, vestirse e que com o passar dos anos é comprometido. É também considerado um importante fator de risco para quedas e atinge de 20 a $50 \%$ das pessoas com idades acima de 65 anos (Rubenstein e Josephson, 2006).

Conhecido também como controle postural, o equilíbrio, é definido como a capacidade que o indivíduo possui de posicionar o centro de gravidade dentro da sua base de suporte. Essa capacidade, diminuída com o processo de envelhecimento, são requeridas em situações de perturbações de caráter voluntário ou não. Após uma situação de perturbação, é necessário que o corpo seja capaz de retornar à uma posição de equilíbrio, ou seja, que o centro de massa retorne para a base de suporte para que um tropeço ou queda sejam evitados (Shumway-Cook e Horak, 1986; Chandler, Duncan et al., 1998).

Dentre os instrumentos existentes para avaliar o equilíbrio corporal, encontram-se o 8 - Foot up and Go, pertencente ao TAFI proposto por Rikli \& Jones, e o Teste de Alcance Funcional (TAF). O primeiro, avalia a agilidade e o equilíbrio dinâmico, e compoe a bateria de teste de capacidades funcionais(Rikli e Jones, 1999). O segundo teste, determina apenas o equilíbrio dinâmico e está relacionado com a capacidade máxima que o indivíduo tem de alcançar à sua frente com o braço estendido mantendo sua base fixa. Quanto maior a distância alcançada, maior o equilíbrio dinâmico e menor o risco de queda (Duncan, Weiner et al., 1990).

Alguns autores sugerem que TR e o treinamento de equilíbrio devem fazer parte de um programa de prevenção de quedas. Os exercícios propostos em um programa de prevenção de quedas precisam de uma intensidade adequada, pois, a maioria dos estudos subestimam a carga que o idoso é capaz de treinar (Buchner, Cress et al.; Gardner, Robertson et al., 2000).

Sendo assim, o TR tem sido proposto como meio para promover e melhorar a capacidade funcional e o equilíbrio em idosos. 


\subsection{TREINAMENTO RESISTIDO NO ENVELHECIMENTO}

Uma das maneiras de intervir e modificar os efeitos do envelhecimento na perda de força, capacidades funcionais, equilíbrio e de massa magra é por meio do treinamento resistido progressivo (TRP). De acordo Liu (2009), o TRP é um exercício onde o participante exercita seus músculos contra algum tipo de resistência e progressivamente aumenta sua carga. O TRP é uma modalidade de exercício que vem crescendo em popularidade há duas décadas com o intuito de aumentar a performance através do incremento da força muscular, potência, hipertrofia, equilíbrio e coordenação (Kraemer, Ratamess et al., 2000). O fator chave para a realização de um TRP efetivo seria o delineamento do programa correto incluindo a orientação apropriada da realização do exercício, do método de progressão, do estabelecimento de metas, e da prescrição correta das variáveis agudas que serão descritas no decorrer desse trabalho (Kraemer e Ratamess, 2004).

Uma das características vitais em programas de treinamento é a progressão do treino. Ela consiste no ato de avançar para um especifico objetivo/meta dentro de um tempo até que esse objetivo seja alcançado. Para isso, processos fisiológicos adaptativos serão produzidos a partir do stress gerado por uma carga externa. Considerando que o TRP refere-se a programas específicos para manter e/ou melhorar o nível de atividade física em determinadas populações, se faz necessário o conhecimento de como as variáveis agudas do treinamento podem interferir na saúde daqueles que praticam essa modalidade(Pollock, Gaesser et al., 1998; Feigenbaum e Pollock, 1999).

A prescrição de um TRP envolve a manipulação de variáveis como intensidade, frequência, escolha doexercício, tipo de contração muscular, volume e intervalo de recuperação(Kraemer e Ratamess, 2004). No modelo clássico de periodização linear, é comum que a fase inicial de treinamento ocorra com um volume alto de treino com baixas cargas e a medida que o treino progride, o volume tende a diminuir enquanto que a intensidade aumenta juntamente com o aumento da carga. Vale ressaltar que o volume de treinamento é igual a soma do número total de repetições em cada série, multiplicadas pelo número de séries e pela carga utilizada, em cada exercício. Assim, cada fase do TRP enfatiza uma adaptação neurofisiológica específica (Fleck, 1999).

O presente estudo seguiu o modelo clássico de periodização, iniciando com um volume maior de treino nas primeiras 4 semanas de TR realizando três séries de 15 repetições, finalizando com um volume menor na $12^{\mathrm{a}}$ semana, porém, com uma intensidade maior. 
A escolha por exercícios uniarticulares e pluriarticulares deve-se ao fato de que eles tem sido utilizado com frequência devido a sua comprovação na literatura quanto à eficácia para o ganho de força muscular e é recomendado pelo ACSM. Uma das principais características dos exercícios uniarticulares, é reduzido risco de lesão, pois, esse tipo de exercício recruta um grupo muscular especifico e consequentemente requer uma menor habilidade técnica de execução. Os exercícios pluriarticulares, envolvem uma ativação neural e coordenação complexas, pois, envolvem largos grupamentos musculares necessitando de um maior controle e consciência corporal (Kraemer, Adams et al., 2002). A fim de promover ganhos específicos e também desenvolver uma maior coordenação e ativação neural, foram escolhidos exercícios uniarticulares e pluriarticulares para o presente estudo.

O intervalo de recuperação entre as séries foi de 1 minuto e o intervalo de descanço entre as sessões de treino foi de 48 a 72 horas (Bottaro, Ernesto et al., 2010).

Em relação à frequência, essa modalidade deve ser conduzida em idosos de duas a três vezes por semana com intensidades de moderada à alta, utilizando diferentes tipos de materias para treinamento (Chodzko-Zajko, Proctor et al.; Liu e Latham, 2009). O treinamento do presente estudo foi conduzido duas vezes por semana e utilizou resistência elástica e máquinas pneumática nos diferentes grupos.

\subsection{RESISTÊNCIA ELÁSTICA E MÁQUINAS PNEUMÁTICAS}

O treinamento resistido, realizado por meio do uso de resistência elástica progressiva (REP), é um método em ascensão devido a características intrínsecas do equipamento que possibilita uma variedade de exercícios de forma prática, segura, de baixo custo e permitindo a utilização em qualquer local devido sua versatilidade.

Tem sido recomendado por ser um método eficaz para promover ganhos funcionais em idosos gerando a oportunidade de inserir programas de treinamento para idosos mesmo em locais com poucos recursos físicos ou financeiros (Sakanoue e Katayama, 2007; Colado, Garcia-Masso et al., 2010; Motalebi e Loke, 2014).

Uma das questões limitantes para o uso da REP era a falta de padronização de carga dos equipamentos. Esse fator limitante tem sido transposto, pois, um estudo recente conseguiu quantificar a carga produzida pelo percentual de estiramento do equipamento em um ensaio mecânico realizado no Laboratório de Engenharia Mecânica da UnB. Esse estudo demonstrou 
um comportamento de progressão linear da carga de acordo com o alongamento do material e espessura do mesmo. $\mathrm{O}$ equipamento usado na pesquisa de ensaio mecânico foi o Elastos®, mesmo material utilizado para o presente estudo(Martins, Carvalho et al., 2014).

Além de utilizar a REP para o TR, o presente estudo utilizou máquinas pneumáticas em um dos grupos de intervenção. Por definição, o termo "pneumático" está relacionado com o "uso de ar" e seus dispositivos geram cargas sem depender da massa de objeto. Assim, existe uma relação entre a pressão produzida pelo ar e a área na qual essa pressão é exercida gerando a seguinte equação: $\mathrm{P}=\mathrm{F} / \mathrm{A}$, onde "P" significa Pressão do Ar, "F" é a força resultante em newtons(N) e "A" a área em $\mathrm{m}^{2}$ de ar comprimido(Frost, Cronin et al., 2010).

A primeira máquina pneumática foi desenvolvida por Keiser em 1978, o objetivo dela era de superar as máquinas tradicionais (Keiser, 1978 patente). Máquinas pneumáticas apresentam resistências similares às resistências constantes de máquinas tradicionais e tem sido utilizada em protocolos de treinamento com idosos (Jozsi, Campbell et al., 1999; Fielding, Lebrasseur et al., 2002; Herman, Kiely et al., 2005; Orr, De Vos et al., 2006). 


\section{MATERIAIS E MÉTODO}

\subsection{TIPO DE ESTUDO}

O presente estudo é classificado como ensaio clínico randomizado (El Dib, 2007) e registrado no Clinicaltrials.gov com o título de "Effects of Resistance Training in Untrained Older Adults" e número de registro NCT 02253615.

\subsection{LOCAL DO EXPERIMENTO}

O programa de Treinamento Resistido Progressivo foi realizado no Ginásio Terapêutico e no Espaço de Convivência da Universidade de Brasília - UnB, localizado na QNN 14 Área Especial, Guariroba, Ceilândia Sul. O período de treinamento foi conduzido no início com duas semanas de exercícios de familiarização em julho de 2014, seguidas de 12 semanas de TRP realizado duas vezes por semana (terças e sextas-feiras) no período da manhã e tarde. As avaliações de capacidade funcional, equilíbrio e de força foram realizadas na mesma instituição, no Laboratório de Desempenho Humano e Ginásio Terapêutico nos períodos que antecederam o início do projeto e uma semana após o término das 12 semanas de intervenção. $\mathrm{O}$ mesmo ocorreu para avaliação do pico de torque isocinético realizado no Laboratório de Força da UnB - FEF.

\subsection{AMOSTRA}

A amostra do presente estudo foi composta por 44 sujeitos do sexo feminino, recrutadas por conveniência a partir de convites diretos por meio de mídia impressa distribuídas na comunidade da Ceilândia, quatro palestras realizadas na UnB-FCE (Figura 3) ou encaminhados através de atendimentos prévios em Postos de Saúde da região devido a parcerias com gestores de saúde e geriatras. 


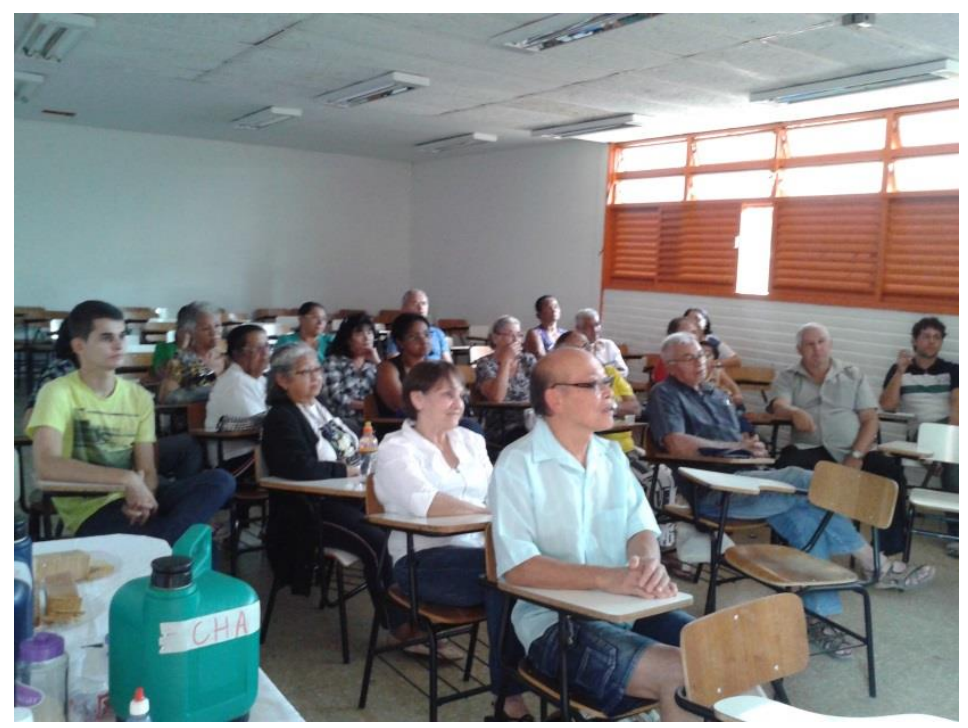

Figura 3 - Palestra realizada no CEM 4 - UnB - FCE Fonte: Autora, 2014.

Para participar do programa de treinamento resistido foi estabelecido que as voluntárias deveriam possuir no mínimo 60 anos de idade, residirem no Distrito Federal e apresentarem atestado médico que as liberassem para a prática de treinamento resistido.

Todos as interessadas foram informadas sobre os riscos e benefícios do experimento e participação dos mesmos ocorreu de forma voluntária mediante a assinatura do Termo de Consentimento Livre e Esclarecido (TCLE) antes do início do estudo afirmando estarem cientes de todos os procedimentos que foram realizados no decorrer do desenvolvimento do projeto(APÊNDICE A).

O presente projeto de estudo foi submetido e aprovado pelo Comitê de Ética em Pesquisas com Seres Humanos (CEP) da Faculdade de Ciências da Saúde da Universidade de Brasília (UnB), conforme a Resolução n 196/96 do Conselho Nacional de Saúde (CNS) que regulamenta as pesquisas envolvendo seres humanos(ANEXO A).

\subsubsection{CRITÉRIOS DE INCLUSÃO}

1) Obter liberação médica (atestado) para a prática de exercícios resistidos.

2) Não ter realizado nenhuma modalidade de treinamento resistido nos últimos seis meses.

3) Concordar e assinar TCLE. 


\subsubsection{CRITÉRIOS DE EXCLUSÃo}

1) Voluntários que apresentarem doenças crônicas degenerativas (metabólicas, cardiovasculares, mentais, vasculares, reumatológicas e ortopédicas) que inviabiliza a prática de atividade física.

2) Cirurgias traumato-ortopédicas nos últimos 6 meses.

3) Uso de dispositivos de auxilio locomoção.

4) Restrição da amplitude de movimento devido a traumas ou cirurgias em qualquer articulação do corpo. Bem como uso de próteses ou órteses em membros superiores ou inferiores.

5) Histórico de fraturas que comprometam a mobilidade.

\subsubsection{TRIAGEM}

As mulheres que demonstratam interesse em participar da pesquisa entraram em contato com os pesquisadores responsáveis de maneira presencial na Faculdade da Ceilândia no CEM4 ou efetuaram ligação e agendaram o dia de sua entrevista. Nesse momento, as voluntárias foram entrevistadas para caracterização dos aspectos sociodemográficos e de saúde inerentes aos critérios de seleção da amostra por um questionário semiestruturado (APÊNDICE B). Essa etapa permitiu realizar uma seleção inicial daquelas que possuíam parte dos critérios para participar do estudo. Nessa etapa, também, utilizou-se do questionário Minnesota Leisure Time Physical Activity Questionnarie em uma versão traduzida para o português para fosse avaliado o nível de atividade física das participantes (ANEXO B).

Aquelas voluntárias consideradas aptos na triagem e que consentiram aos pesquisadores a sua participação na pesquisa, assinaram o Termo de Consentimento Livre e Esclarecido (TCLE). Com a divulgação da pesquisa, 113 indivíduos efetivaram contato telefônico ou compareceram na UnB-FCE, apresentando interesse em participar da pesquisa. Porém, apenas 74 compareceram e foram avaliadas para critério de elegibilidade. Dessas, 10 foram excluídas pelos critérios de seleção da amostra e 10 não apresentaram interesse em participar após a explicação dos objetivos da pesquisa. Foram motivos de exclusão: trombose venosa profunda $(n=1)$, prática de treinamento resistido $(n=1)$, insuficiência cardíaca congestiva $(n=1)$, acidente vascular cerebral $(n=2)$, artrite reumatóide $(n=1)$, idade inferior 
a $60 \operatorname{anos}(n=4)$. Assim, 54 das voluntárias avaliadas para elegibilidade foram selecionadas e distribuídas, randomicamente, nos dois grupos de pesquisa. Como dez participantes não completaram as doze semanas de treinamento, a amostra foi composta por 44 mulheres, sendo 26 no Grupo de Treinamento Máquina(GTM) e 18 no Grupo de Treinamento Resistência Elástica(GTRE). O fluxo de indivíduos durante as etapas da pesquisa pode ser visto na Figura 4.

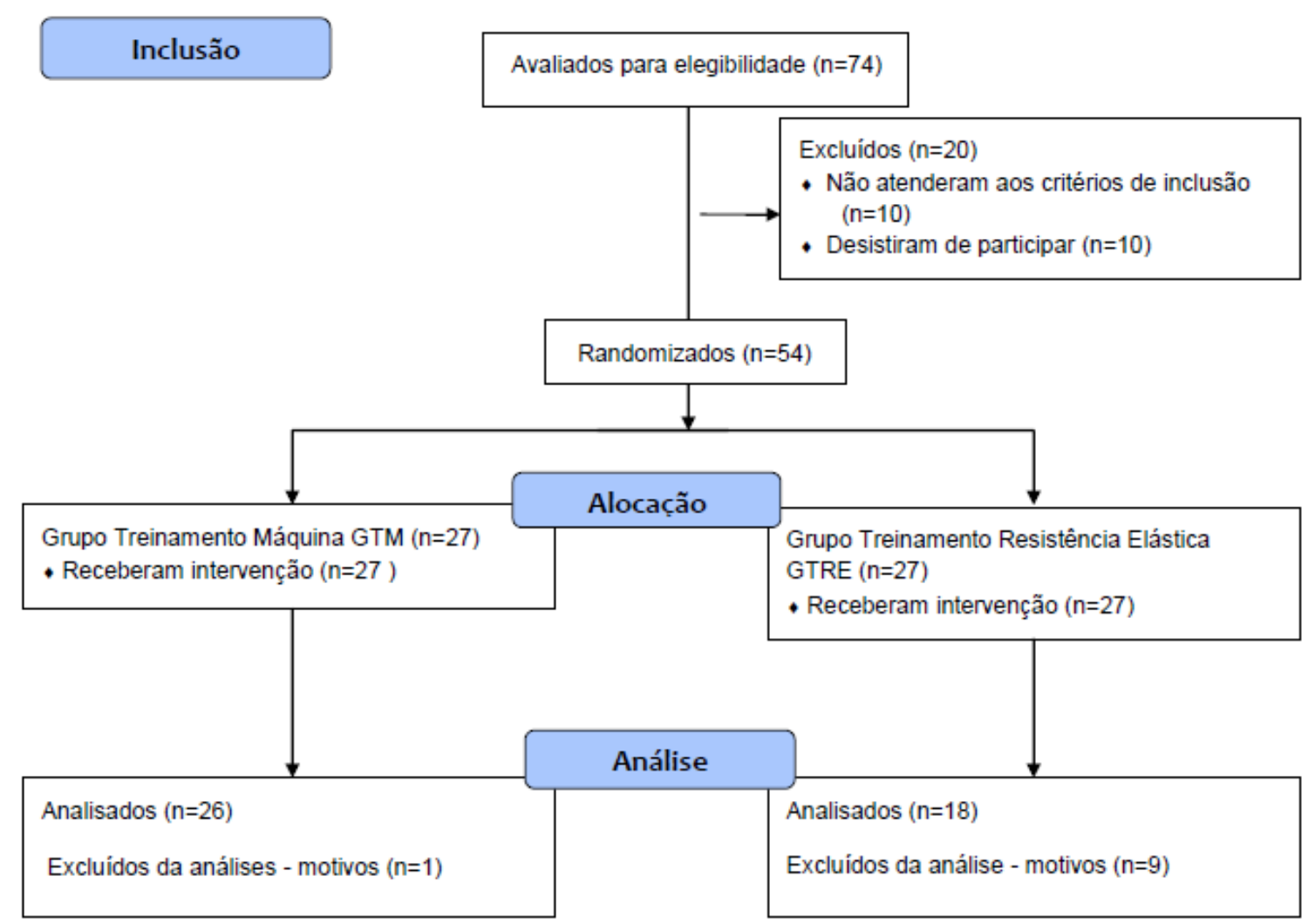

Figura 4 - Fluxo dos indivíduos ao longo da pesquisa. Fonte: Autora, 2015.

As razões para as voluntárias não completarem o treinamento no GRE incluíram no a ocorrência de problemas de saúde familiar impedindo o comparecimento nos treinos $(n=2)$, incompatibilidade de horário $(n=1)$, acidente domiciliar com sequela $(n=3)$, pneumonia $(n=1)$, cirurgia de vesícula $(n=1)$ e por motivo de viajem $(n=1)$ totalizando uma perda amostral de 9 idosas. No GM apenas uma voluntária desistiu por incompatibilidade de horários. Toda a fase de execução da pesquisa ocorreu entre os meses de março e julho de 2014. 


\subsection{INSTRUMENTOS}

Os instrumentos de avaliações físicas no momento pré-intervenção e pós-intervenção pertencem ao Laboratório de Desempenho Humano da Universidade de Brasília - Campus Ceilândia e ao Laboratório de Força da Faculdade de Educação Física da Universidade de Brasília - Campus Darcy Ribeiro. A calibragem de todos os materiais utilizados na coleta de dados foram realizadas sempre antes do primeiro teste do dia seguindo as orientações do manual do fabricante.

\subsubsection{ENTREVISTA}

Foram realizadas com as voluntárias interessadas em participar da pesquisa uma entrevista estruturada (APÊNDICE B) e logo em seguida, o nível de atividade física foi avaliado por autorrelato sobre a frequência semanal e a duração diária de exercícios físicos e atividades do cotidiano, utilizando como referência os itens do Minnessota Leisure Time Activity Questionare validado e traduzido para a população brasileira (Lustosa, Pereira et al., 2011).

\subsubsection{ANTROPOMETRIA}

A massa corporal foi mensurada utilizando uma balança digital, com resolução em gramas (modelo 2006pp TOLEDO, Brasil), os voluntários foram orientados a utilizar roupas leves e retirar os sapatos e demais acessórios. A estatura foi aferida utilizando um estadiômetro, com resolução em centímetros (CARDIOMED, Brasil) fixado na parede. O índice de massa corporal (IMC) foi calculado dividindo-se a massa corporal pela estatura ao quadrado $\left(\mathrm{Kg} / \mathrm{m}^{2}\right)$.

\subsubsection{AVALIAÇÃO DE FORÇA MUSCULAR}

Para avaliação da força muscular foram utilizados métodos de dinamometria isométrica e isocinética. A força de preensão palmar, dinamometria isométrica, foi avaliada utilizado dinamômetro Saehan ${ }^{\circledR}$ e para avaliação do pico de torque (PT) isocinético para 
extensão de joelhos e flexão de cotovelo foi utilizado um dinamômetro isocinético da marca Biodex System ${ }^{\circledR}$ modelo III. Esses dois tipos de dinamômetros têm sido considerados como o padrão ouro pela literatura, no que concerne a medidas de força isocinética e isométrica (Mathiowetz, Kashman et al., 1985; Guerra e Amaral, 2009; Caruso, Brown et al., 2012).

\subsubsection{AVALIAÇÃO DA CAPACIDADE FUNCIONAL E EQUILÍBRIO}

Todas as voluntárias foram previamente orientadas para o uso de vestimenta adequada para a realização da bateria de testes e orientadas quanto a forma de execução dos mesmos. Foi solicitado que as voluntárias comparecessem ao local de teste com vestimentas que permitissem a avaliação, como por exemplo: blusa de algodão, calça de malha ou bermuda (cotton, algodão) e tênis.

Para a avaliação da capacidade funcional aplicou-se três testes que simulam atividades de vida diária dessa população, são eles: Teste de sentar e levantar (TSL) durante 30 segundos, teste de flexão de cotovelo(TFC) durante 30 segundos e o 8-foot up and go.

O TFC 30" avaliou a força indireta de MMSS e é determinado pelo número de repetições completas que a avaliada consegue realizar com $2 \mathrm{~kg}$ durante esse tempo. Para que o teste fosse realizado utilizamos um cronômetro, uma cadeira com altura de $43 \mathrm{~cm}$ e um halteres de $2 \mathrm{~kg}$.

O TSL 30" avaliou a força indireta de MMII e foi determinada pelo número de repetições completas que a avaliada realizou para sentar e levantar da cadeira durante esse tempo. Para que o teste fosse realizado foi utilizado uma cadeira de $43 \mathrm{~cm}$ de altura e um cronômetro.

O teste 8 foot up and go avalia a agilidade e o equilíbrio dinâmico. Nele a voluntária inicia o teste sentada em uma cadeida de $43 \mathrm{~cm}$ de altura, e ao comando verbal do avaliador levanta-se e caminha $2,44 \mathrm{~m}$ na maior velocidade que conseguir, porém, sem correr, da a volta no cone e retorna a cadeira. $\mathrm{O}$ avaliador cronometra o tempo gasto para completar o teste. Para que o teste fosse realizado, foram necessários cronômetro, cone e uma cadeira de $43 \mathrm{~cm}$.

Todo procedimento foi conduzido de acordo com o protocolo proposto por Rikli e Jones (1999).

A avaliação do equilíbrio dinâmico foi realidada por meio do teste de alcance funcional proposto por Duncan (1990). O Teste de Alcance Funcional (TAF) mede a 
capacidade que o indivíduo tem de mover-se voluntariamente até os limites da estabilidade anterior.

\subsubsection{EQUIPAMENTOS DE TREINAMENTO RESISTIDO}

\subsubsection{MÁQUINAS PNEUMÁTICAS}

Para o TRM foram utilizados oito equipamentos pneumáticos da marca En-dynamic Enraf Nonius, fabricadas na Holanda, para execusão dos exercícios conforme as figuras 5 e 6 abaixo. Cada equipamento permite cargas de 0-100 X 10N (kgf) mostradas em um dysplay digital em cada máquina. A carga é fornecida por um compressor do mesmo fabricante do modelo "Jun-Air 6-15 Standard".
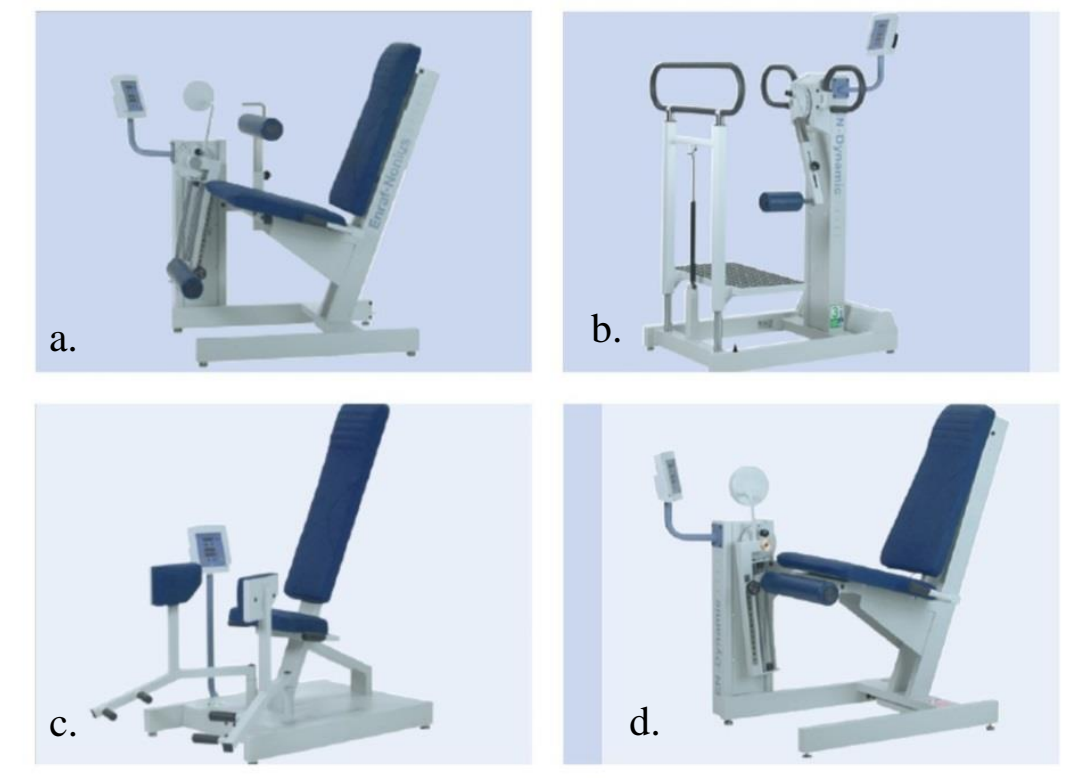

Figura 5 - Exercícios MMII (a. extensão de joelhos, b. extensão ou abdução de quadril, c. abdução de quadril e d. extensão de joelhos) 

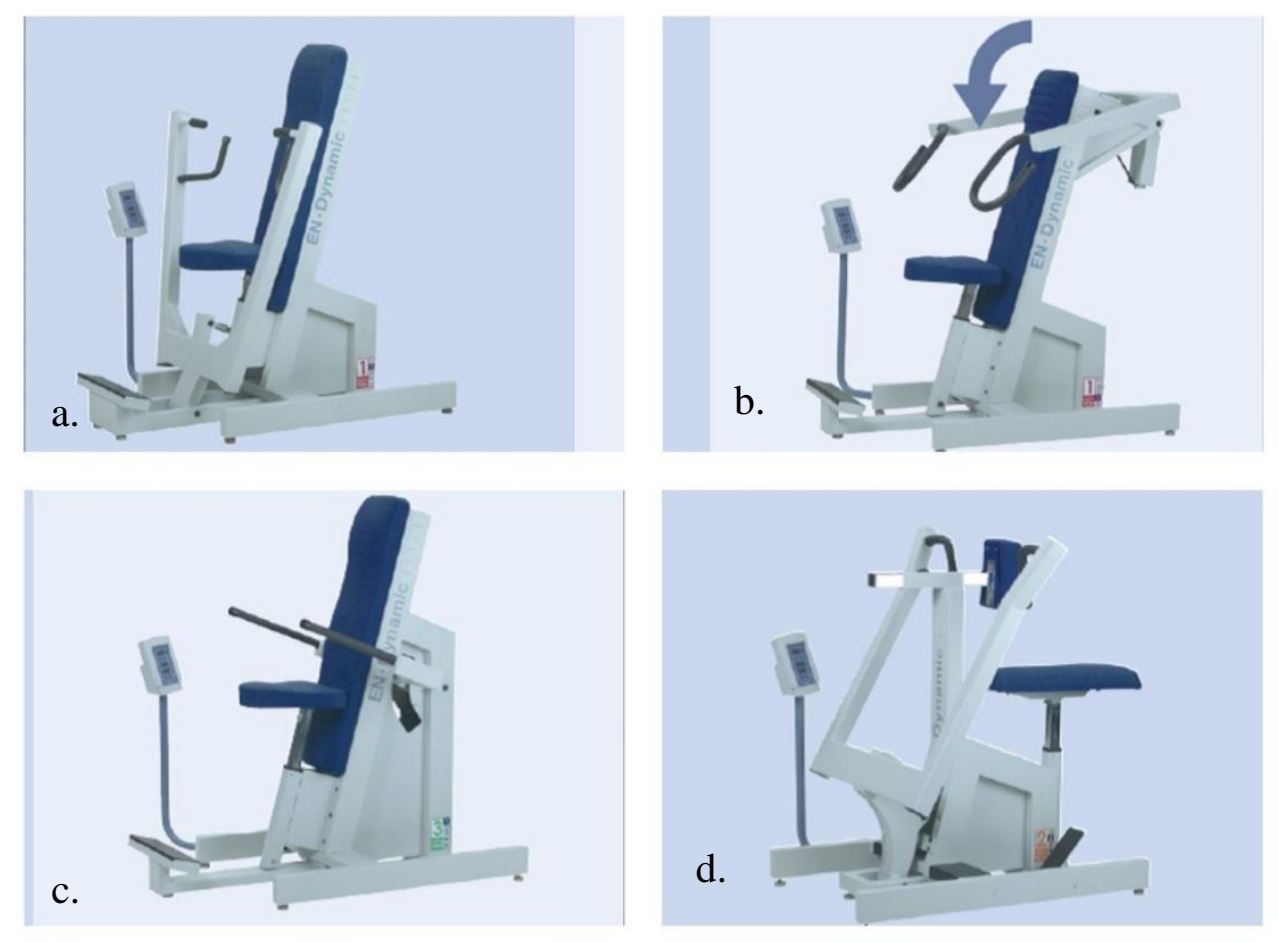

Figura 6 - Exercícios de MMSS (a. supino, b. puxada alta, c. tríceps e d. remada).

\subsubsection{ELASTOS}

Para o TRE foram utilizados equipamentos da marca Elastos®, esse material possui sete níveis diferentes de carga identificadas por cores, em ordem crescente são: amarelo, vermelho, verde, azul, preto, roxo e dourado. O Elastos ${ }^{\circledR}$ ainda apresenta um comprimento padronizado de $50 \mathrm{~cm}$ e interfaces para fixação em suas extremidades e era acoplado em ganchos específicos fixados na parede ou em alças de poste do local de treinamento(Figura 7). Alças de mão foram utilizadas para realização dos exercícios de supino, puxada e remada alta, barra de mão para o exercício de tríceps, alças de tornozelo para os exercícios de flexão e extensão de joelhos, abdução e extensão de quadril(Figura 8), e acessório e-loop para realização do deslocamento lateral (Figura 9). Para assegurar que o treinamento era realizado dentro da intensidade desejada e também de maneira progressiva marcações no chão, utilização de cones e réguas de estiramento foram utilizadas para controle de carga. Esse equipamento foi utilizado pelo fato de ensaios mecânicos realizados no Laboratório de Engenharia da UnB já terem demonstrado uma correlação entre força e alongamento(Figura 10) para cada nível de resistência em percentuais de estiramento específicos de 50\%, 100\%, 
$150 \%$ e $200 \%$. Os valores de força em $(\mathrm{N})$ de cada tubo elastico podem ser vistos em percentuais de estiramento na tabela Tabela 01 .
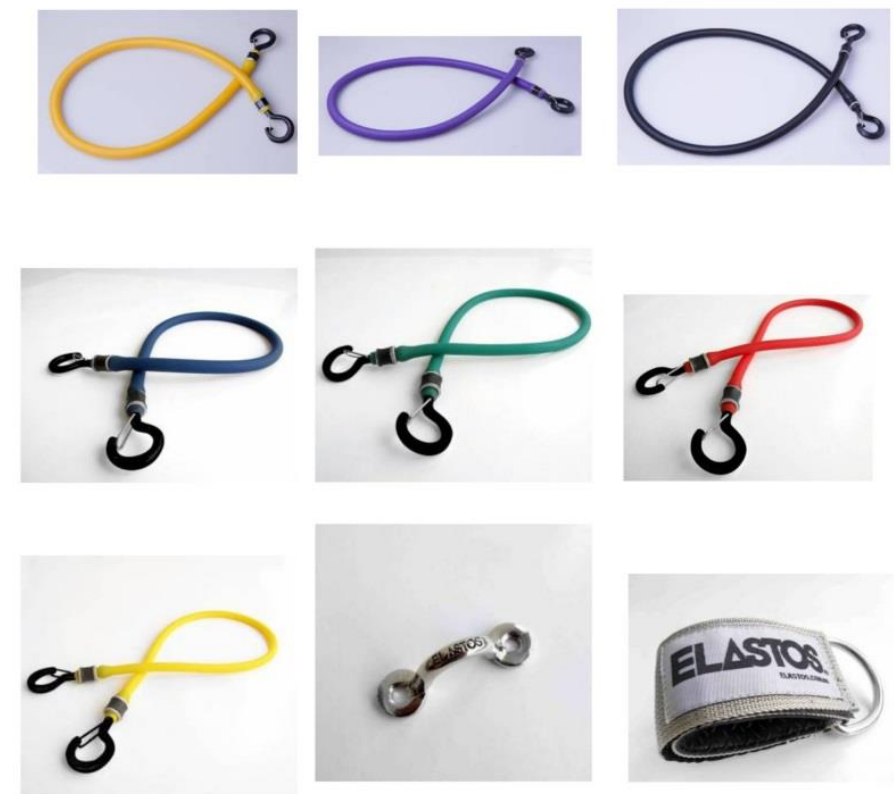

Figura 7 - Sete níveis de resistência elástica e acessórios para fixação Fonte: $\underline{w w w . e l a s t o s . c o m} \cdot \mathrm{br}$
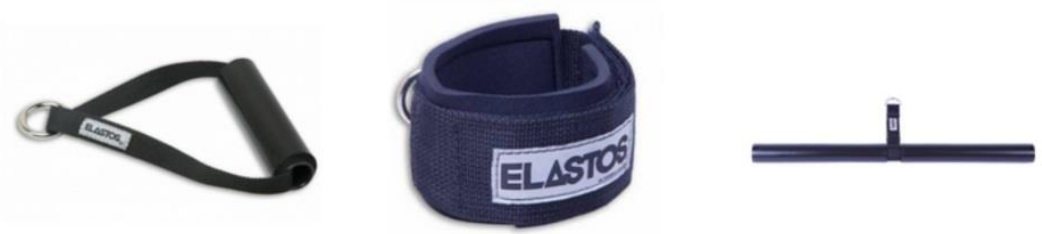

Figura 8 - Acessórios exercitadores: Alça de mão, alça de tornozelo e barra de mão. Fonte: www.elastos.com.br

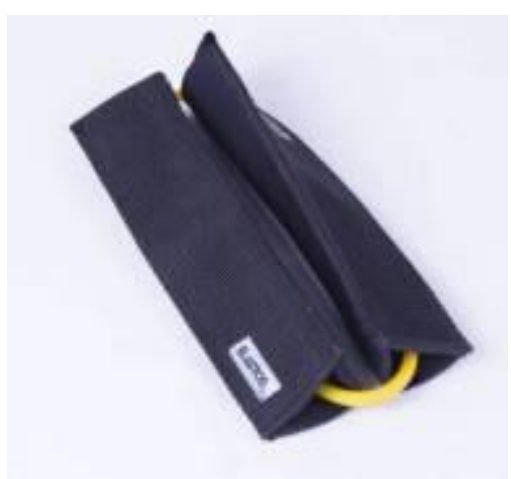

Figura 9 - Acessório e-loop para exercício de deslocamento lateral. 


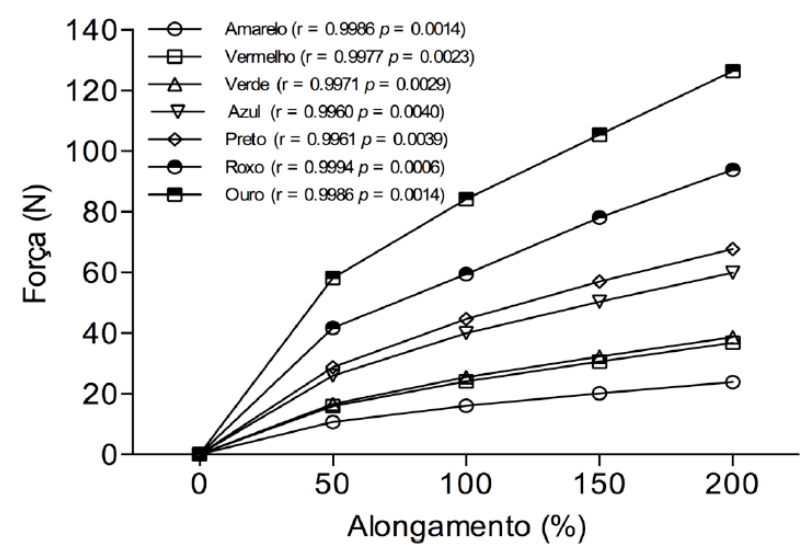

Figura 10 - Coeficiente de correlação de Pearson (r) e valor de $p$ entre as variáveis força e alongamento em cada nível de resistência.

Fonte: Martins et al, 2014.

Tabela 1 - Valores de força e alongamento em cada um dos 7 níveis de resistência.

\begin{tabular}{ccccccccc}
\hline \multirow{2}{*}{ Alongamento } & Amarelo & Vermelho & Verde & Azul & Preto & Roxo & Ouro \\
& $(n=15)$ & $(n=15)$ & $(n=15)$ & $(n=15)$ & $(n=15)$ & $(n=15)$ & $(n=15)$ \\
\hline $50 \%$ & $10.6(0.7)$ & $15.8(0.7)$ & $16.6(1.1)$ & $25.9(1.7)$ & $28.8(2.4)$ & $41.7(2.8)$ & $58.1(5.8)$ \\
$100 \%$ & $16.0(0.8)$ & $24.0(0.7)$ & $25.4(1.4)$ & $39.9(1.6)$ & $44.6(2.7)$ & $59.4(1.2)$ & $84.1(5.2)$ \\
$150 \%$ & $20.0(0.9)$ & $30.5(0.7)$ & $32.2(1.7)$ & $50.2(1.3)$ & $56.9(2.6)$ & $78.1(2.8)$ & $105.4(7.2)$ \\
$200 \%$ & $23.8(0.9)$ & $36.7(0.5)$ & $38.6(2.1)$ & $59.9(0.8)$ & $67.7(2,1)$ & $93.8(3.4)$ & $126.4(9.9)$
\end{tabular}

Valores apresentados em média e desvio padrão.

Tabela 01 - Valores de força e alongamento em cada um dos 7 níveis de resistência. Fonte: Martins, 2014.

\subsection{PROCEDIMENTOS}

Após a triagem as voluntárias foram alocadas aleatoriamente em dois grupos: GTM $(\mathrm{n}=27)$ ou GTRE $(\mathrm{n}=27)$. Para divisão das participantes, foi utilizado o método de randomização em blocos (Moher, Hopewell et al., 2010). As três semanas que antecederam o experimento foram dedicadas à avaliação 1 e 2 pré-intervenção (PRÉ) dos voluntários de ambos grupos. Após essa etapa, as voluntárias de cada grupo participaram de duas semanas de 
exercícios de familiarização, seguidas por doze semanas de TRP, sempre duas vezes por semana(terças e sextas-feiras).

Com o término do período de treinamento, iniciou-se a avaliação 1 e 2 pós-intervenção (PÓS) de ambos os grupos, sendo respeitado, para isso, o intervalo mínimo de dois dias entre a última sessão de treino e o momento dos testes PÓS.

\subsubsection{AVALIAÇÕES 1 E 2 - PRÉ E PÓS}

\subsubsection{AVALIAÇÃO 1 - FEF UnB}

A avaliação 1 foi realizada no Laboratório de Força da FEF-UnB e foi avaliado o PT isocinético. Para isso, todas as participantes foram levadas do Campus Ceilândia para o Campus Darcy Ribeiro por meio de transporte fornecido pela instituição nos períodos da manhã e tarde. Foi oferecido gratuitamente nos dois períodos de avaliação um lanche composto por frutas, bolos e sucos. Em cada período de teste eram avaliadas 6 voluntárias previamente agendas e confirmadas pelos pesquisadores participantes do estudo e a duração total para essa avaliação foi em torno de quatro horas por conta dos deslocamentos necessários.

\subsection{PICO DE TORQUE ISOCINÉTICO}

Com o dinamometro Biodex System ${ }^{\circledR}$ modelo III foram avaliados os picos de torque nos membros dominantes para os movimentos de extensão e flexão de joelho(Figura 11) e cotovelo (Figura 12) na velocidade de $60 \%$ e $180 \%$ segundo protocolo adaptado proposto por Bottaro (Bottaro, Russo Aé et al., 2005).

O membro inferior dominante foi definido pela preferência de um lado em chutar uma bola (Hartmann, Knols et al., 2009). O membro superior dominante foi definido como o membro usado, preferencialmente, para escrever, se alimentar e carregar objetos pesados (Mitsionis, Pakos et al., 2009) 


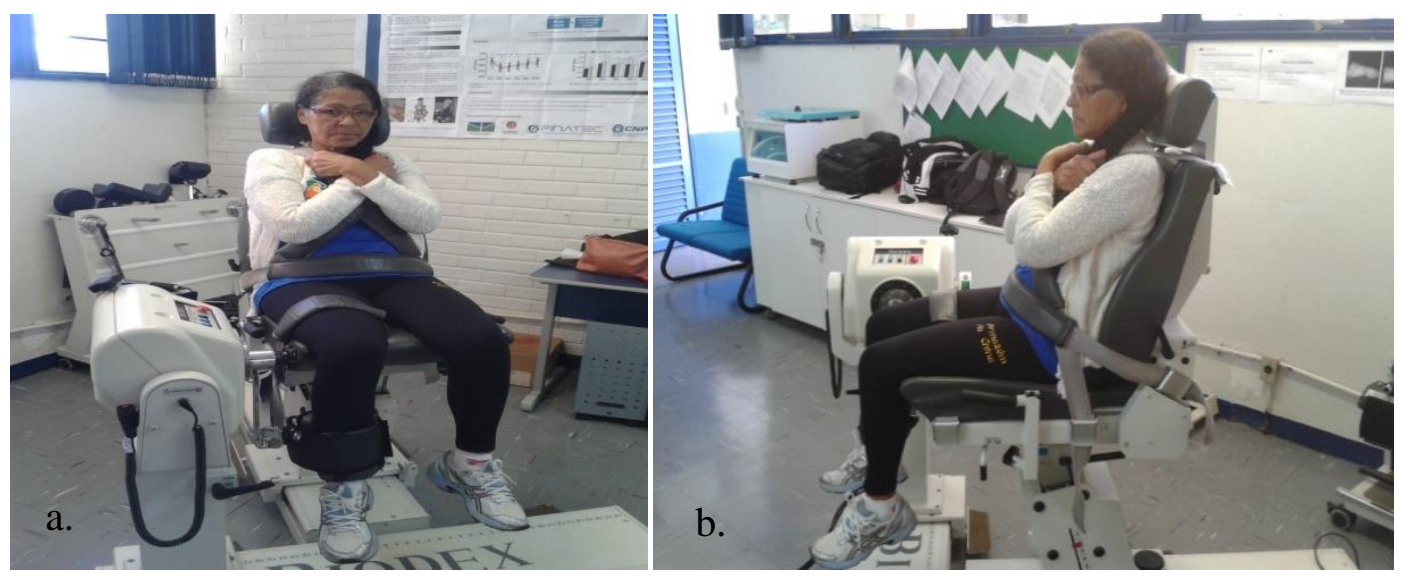

Figura 11 - Avaliação de PT isocinético para flexão e extensão de joelhos; a. vista frontal dos ajustes; b. vista lateral dos ajustes. Fonte: Autora, 2015.
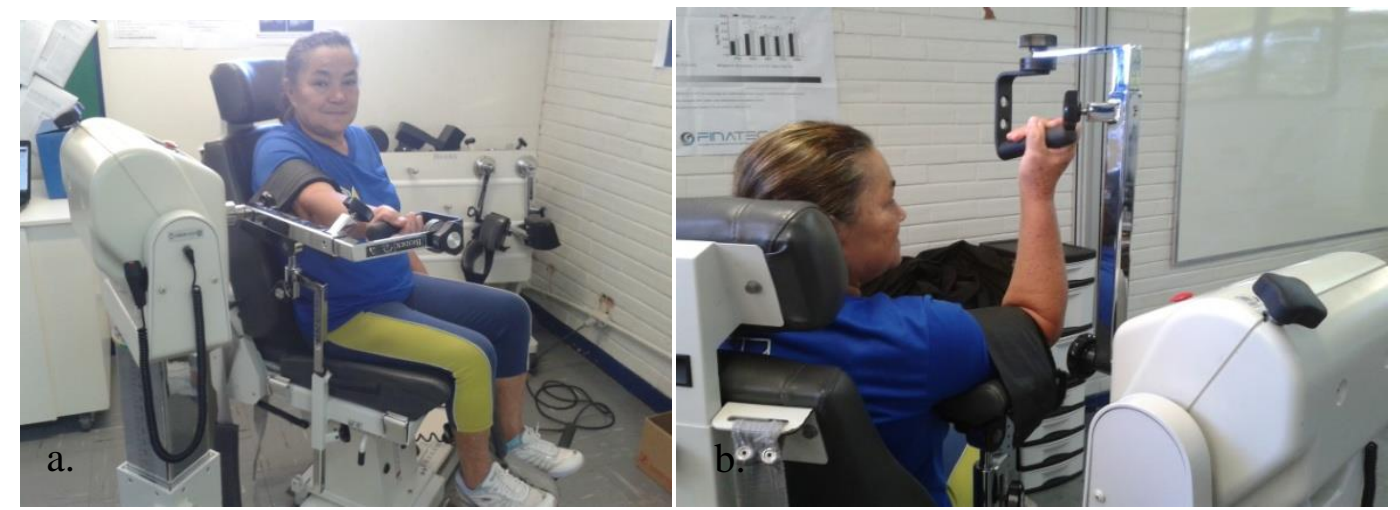

Figura 12 - Avaliação de PT isocinético para flexão/extensão de cotovelo; a. posição inicial do movimento de flexão de cotovelo; b. posição final do movimento de flexão de cotovelo. Fonte: Autora, 2015.

O protocolo de aferição do PT no momento PRÉ e PÓS-12 foi realizado aleatóriamente por sorteio da seguinte maneira:

Protocolo 1 - uma série de aquecimento de dez repetições de extensão do joelho ou cotovelo dominante a $300 \%$ s; duas séries de quatro repetições a $60 \%$ de extensão do joelho ou cotovelo; duas séries de quatro repetições a $180^{\circ}$ s.

Protocolo 2 - uma série de aquecimento de dez repetições de extensão do joelho ou cotovelo dominante a $300 \%$ s; duas séries de quatro repetições a $180 \%$ s de extensão do joelho ou cotovelo; duas séries de quatro repetições a $60 \%$ s.

O intervalo entre as três de contrações foi de um minuto. Por questões de logistica, todas as voluntárias realizavam o protocolo intervenção para o PT de membro inferior e em seguida o instrumento era regulado e calibrado para realização do teste para PT de membro superior. 
Para estabilizar o corpo ao máximo e minimizar movimentos extras, os voluntários forma posicionados na cadeira do dinamômetro em posição confortável e fixado os cintos de segurança. Os posicionamentos foram regulados de acordo com as instruções contidas no manual do fabricante para o membro superior e inferior. Foram registrados no momento PRÉ para cada indivíduo; (a) altura da cadeira; (b) regulagem do encosto; (c) posição da cadeira; (d) posição do dinamômetro; (e) posição do braço de resistência: (f) altura do suporte para os pés; $(\mathrm{g})$ altura do encosto do braço. Foi utilizado encorajamento verbal e visual para tentar alcançar o nível máximo de esforço.

\subsubsection{AVALIAÇÕES 2 - FCE-UnB}

As avaliações 2 foram realizadas no Ginásio Terapêutico da UnB - Faculdade de Ceilândia. Todas as voluntárias foram previamente agendas e confirmadas pelos pesquisadores participantes do estudo. As avaliações seguiram a sequência demonstrada na figura 13.

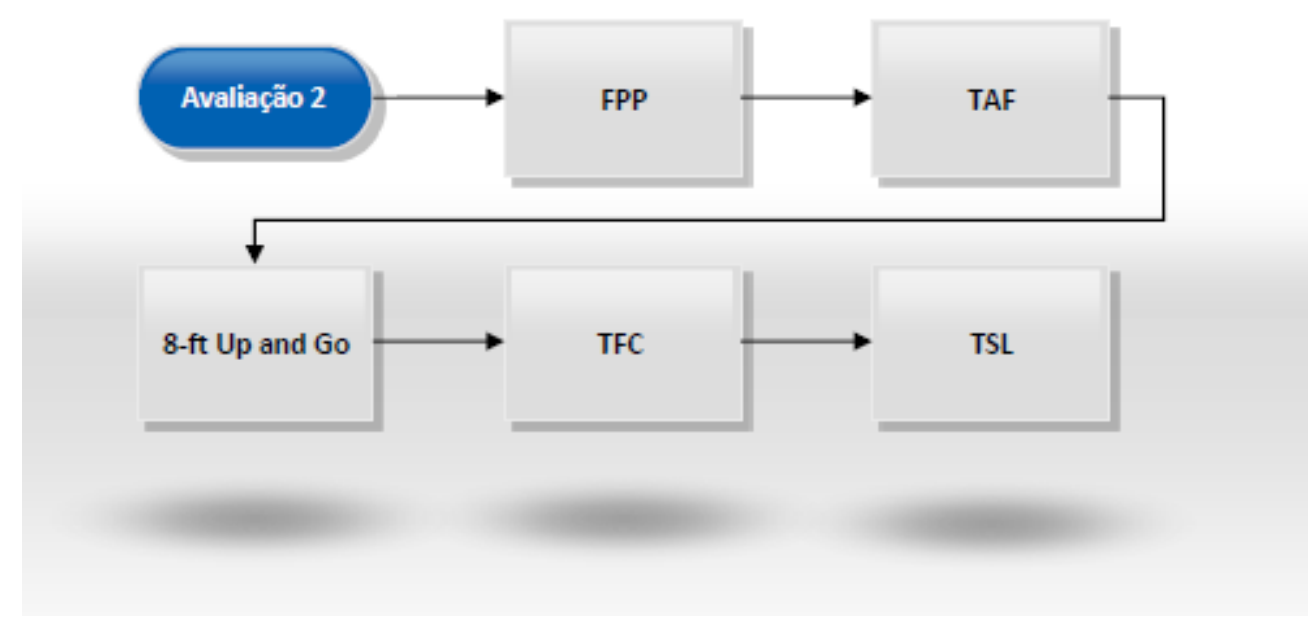

Figura 13 - Avaliação 2 - Sequência: 1) Força de Preensão Palmar; 2) Teste de alcance funcional; 3) 8 foot up and go, 4) Teste de Flexão de Cotovelo; 5) Teste de Sentar e Levantar. Fonte: Autora, 2015.

\subsection{FORÇA DE PREENSÃO MANUAL}

Todo procedimento de avaliação foi realizado de forma sistemática e com o mesmo rigor de protocolo em todas as avaliações . As voluntárias foram posicionadas de acordo com as recomendações da ASTH (American Society of Hand Therapist) no qual devem 
permanecer sentada em uma cadeira uma sem apoio lateral, com o ombro do membro superior a ser medido em adução, rotação neutra, cotovelo a $90^{\circ}$ de flexão e com o antebraço e punho em posição neutra (Figura 14). Nessa posição as voluntárias realizaram três contrações máximas de cinco segundos com intervalo de um minuto e encorajamento verbal pelo avaliador durante as contrações máximas. Foi registrado o maior valor entre as três tentativas para fins de análise estatística. No intervalo entre as tentativas o avaliador segurava o dinamômetro para o descanso da voluntária (Therapists, 1992).

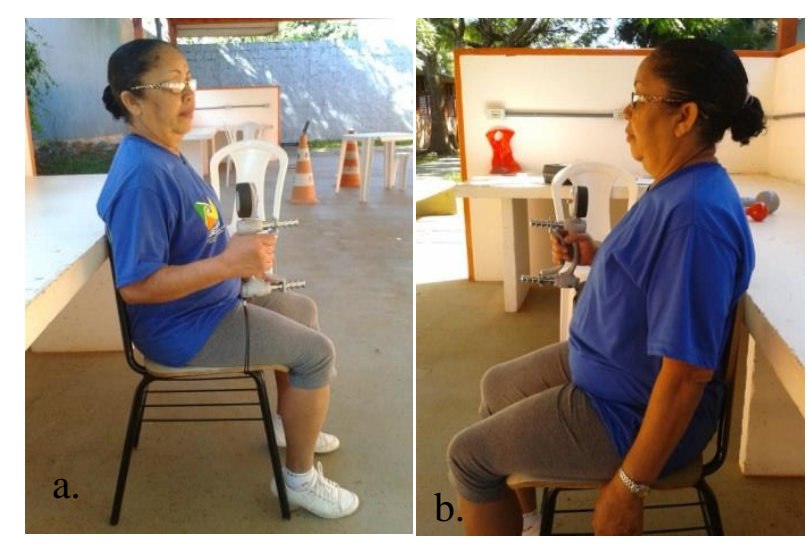

Figura 14 - Teste de Força de Preensão Palmar. Fonte: Autora, 2015.

\subsection{TESTE DE ALCANCE FUNCIONAL}

No teste de alcance funcional a voluntária permaneceu na posição ortostática com coluna ereta, braço em flexão a $90^{\circ}$ e corpo próximo a parede onde deve ser fixada uma fita métrica. A partir dessa posição, foi solicitado que a voluntária se deslocasse anteriormente o máximo que conseguisse sem que a base fixa dos pés fossem alteradas, mantendo-se dentro dos limites da estabilidade. Foram realizadas três tentativas e para análise foi utilizada a maior distância em centímetros alcançada nas três tentativas (Duncan, Weiner et al.).

\subsection{TESTE DE FLEXÃO DE COTOVELO}

No teste de flexão de cotovelo, o principal objetivo é avaliar a força indireta dos membros superiores. Serão utilizados cadeira, cronometro e halteres de mão de $2 \mathrm{~kg}$. $\mathrm{Na}$ Figura 15, temos o posicionamento da voluntária para o teste. Ela permaneceu sentada em uma cadeira com as costas retas, os pés no chão e o lado dominante do corpo próximo à borda 
da cadeira. A voluntária segura o halter com a mão dominante, utilizando uma empunhadura de aperto de mão. O teste começa com o braço estendido perto da cadeira e perpendicular ao chão. Ao sinal indicativo, a voluntária realiza a flexão de cotovelo e retorna o braço para uma posição completamente estendida. Foi registrada a quantidade máxima de repetições completas realizadas em 30 segundos. A variável a ser utilizada para análise será o número de repetições realizadas (Rikli, 2008).
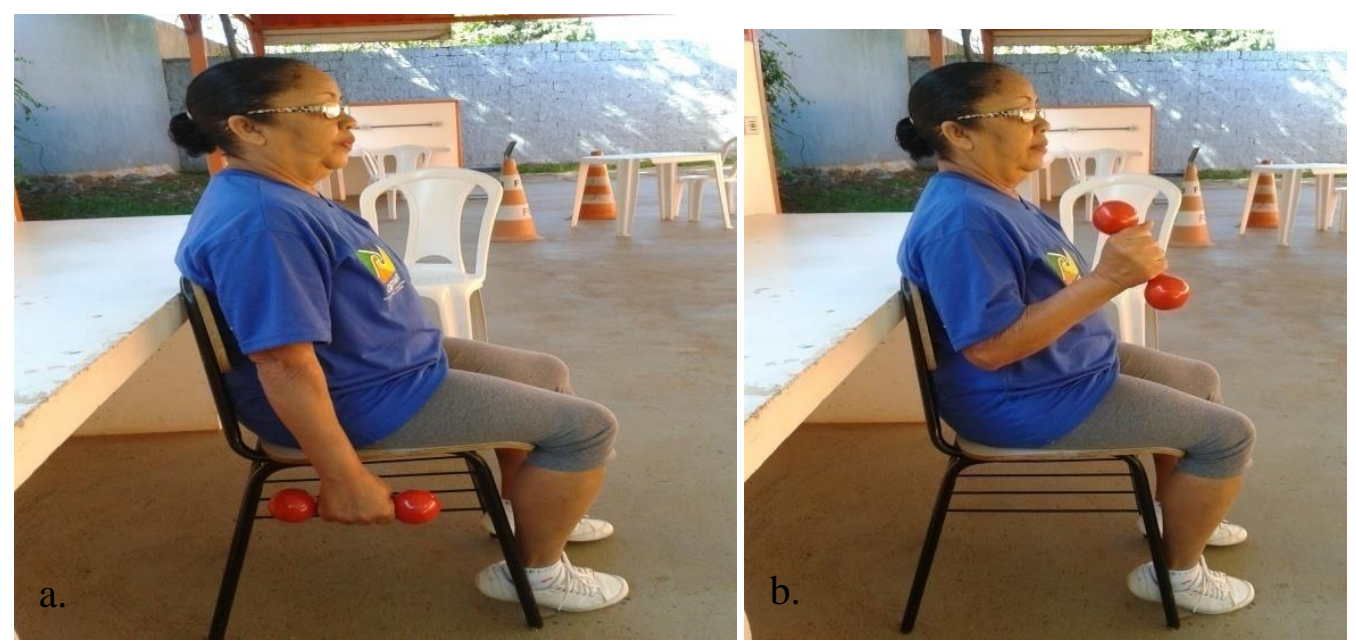

Figura 15 - Teste de Flexão de Cotovelo; a. posição inicial do TFC; b. execução do TFC. Fonte: Autora, 2015.

\subsubsection{4. $\quad 8$ FOOT UP AND GO}

Foi avaliada o tempo em que o indivíduo consegue levantar-se da cadeira, caminhar 2,44m e retornar a cadeira e sentar-se (Figura 16). O desempenho é afetado pelo tempo de reação, força muscular de MMII, equilíbrio e desempenho na marcha. O objetivo do teste é avaliar a agilidade e equilíbrio dinâmico.

As participantes iniciaram o teste em posição sentada, em uma cadeira, com a coluna ereta o mais próximo da borda do assento. Uma linha de demarcação foi utilizada sob o solo para o posicionamento correto dos pés. As participantes apoiaram as palmas das mãos sobre as coxas e ao sinal do avaliador, ela levantou da cadeira, caminhou rapidamente, sem correr, ao redor de um cone e retornou à cadeira. Foram conduzidas 3 tentativas, com intervalo de recuperação de 1 minuto entre elas, sendo utilizada para análise estatística pontuação referente ao menor tempo percorrido para a realização do teste. Em todas as avaliações, a cadeira foi encostada na parede para evitar acidentes. $\mathrm{O}$ cone foi posicionado a uma distância de 2,44 metros da marcação feita para o posicionamento dos pés. 


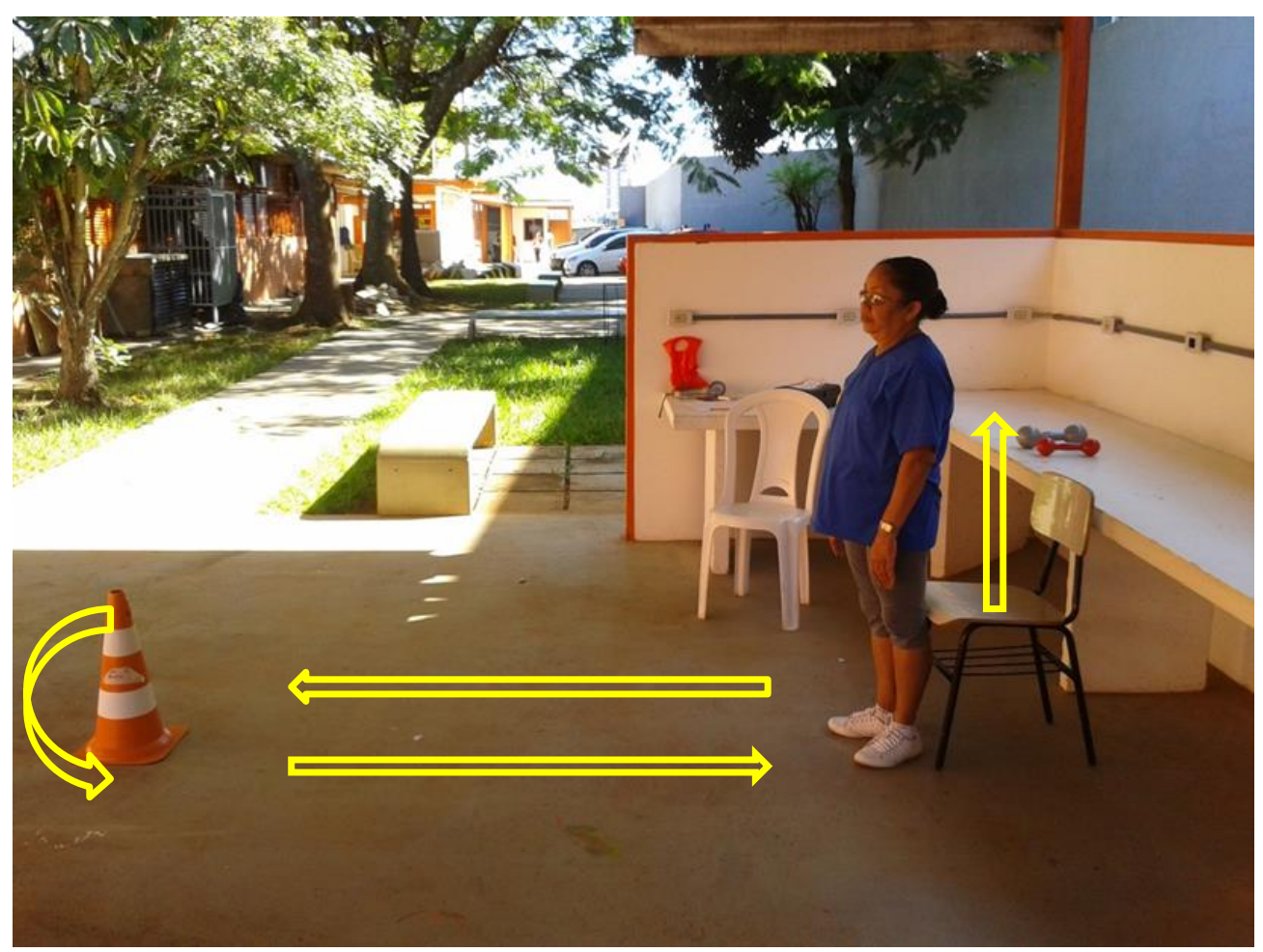

Figura 16 - Teste 8 foot up \& go. Fonte: Autora, 2015.

\subsection{TESTE DE SENTAR E LEVANTAR}

No Teste de Levantar da cadeira, o principal objetivo é avaliar a força indireta dos membros inferiores. Serão utilizados cadeira e cronômetro. O teste inicia com o voluntário sentado na cadeira de $43 \mathrm{~cm}$ de altura com as plantas dos pés sobre o solo e braços cruzados a região peitoral. Ao sinal "Preparar, vai!", o avaliado deve levantar-se totalmente e retornar a posição inicial e repetir esses movimentos durante 30 segundos(Figura 16). Foi registrada a quantidade máxima de repetições completas realizadas em uma tentativa.

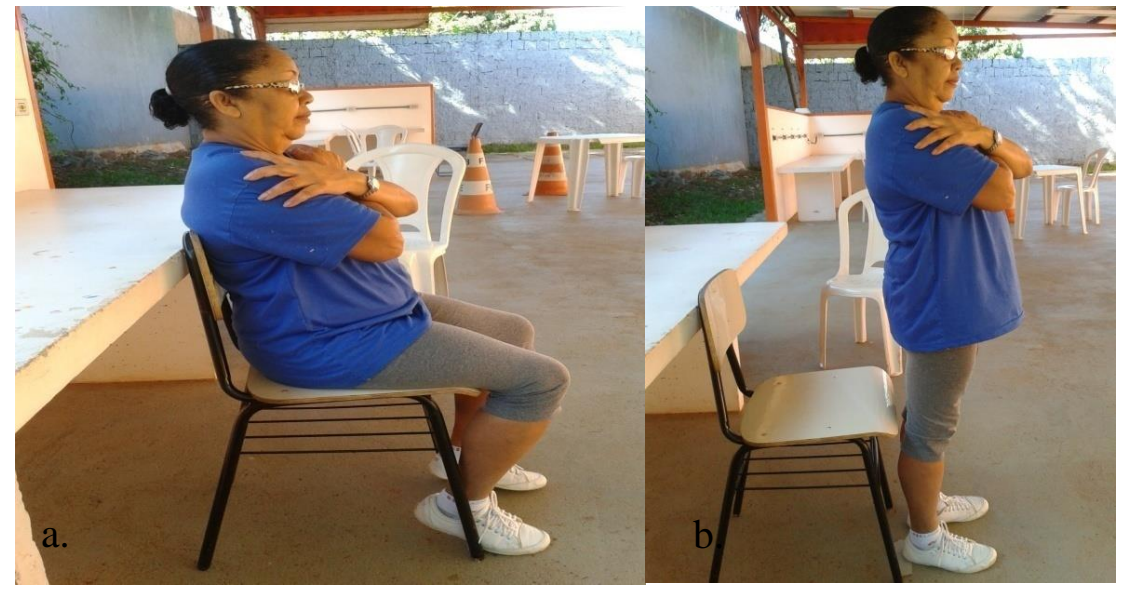

Figura 17 - Teste Sentar e Levantar; a. posição inicial; b. posição final. Fonte: Autora, 2015. 


\subsection{INTERVENÇÃO}

O treinamento resistido teve duração de 12 semanas e foi realizado nas dependências do Ginásio Terapêutico pelo GTM e Espaço de Convivência pelo GTRE da Universidade de Brasília - Campus Ceilândia. Todos as participantes passaram por um período de adaptação neuromuscular de duas semanas antes de iniciarem o programa específico de treinamento. A fase de familiarização é importante para que além da adaptação muscular, as participantes aprendam a manusear os aparelhos, realizem o treinamento de forma correta e recebam instruções sobre o andamento do projeto.

Tanto na fase de familiarização quanto na intervenção, foram realizados dois treinos semanais com intervalo de descanso entre as sessões de $48 \mathrm{hs}$. Ao final do programa cada voluntária realizou 24 sessões de treinamento ou até $75 \%$ dos treinamentos. Foram propostos treinamentos extras para reposição e as voluntárias que faltaram três vezes consecutivas foram eliminadas do projeto conforme elucidado no TCLE.

Cada sessão de treino teve duração aproximada de uma hora em ambos os grupos. Os treinos foram compostos por nove exercícios para os dois grupos (GTM e GTRE), são eles: Supino, remada, puxada, tríceps, abdução de quadril, extensão de quadril e extensão e flexão de joelhos sendo que para os exercícios de membros superiores e quadril as participantes do GTRE executavam os exercícios na posição ortostática enquanto que no GTM era realizado com as participantes sentadas ou com o apoio das máquinas conforme Tabela 2.

\begin{tabular}{|c|c|c|c|c|}
\hline \multirow{5}{*}{ 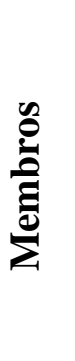 } & \multirow{5}{*}{ 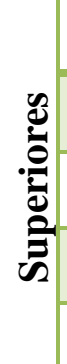 } & $\mathbf{N}^{\mathbf{o}}$ & GTRE & GTM \\
\hline & & 1 & Supino Reto & Supino Reto \\
\hline & & 2 & Puxada Alta & Puxada Alta \\
\hline & & 3 & Tríceps & Tríceps Máquina \\
\hline & & 4 & Remada & Remada Sentado \\
\hline \multirow{5}{*}{ 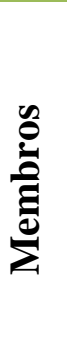 } & \multirow{5}{*}{ 窇 } & 5 & Flexão de Joelhos & Cadeira Flexora \\
\hline & & 6 & Extensão de Joelhos & Cadeira Extensora \\
\hline & & 7 & Abdução de Quadril & Abdução de Quadril (sentado) \\
\hline & & 8 & Extensão de Quadril & Extensão de Quadril \\
\hline & & 9 & Deslocamento Lateral & Abdução de Quadril (em pé) \\
\hline
\end{tabular}

Tabela 2 - Exercícios realizados durante o período de treinamento no GTM e GTRE 
Os testes de Repetições Máximas (RM) e as intervenções ocorreram na Faculdade da Ceilândia-UnB em dois dias distintos e com intervalo de descanso de 48hs antes da fase de familiarização em ambos os grupos. Durante a familiarização, os voluntários realizaram duas séries de 15 a 20 repetições, utilizando um minuto de recuperação e com intensidade leve a moderada, utilizando a carga definida nos testes de RM em todos os exercícios. As doze semanas de treinamento foram divididas em três meso ciclos (quatro semanas cada meso ciclo), utilizando uma periodização clássica (Linear), conforme a tabela 3 apresentada abaixo. O controle das variáveis agudas do treinamento seguiu as recomendações do American Colloge of Sports Medicine (ACMS, 2009).

\begin{tabular}{|c|c|c|c|c|c|c|}
\hline & Semana & $\mathbf{N}^{0}$ Séries & $\mathbf{N}^{0}$ Repetições & Recuperação & $\begin{array}{l}\text { Ordem de } \\
\text { Exercício }\end{array}$ & Carga \\
\hline Teste RM & $1^{a}$ & & & & \multirow{5}{*}{ 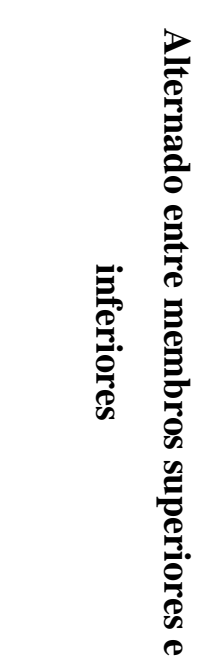 } & \multirow{5}{*}{ 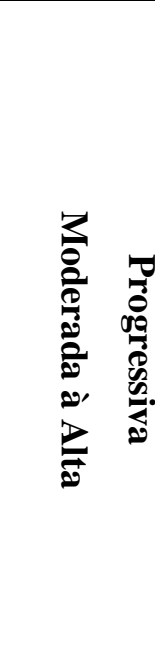 } \\
\hline Familiarização & $2^{a}$ e $3^{a}$ & 2 & $15-20$ & $60 \mathrm{~s}$ & & \\
\hline Mesociclo I & $4^{a}$ a $7^{a}$ & 3 & $12-15$ & $60 \mathrm{~s}$ & & \\
\hline Meso ciclo II & $8^{\mathrm{a}}$ a $11^{\mathrm{a}}$ & 3 & $10-12$ & $60 \mathrm{~s}$ & & \\
\hline Mesociclo II & $12^{\mathrm{a}}$ a $15^{\mathrm{a}}$ & 3 & 08-10 & $60 \mathrm{~s}$ & & \\
\hline
\end{tabular}

Tabela 3 - Divisão dos meso ciclos de treinamento, duração, número de séries e repetições, intervalo de recuperação, ordem de exercício e carga utilizada ao longo de 12 semanas de treinamento.

As figuras de 18 a 26 a seguir demonstram os exercícios realizados por cada grupo e a maneira para executá-los com Resistência Elástica Progressiva ou Máquinas Pneumáticas nos distintos grupos. 

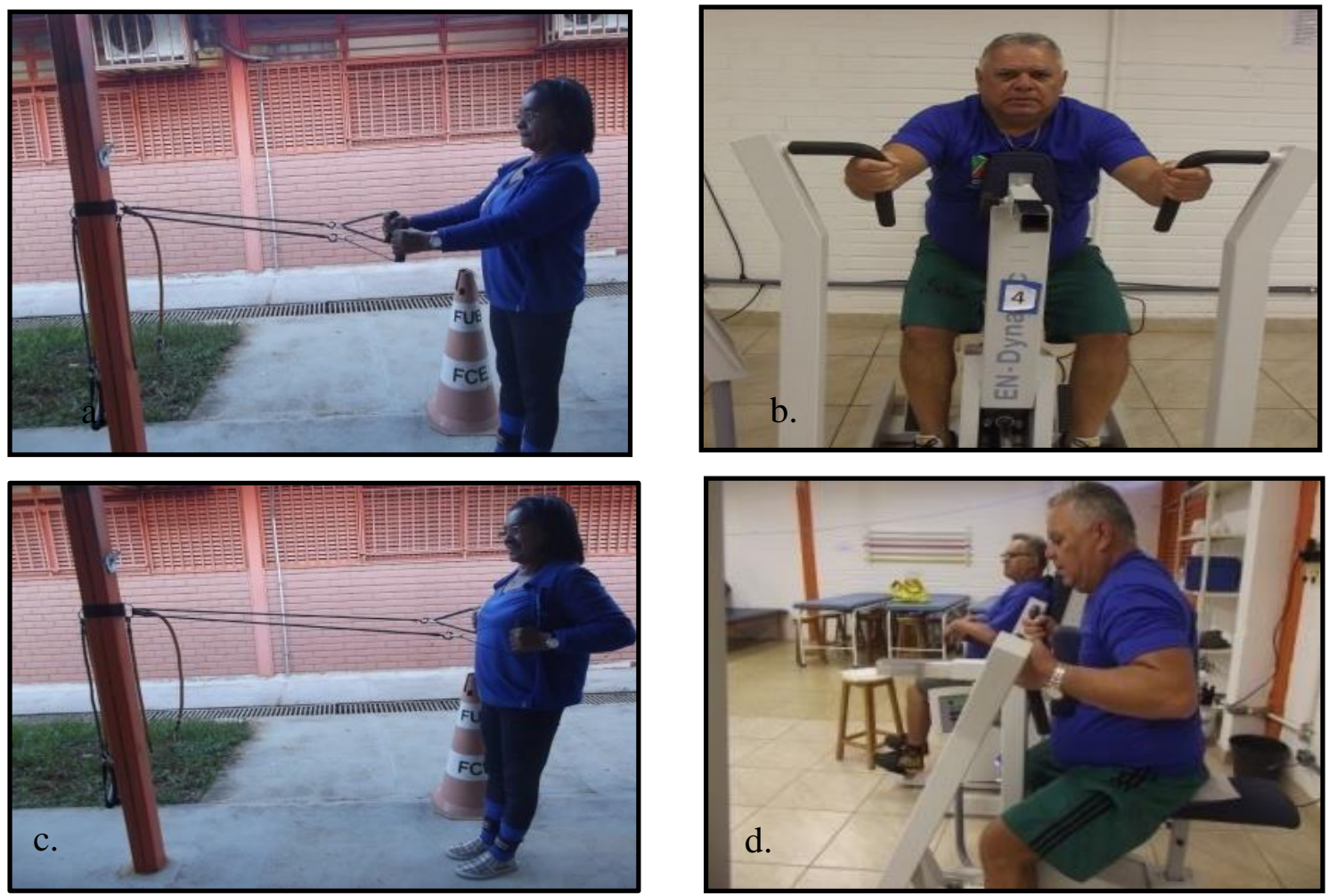

Figura 18 - Exercício Remada - a. e b. Posicionamento inicial RE e MP; c. e d. Posicionamento final RE e MP. Fonte: Autora 2015.
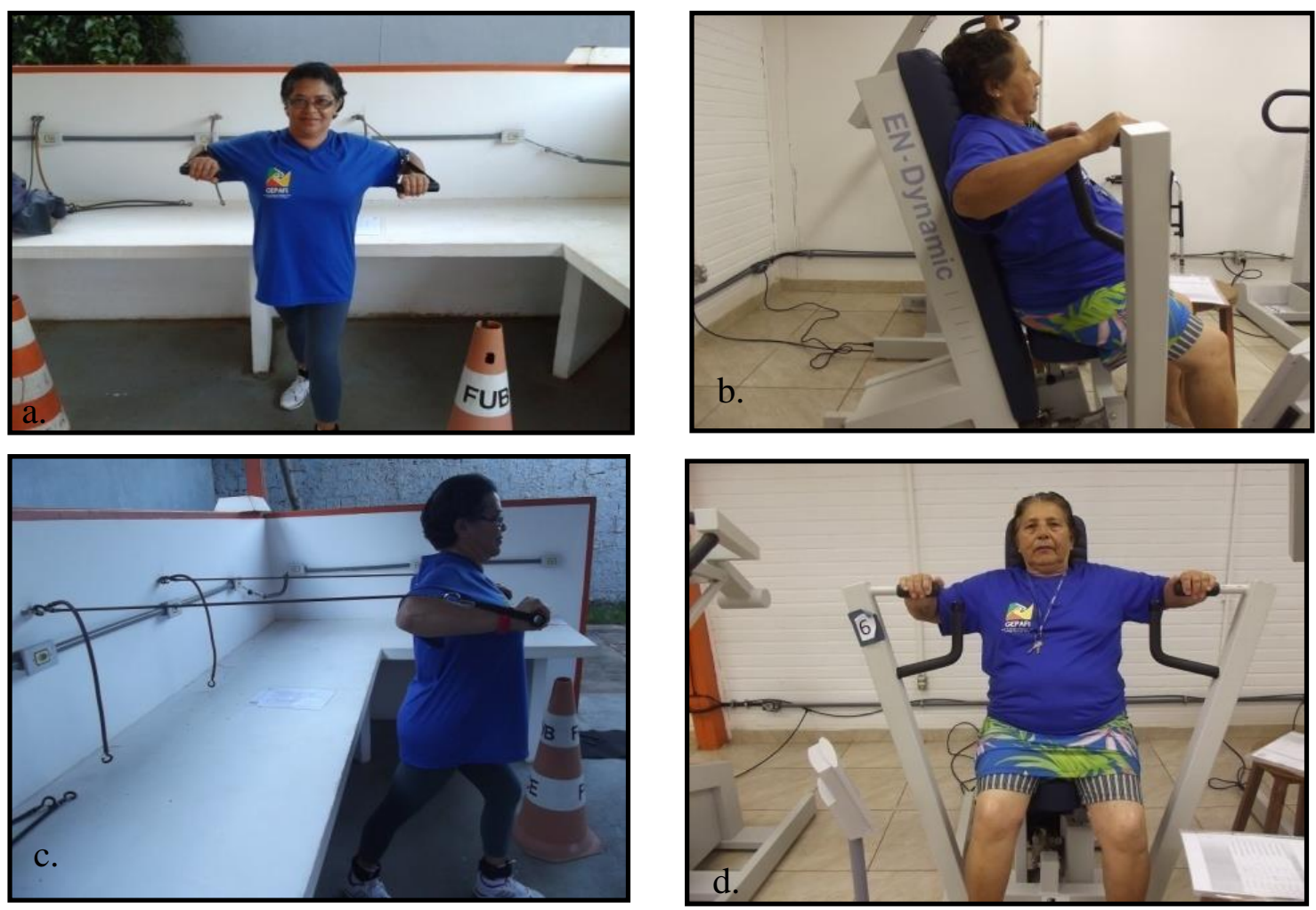

Figura 19 - Exercício Supino a. e b. Posicionamento inicial RE e MP; c. e d. Posicionamento final RE e MP.

Fonte: Autora, 2015. 

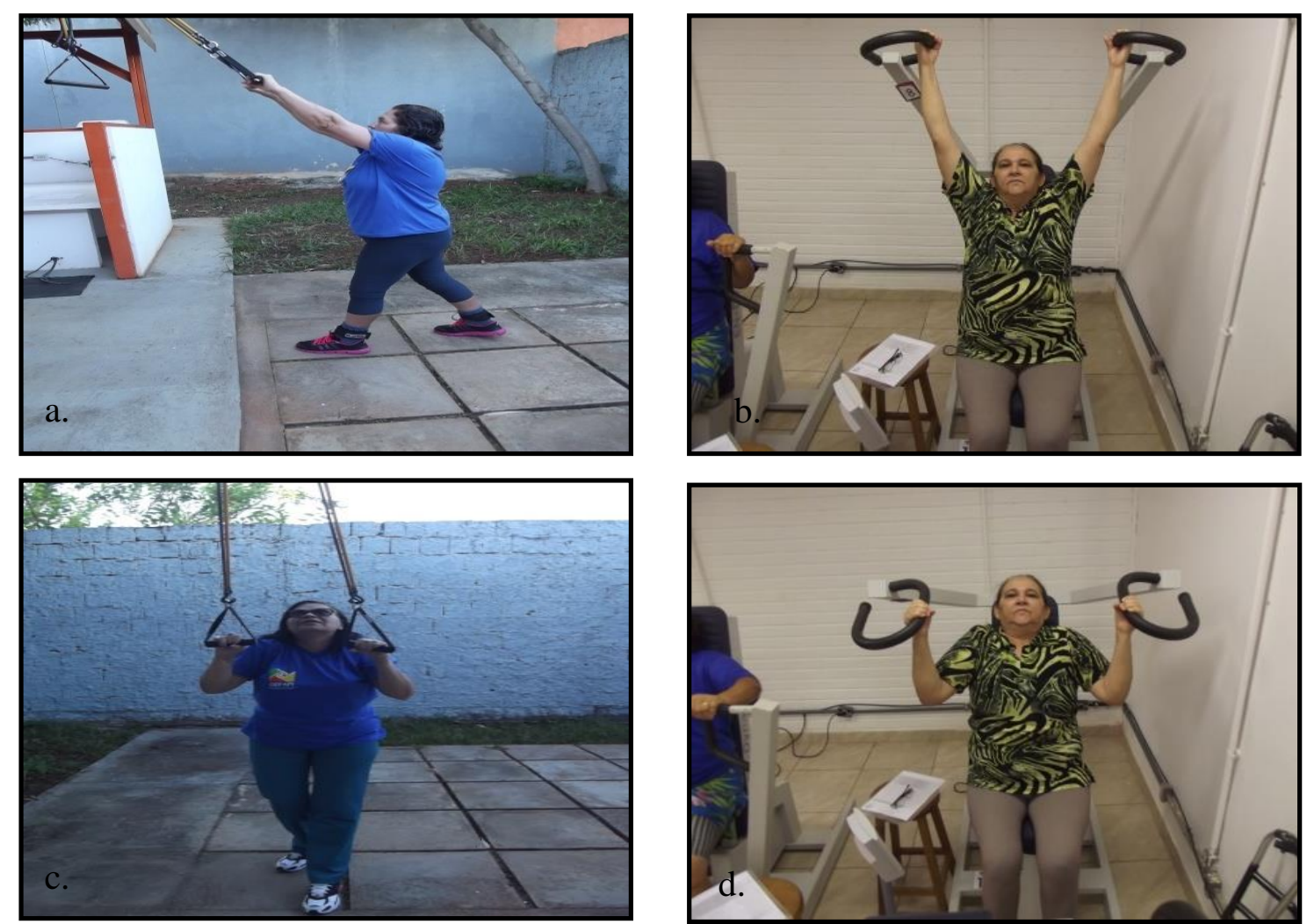

Figura 20 - Exercício Puxada alta - a. e b. Posicionamento inicial RE e MP; c. e d. Posicionamento final RE e MP. Fonte: Autora 2015
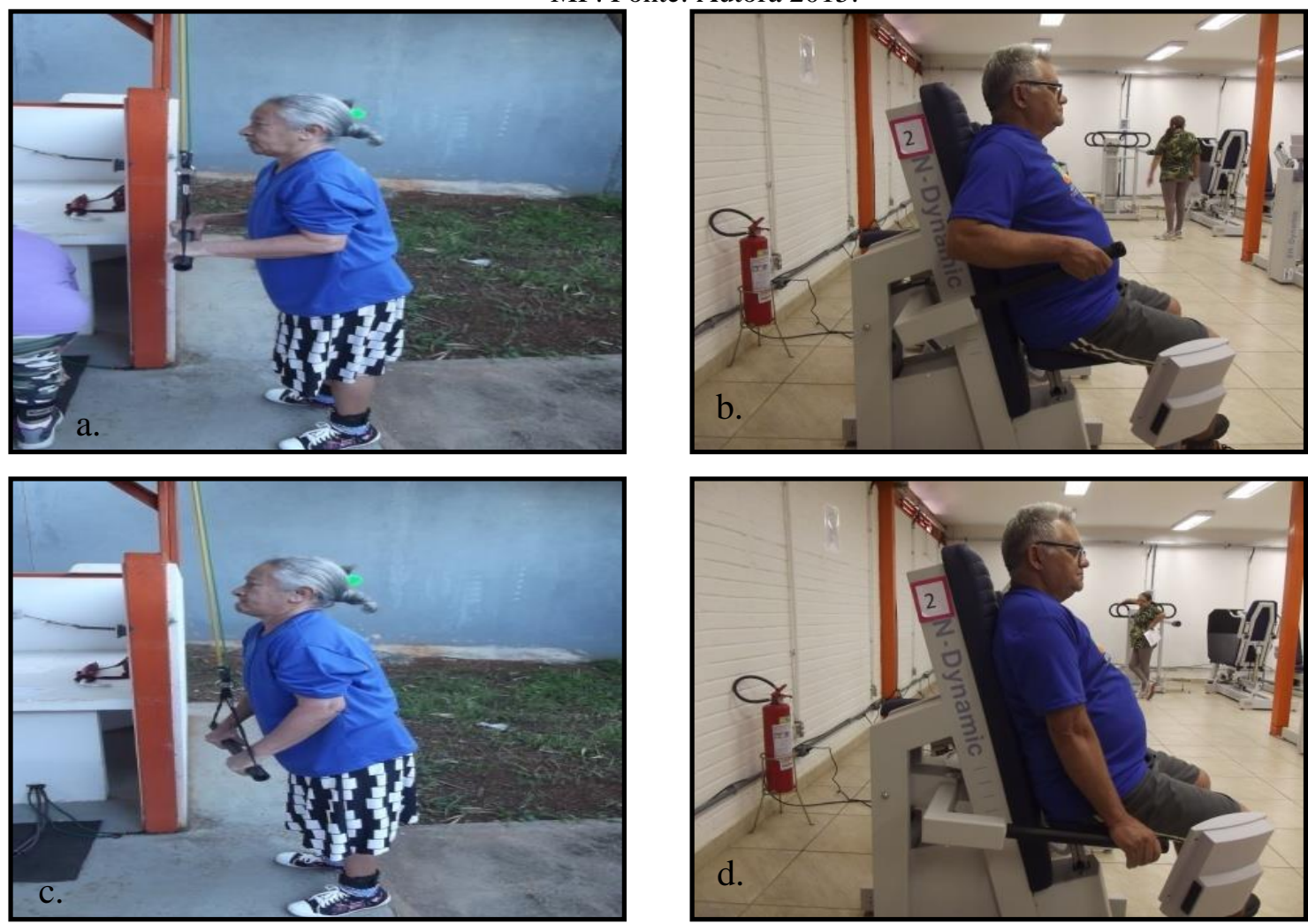

Figura 21 - Exercício Tríceps - a. e b. Posicionamento inicial RE e MP; c. e d. Posicionamento final RE e MP. Fonte: Autora, 2015. 

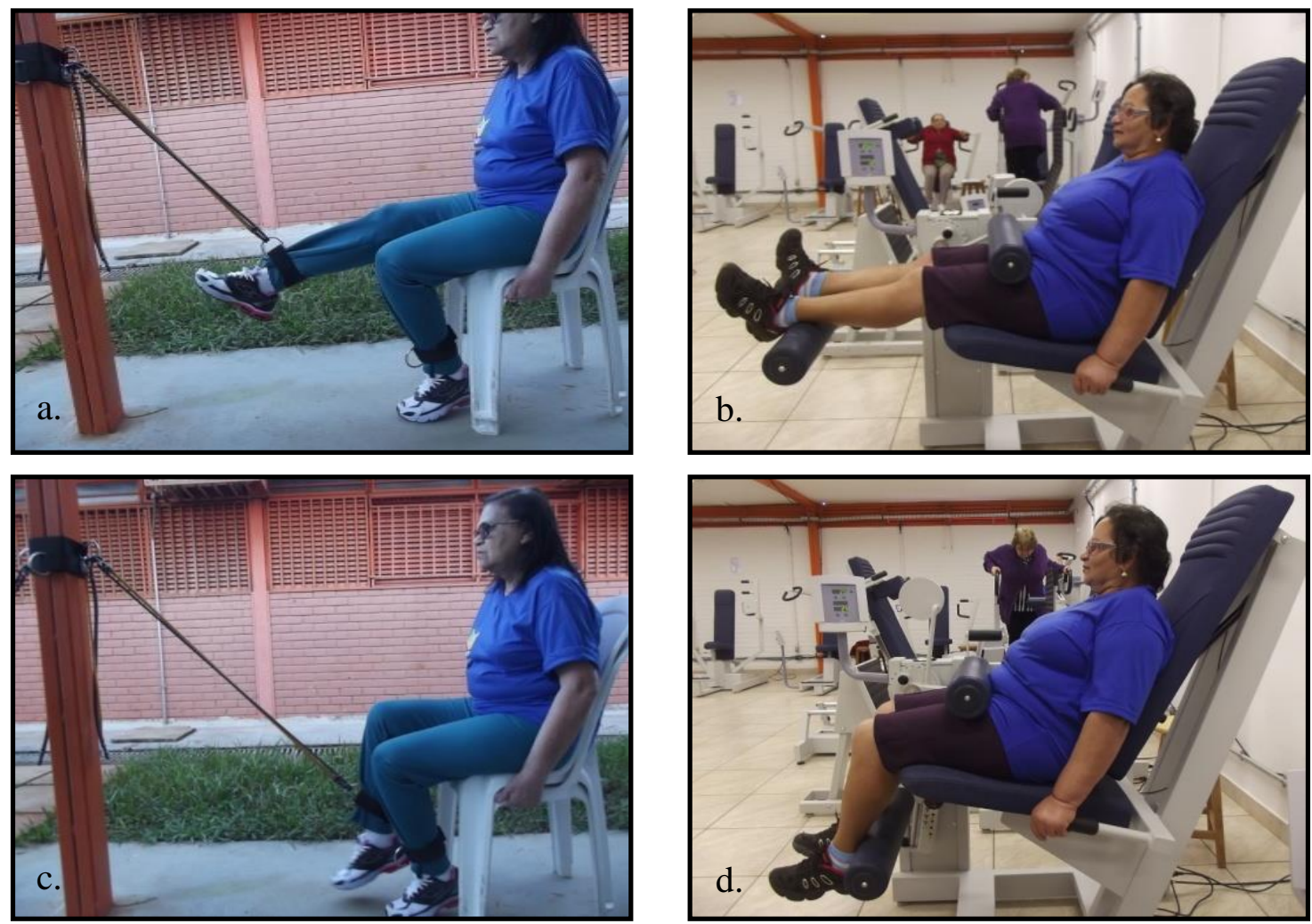

Figura 22 - Exercício Flexão de Joelhos - a. e b. Posicionamento inicial RE e MP; c. e d. Posicionamento final RE e MP. Fonte: Autora, 2015
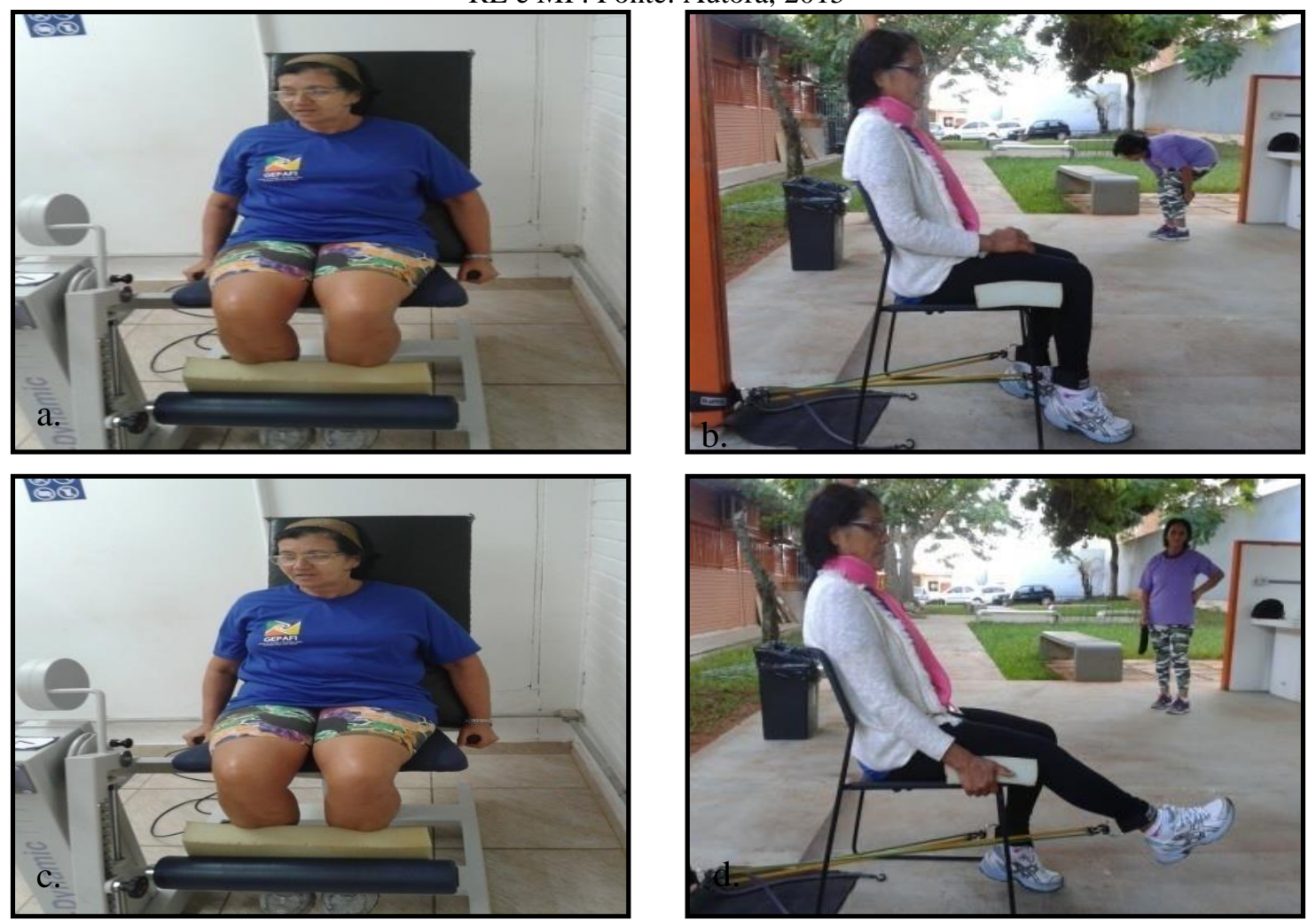

Figura 23 - Exercício Extensão de Joelhos - a. e b. Posicionamento inicial RE e MP; c. posição MP; d. Posicionamento final RE. Fonte: Autora, 2015 

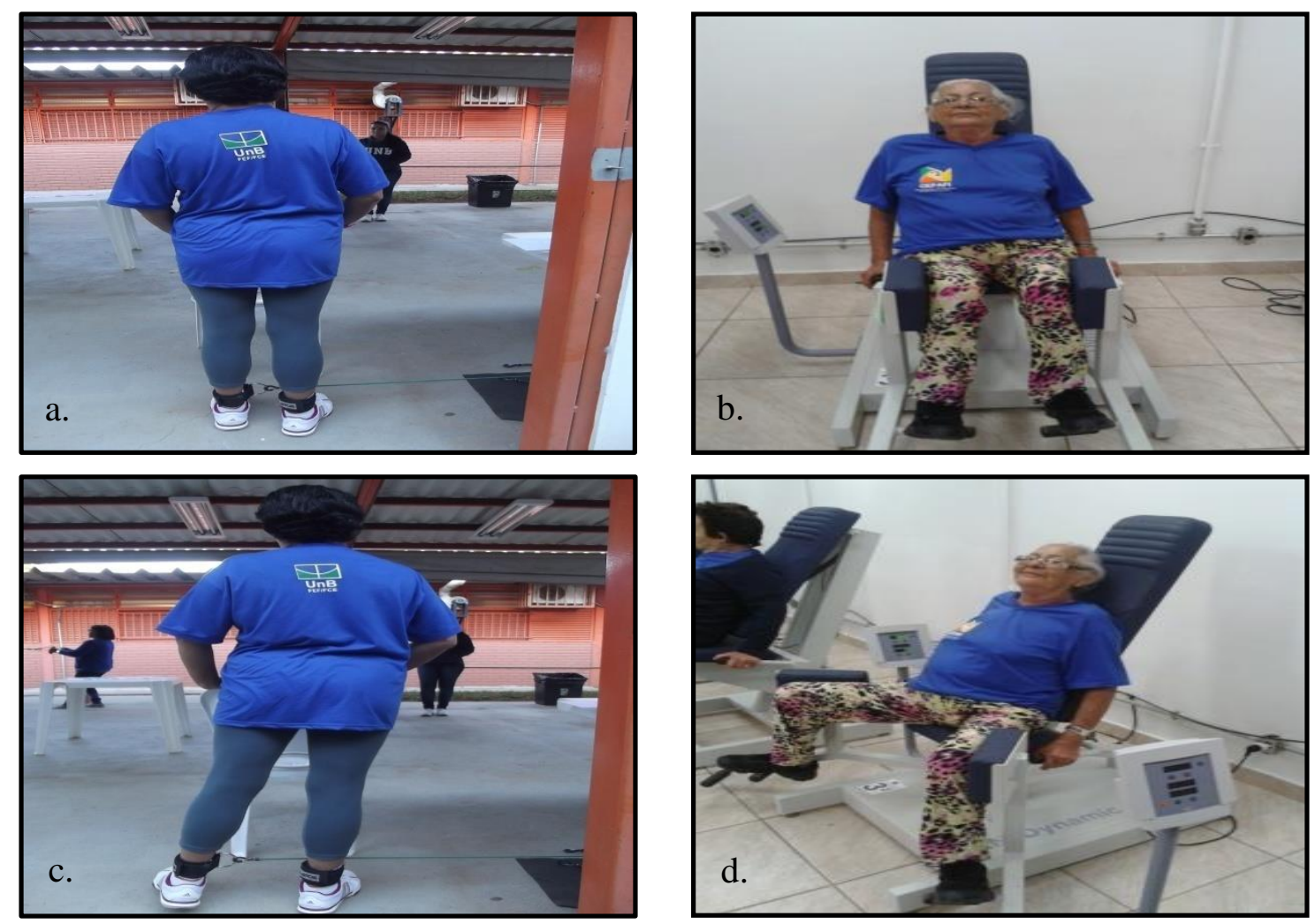

Figura 24 - Exercício Abdução de quadril - a. e b. Posicionamento inicial RE e MP; c. e d. Posicionamento final RE e MP. Fonte: Autora, 2015.
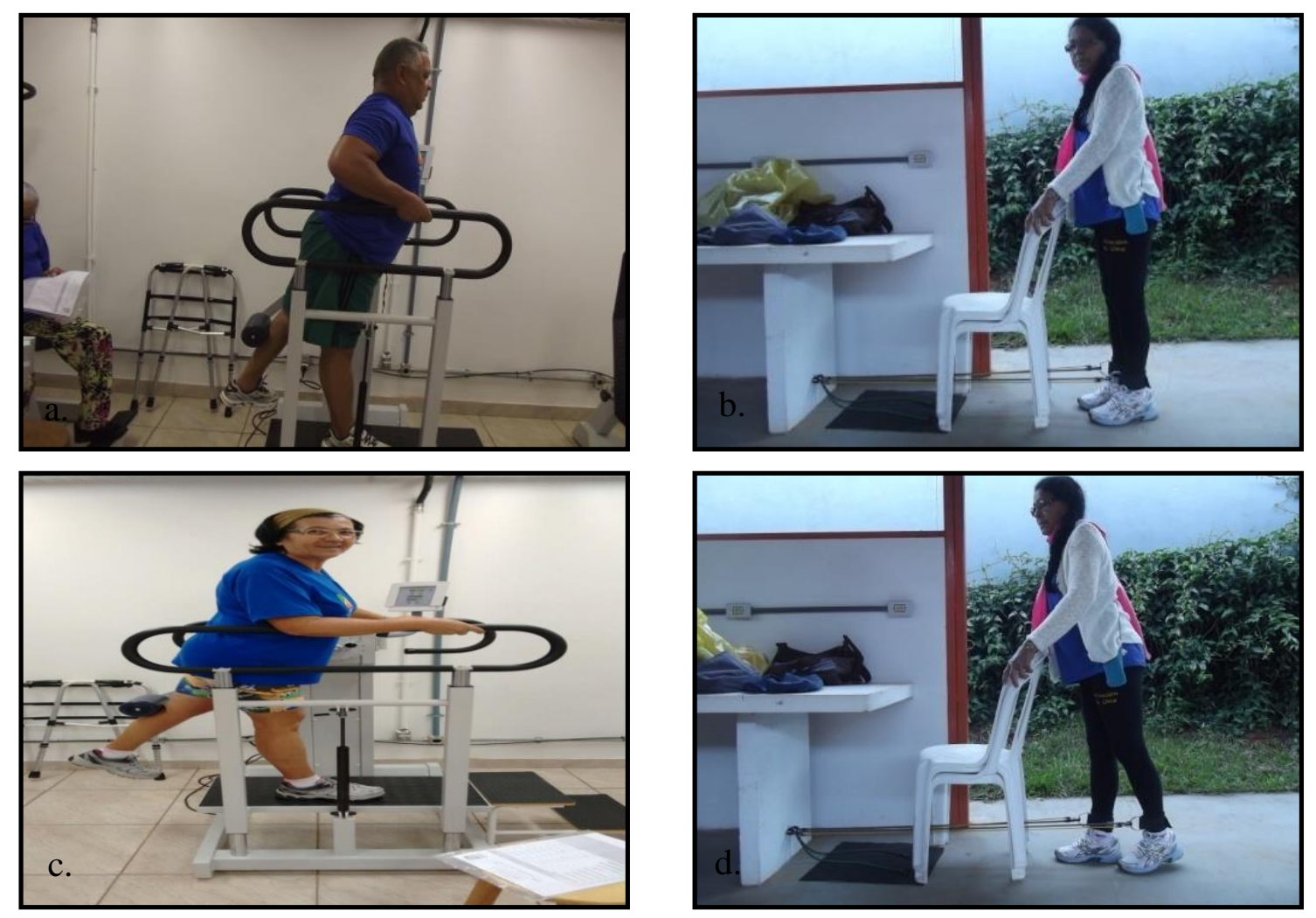

Figura 25 - Exercício Extensão de quadril - a. e b. Posicionamento inicial RE e MP; c. e d. Posicionamento final RE e MP. Fonte: Autora, 2015. 

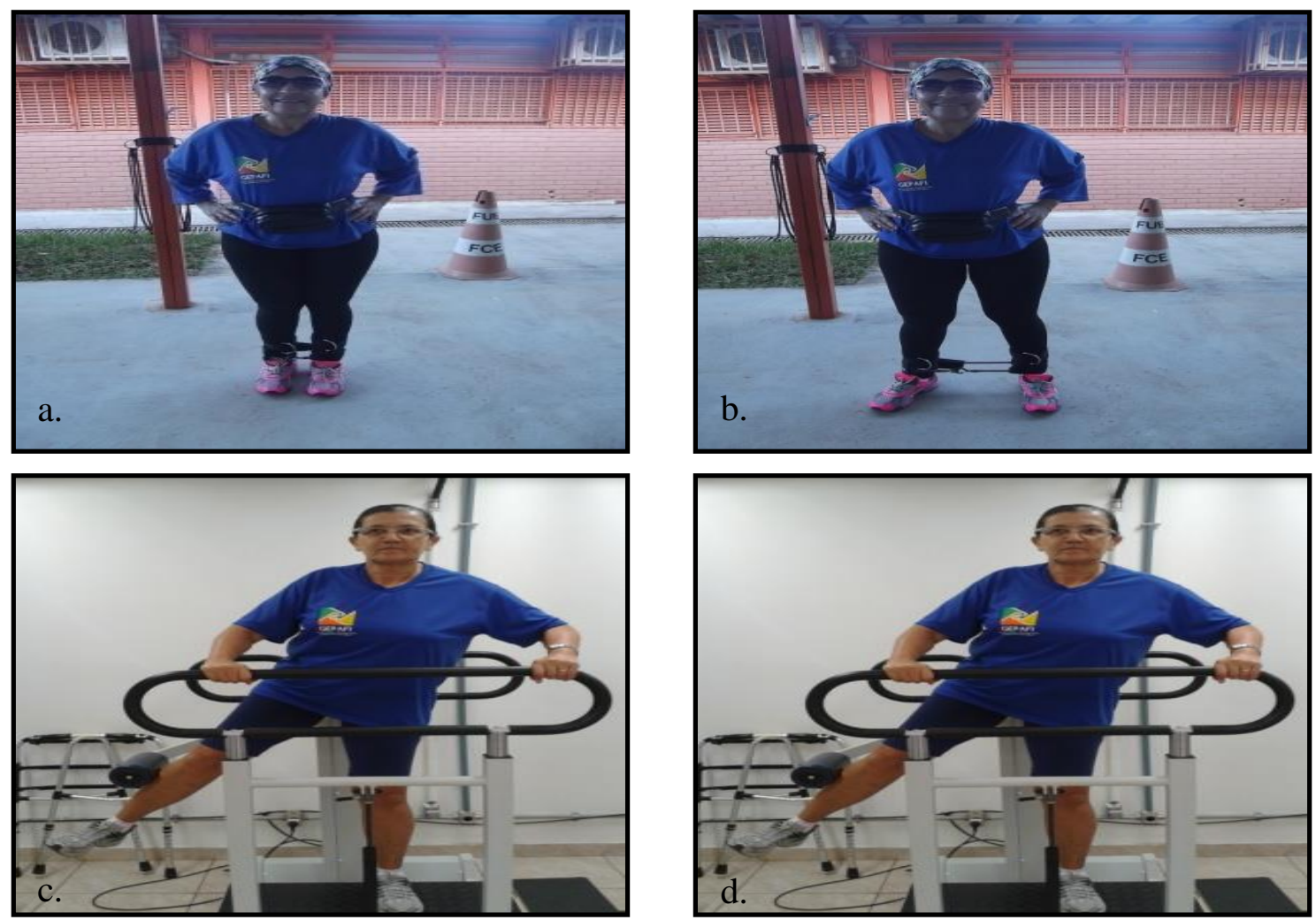

Figura 26 - Exercício Deslocamento RE e Abdução de quadril MP. - a. e b. Posicionamento inicial RE e MP; c. e d. Posicionamento final RE e MP. Fonte: Autora, 2015.

Conforme dito anteriormente, para que a intensidade da carga fosse determinada, foi adotado um método que monitora o número de repetições máximas alvo para cada meso ciclo de treino. Nas duas semanas que antecederam o período de treinamento, foram realizada 2 séries de 15 a 20 RM e a cada meso ciclo o número de repetições diminuiu juntamente com um aumento da carga. A progressão da carga foi realizada de acordo com o número de RM alvo com a maior carga possível para atingir esse número alvo. Diante disso, a intensidade do TR progrediu ao longo das semanas de acordo com o aumento da carga e a diminuição do número de repetições para que a zona alvo de repetições fossem atingidas.

Desta maneira, toda vez que uma voluntária realizasse uma quantidade superior de repetições máximas que fora estipulada para a zona alvo de acordo com a fase de treinamento, uma carga adicional era acrescentada, seja no GTRE ou no GTM.

No GTRE, a progressão foi feita por meio dos diferentes níveis de carga de acordo com as cores dos componentes elásticos. Por se tratar de uma resistência variável que depende do percentual de estiramento e espessura do tubo, os exercícios foram realizados no momento inicial com $0 \%$ de alongamento e momento final de $150 \%$. Os momentos iniciais e finais dos 
exercícios foram demarcados com a régua de percentual de estiramento que acompanha o kit do material utilizado no presente estudo e que permite medir quatro diferentes alongamentos dos tubos $(50 \%, 100 \%, 150 \%$ e 200\%). Assim, após determinado o alongamento final máximo de $150 \%$ para os exercícios, marcações foram feitas com cones e hastes e serviram de referências permanentes ao longo do período de treinamento. Desta maneira, as participantes executaram os exercícios até que a ADM final atingisse o alongamento de $150 \%$ do componente elástico. Vale ressaltar que a medida de estiramento foi realizada independentemente do acessório exercitador utilizado, sendo que, para mensurar o percentual de estiramento foi considerado o comprimento entre os bulbos do componente elástico que possuem corte padronizado para todas as cores conforme Figura 27 abaixo:

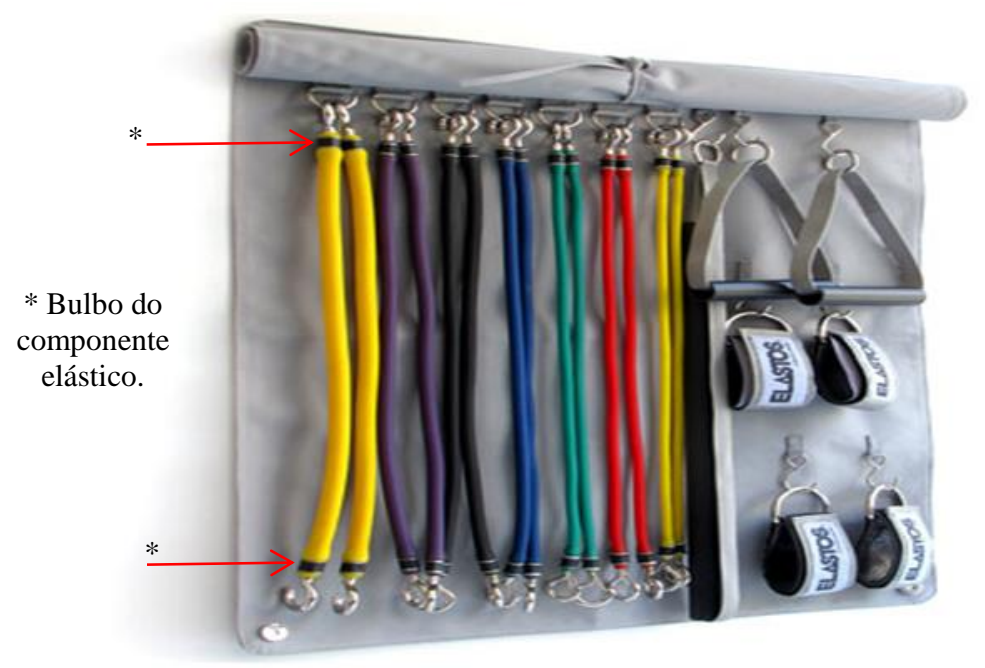

Figura 27 - Sete diferentes níveis de intensidade de acordo com cores e corte padronizado do material. Fonte: www.elastos.com.br

No GTM, o incremento de carga foi feito diretamente no display das máquinas conforme Figura 28, esse aumento foi suficiente para que a carga ideal do número de RM alvo fosse atingida . Para isso, a máquina permitiu um incremento de no mínimo $0,5 \mathrm{~N}$ ou mais até que a voluntária não conseguisse realizar nenhuma repetição a mais do que aquela solicitada para a zona alvo de cada fase de treinamento. 


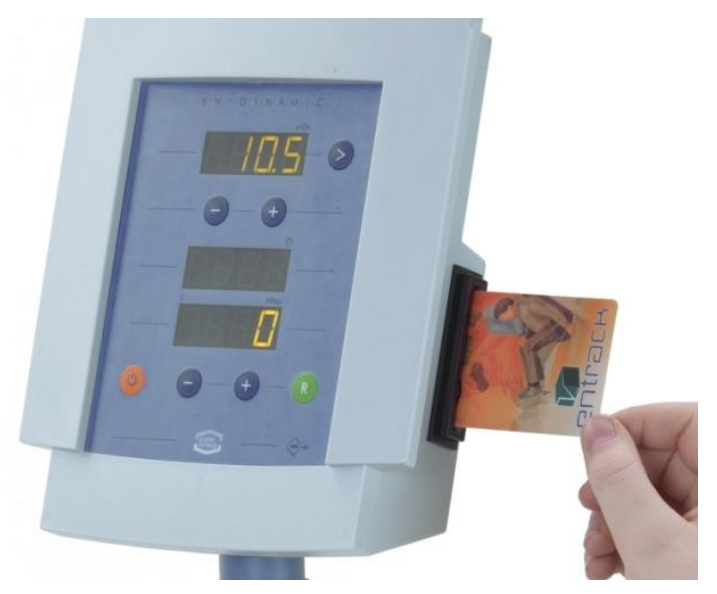

Figura 28 - Display de carga das máquinas pneumáticas. Fonte: En-dynamic Enraf-nonius.

Desta forma, os procedimentos experimentais acerca da realização do treinamento resistido ocorreu de acordo com o fluxograma abaixo para os dois grupos do presente estudo (Figura 29).

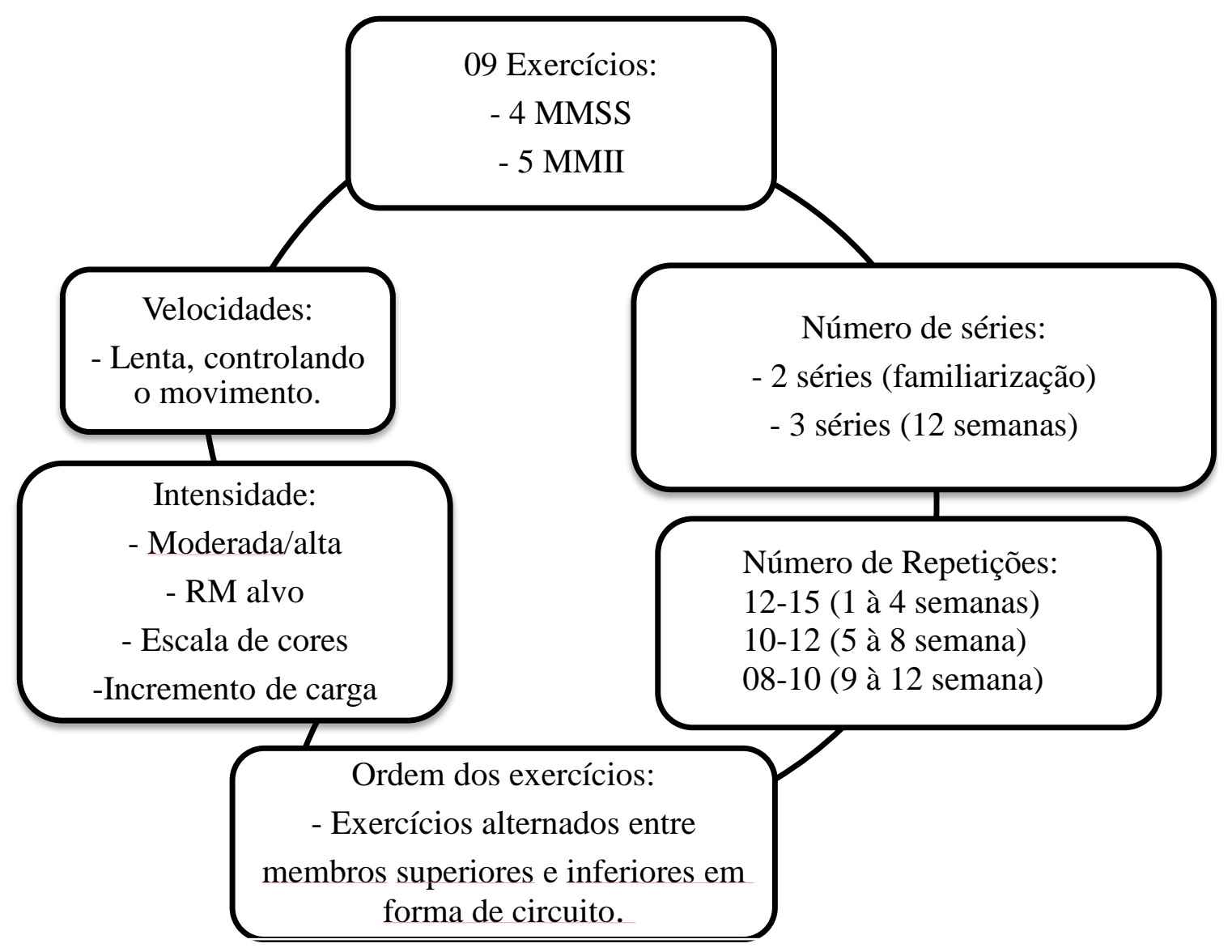

Figura 29 - Fluxograma dos procedimento de treinamento resistido ao longo de 2 semanas de familiarização e 12 semanas de TRP. 


\subsection{ANÁLISE ESTATÍSTICA}

O tamanho da amostra foi calculado considerando-se: (a) teste de ANOVA; (b) dois grupos; (c) erro tipo I = 5\%; (d) erro tipo II = 20\%; (e) poder estatístico $=80 \%$; (f) tamanho do efeito $=20 \%$. Com os paramêtros descritos acima, ficou determinado que o número total de indivíduos para o experimento seria de 32, ou seja, 16 em cada grupo. Esse cálculo foi realizado com o auxílio do programa G Power 3.1.9.2, versão para Windows.

Os dados foram apresentados através da estatística descritiva utilizando-se média e desvio padrão para as características da amostra. Inicialmente foi realizada uma análise exploratória para verificar a simetria e a presença de casos extremos nas distribuições das variáveis.

A normalidade da distribuição dos dados foi testada utilizando o teste de Shapiro-Wilk e a homogeneidade de variância foi testada através do teste de Levene. Após estes procedimentos foram aplicados testes de hipóteses específicas para cada variável analisada.

Para verificar possíveis diferenças nas médias entre os grupos, na linha de base do estudo foram utilizados os testes $t$ de student independente e o teste $\mathrm{U}$ de Mann-Whitney, de acordo com a presença ou não de normalidade dos dados.

Para analisar os efeitos das doze semanas de TR intra-grupo nos momentos (PRÉ x PÓS) foram utilizados os testes $t$ student pareado ou teste de somas de postos de Wilcoxon de acordo com a presença ou não do teste de normalidade. Já para a comparação entre os grupos foi utilizado a análise de variância (ANOVA) ou Kruskal-wallis de modelos mistos 2X2 (Grupo [GE e GM] X [PRÉ E PÓS] para cada variável dependente, utilizando o post-hoc de Bonfferroni quando identificada diferença estatisticamente significante.

Inicialmente foi criado um banco de dados no programa Excel (Microsoft, EUA). Para as análises dos dados foi utilizado o software Statatistical Package for the Social Sciences (SPSS, Chicago, IL) para Windows versão 22.0, e o nível de significância adotado para todas as variáveis foi de $\mathrm{p} \leq 0,05$ (Field, 2009). 


\section{RESULTADOS}

\subsection{CARACTERIZAÇÃO DA AMOSTRA}

A caracterização descritiva da amostra contendo informações sobre idade, aspectos antropompetricos e o nível de atividade física das voluntárias podem ser vistos na Tabela 4. No momento PRÉ não haviam diferenças, estatísticamente, significantes entre os grupo na idade $(p=0.277)$, massa corporal em $\mathrm{kg}(\mathrm{p}=0.0 .155)$, estatura $(\mathrm{p}=0.771), \mathrm{IMC}(\mathrm{p}=0.683)$ e Minnesota $(\mathrm{p}=0.063)$.

Tabela 4 - Caracterização da amostra quanto à idade, nível de atividade física, estatura, massa corporal e índice de massa corporal.

\begin{tabular}{cccc}
\hline & $\begin{array}{c}\text { Grupo Elástico } \\
(\mathrm{n}=18)\end{array}$ & $\begin{array}{c}\text { Grupo Máquina } \\
(\mathrm{n}=26)\end{array}$ & $\mathrm{p}$ \\
\hline Idade $(\mathrm{anos})$ & $67.55 \pm 5.20$ & $69.34 \pm 5.37$ & 0.277 \\
MLTPA (met) & $2167 \pm 1309$ & $4229 \pm 2826$ & 0.063 \\
Estatura $(\mathrm{cm})$ & $1,53 \pm 0,47$ & $1,53 \pm 0,64$ & 0.771 \\
Massa Corporal $(\mathrm{Kg})$ & $69,88 \pm 9,1$ & $69,13 \pm 16,38$ & 0.155 \\
& & & \\
IMC $\left(\mathrm{Kg} / \mathrm{m}^{2}\right)$ & $29,73 \pm 3,22$ & $29,16 \pm 5,97$ & 0.683
\end{tabular}

IMC: índice de massa corporal; MLTPA: Minnessota leisure time physical activity questionnaire; MET: taxa metabólica de repouso - minutos por semana. Dados em média e desvio padrão.

\subsection{FORÇA}

Os dados da variável dependente força estão representados na tabela 04. No momento PRÉ, não haviam diferenças significantes entre os grupos conforme observado na tabela 5 para PT de extensão de joelho a $60 \%$ s $(\mathrm{p}=0.206)$, no PT a $180 \%$ s $(\mathrm{p}=0.189)$ e no PT de flexão de cotovelo a $60 \%$ s $(\mathrm{p}=0.298)$, no PT a $180 \%$ s $(\mathrm{p}=0.524)$ MMSS , na força de preensão manual $(\mathrm{p}=0.142)$. 
Tabela 5 - Tabela com valores de base para PT de flexores de cotovelo e extensores de joelhos nas velocidades angulares de $60 \%$ s e $180 \%$ e para FPP.

\begin{tabular}{|c|c|c|c|}
\hline & $\begin{array}{l}\text { Grupo Elástico } \\
(\mathrm{n}=18)\end{array}$ & $\begin{array}{l}\text { Grupo Máquina } \\
\quad(\mathrm{n}=26)\end{array}$ & $\mathrm{p}$ \\
\hline PT FC $60 \%$ (N.m) ${ }^{a}$ & $25.57 \pm 7.90$ & $23.43 \pm 5.38$ & 0.298 \\
\hline PT FC $180 \%$ (N.m) ${ }^{c}$ & $22.55 \pm 7.98$ & $21.30 \pm 4.93$ & 0.524 \\
\hline PT EJ $60 \%$ s (N.m) a & $91.99 \pm 14.38$ & $84.89 \pm 20.13$ & 0.206 \\
\hline PT EJ $180 \%$ (N.m) a & $60,04 \pm 9.32$ & $55.90 \pm 13.00$ & 0.189 \\
\hline $\operatorname{FPP}(\mathrm{Kgf})^{a}$ & $24.27 \pm 3.61$ & $26.23 \pm 4.65$ & 0.142 \\
\hline
\end{tabular}

PTFC: pico de torque flexão do cotovelo; PTEJ: pico de torque extensão de joelho; FPP: força de preensão palmar; a Teste $t$ student independente; ${ }^{\mathrm{c}}$ Teste $U$ deMann-Whitney

Todos os valores PRÉ e PÓS das variáveis dependentes de força, os efeitos intra-grupo (tempo) e inter-grupos (tempo x grupo) podem ser observados na Tabela 6.

Tabela 6 - Comparação entre as variáveis de força nos momentos pré e pós da intervenção. Dados expressos em média e desvio padrão.

\begin{tabular}{|c|c|c|c|c|c|c|}
\hline & & & édia & & & feito \\
\hline Variáveis & Grupo & Pré & Pós & $\Delta \%$ & Tempo & GrupoX Tempo $\dagger$ \\
\hline PT FC & GTRE a & $25.57 \pm 7.90$ & $28.46 \pm 6.83$ & 11.3 & $0.033^{*}$ & 0.324 \\
\hline $60 \%$ (N.m) & GTM a $^{a}$ & $23.46 \pm 5.38$ & $27.90 \pm 6.81$ & 18.9 & $<0.001 * *$ & \\
\hline PT FC & GTRE c & $22.55 \pm 7.98$ & $24.64 \pm 5.49$ & 9.2 & 0.136 & 0.459 \\
\hline $180 \%$ s (N.m) & GTM $^{\text {a }}$ & $21.30 \pm 4.93$ & $25.48 \pm 5.47$ & 19.6 & $<0.001 * *$ & \\
\hline PT EJ & GTRE a & $91.99 \pm 14.38$ & $100.76 \pm 16.99$ & 9.6 & $<0.001 * *$ & 0.292 \\
\hline $60 \%$ (N.m) & GTM a & $84.89 \pm 20.13$ & $97.15 \pm 2.66$ & 14.4 & $<0.001 * *$ & \\
\hline PT EJ & GTRE a & $60.04 \pm 9.32$ & $66.87 \pm 11.40$ & 11.4 & $<0.001 * *$ & 0.596 \\
\hline $180 \%$ (N.m) & GTM a & $55.90 \pm 13.00$ & $63.76 \pm 14.91$ & 14.1 & $<0.001 * *$ & \\
\hline FPP & GTRE a & $24.27 \pm 3.61$ & $24.83 \pm 4.32$ & 2.29 & 0.076 & 0.620 \\
\hline (Kgf) & GTM $^{\text {a }}$ & $26.23 \pm 4.65$ & $26.57 \pm 4.40$ & 1.32 & 0.232 & \\
\hline
\end{tabular}

PTFC: pico de torque flexão do cotovelo; PTEJ: pico de torque extensão de joelho; FPP: força de preensão palmar; GTRE: grupo treinamento resistência elástica; GTM: grupo treinamento máquina; ${ }^{*} \mathrm{p}<0.05$; ${ }^{* *} \mathrm{p}<0.001$; ${ }^{a}$ Teste $t$ student independente; ${ }^{\mathrm{c}}$ Teste $U$ deMann-Whitney; †resultados inter-grupos da ANOVA.

A força muscular no GTRE e GTM exibiu um aumento estatisticamente significativo para o PT isocinético em extensores de joelhos nas velocidades angulares de $60 \%$ e $180 \%$ nos dois grupos conforme pode ser visto na figura 27. O PT isocinético em extensores de cotovelo teve um aumento estatisticamente significativo nas velocidades de $60 \%$ e $180 \%$ no GTM e apenas na velocidade de $60 \%$ para o GTRE conforme pode ser visto na figura 28 abaixo.Em relação a FPP, os dois grupos não exibiram qualquer tendência de aumento (Figura 29). 

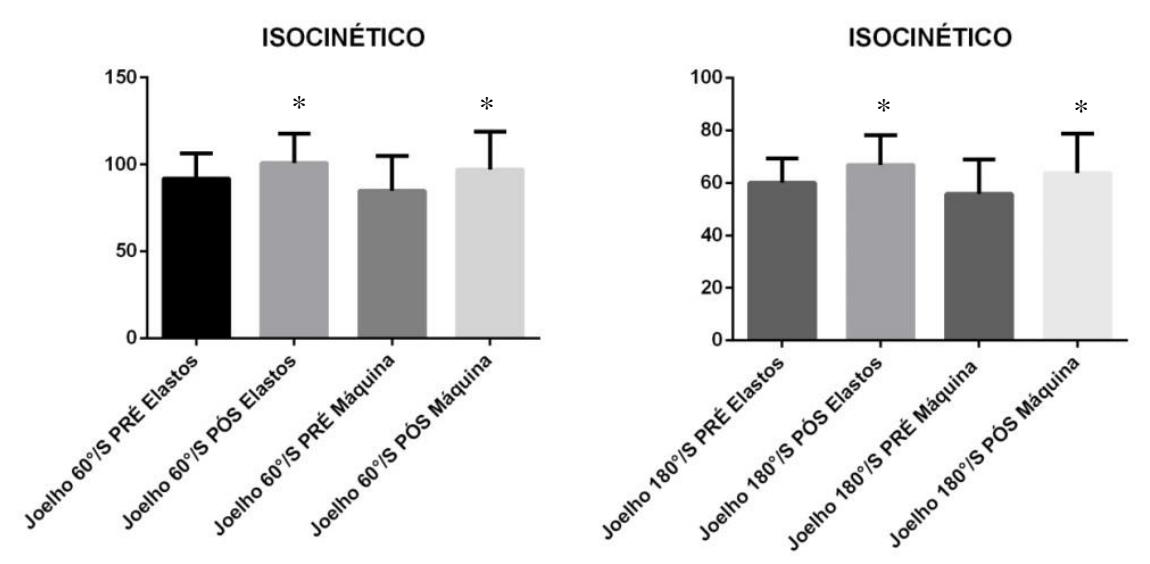

Figura 30 - Comparação PT isocinético para extensão de joelho GTRE e GTM nos momentos PRÉ e PÓS. *diferença intra-grupo, $\mathrm{p}<0,001$
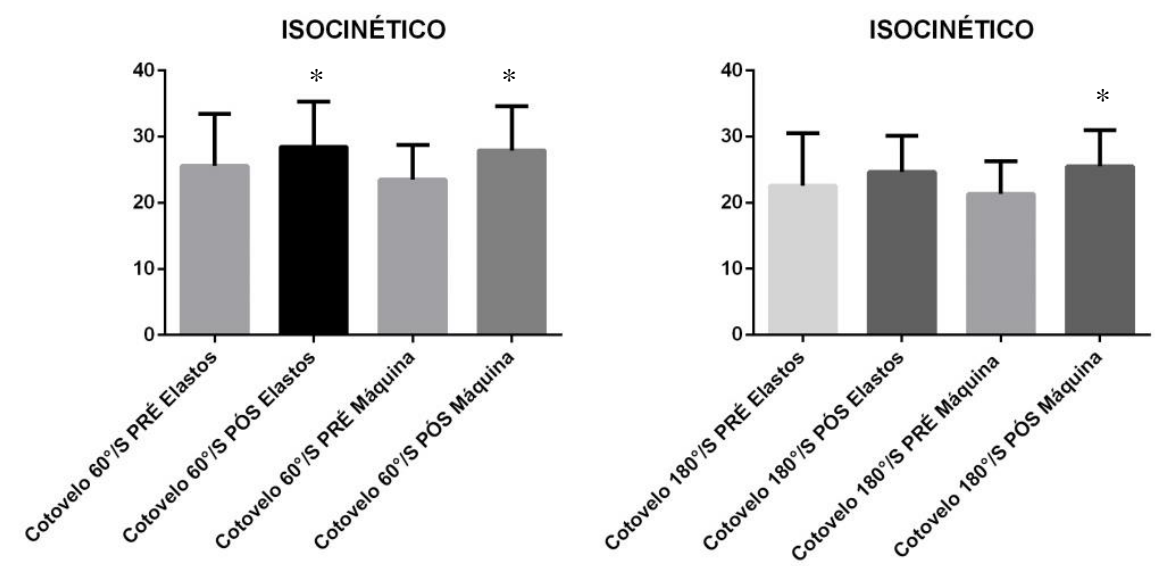

Figura 31 -Comparação PT isocinético para flexão de cotovelo GTRE e GTM nos momentos PRÉ e PÓS. *diferença intra-grupo, $\mathrm{p}<0,001$ 


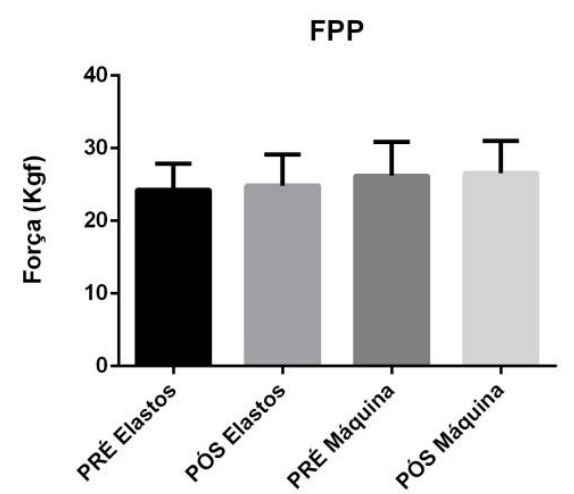

Figura 32 - Comparação da Força de Preensão palmar GTRE e GTM nos momentos PRÉ e PÓS

\subsection{CAPACIDADE FUNCIONAL E EQUILÍBRIO}

Os dados das variáveis dependentes de capacidade funcional e equilíbrio estão representados na tabela 7 . No momento PRÉ, não haviam diferenças significantes entre os grupos conforme observado para o TFC (p=0.696), TSL $(\mathrm{p}=0.384), 8$ FT UP \& GO $(\mathrm{p}=$ $0.364)$ e TAF $(p=0.292)$.

Tabela 7 - Tabela dos valores de base para capacidades funcionais e equilíbrio no momento PRÉ.

\begin{tabular}{|c|c|c|c|}
\hline & $\begin{array}{c}\text { GTRE } \\
(\mathrm{n}=18)\end{array}$ & $\begin{array}{c}\text { GTM } \\
(\mathrm{n}=26)\end{array}$ & $\mathrm{p}$ \\
\hline TFC (rep) ${ }^{\mathrm{a}}$ & $16.66 \pm 3.62$ & $16.30 \pm 2.42$ & 0.696 \\
\hline TSL (rep) ${ }^{\mathrm{a}}$ & $12.50 \pm 2.00$ & $11.92 \pm 2.22$ & 0.384 \\
\hline 8 FT UP \& GO $(s)^{\mathrm{a}}$ & $6.32 \pm 0.85$ & $6.57 \pm 0.91$ & 0.364 \\
\hline $\operatorname{TAF}(\mathrm{cm})^{\mathbf{a}}$ & $37.63 \pm 4.19$ & $36.23 \pm 4.37$ & 0.292 \\
\hline
\end{tabular}

GTRE: grupo treinamento resistência elástica; GTM: grupo treinamento máquina ; TFC: teste de flexão de cotovelo; TSL: teste de sentar e levantar; TAF: teste de alcance funcional; ${ }^{\mathrm{a}}$ Teste $t$ student independente.

Os dados contidos na tabela 8 representam os valores PRÉ e PÓS das variáveis dependentes de capacidade funcional e equilíbrio, os efeitos intra-grupo (tempo) e intergrupos (tempo x grupo). 
Tabela 8 - Comparação entre as variáveis de força nos momentos pré e pós da intervenção. Dados expressos em média e desvio padrão.

\begin{tabular}{llccccc}
\hline & & \multicolumn{2}{c}{ Média } & \multicolumn{2}{c}{ Efeito } \\
Variáveis & Grupo & Pré & Pós & $\Delta \%$ & Tempo & Grupo X Tempo $\dagger$ \\
\hline TFC (rep) & GTRE $^{\text {a }}$ & $16.66 \pm 3.62$ & $26.05 \pm 4.09$ & 56.3 & $<0.001^{* *}$ & 0.368 \\
& GTM $^{\text {a }}$ & $16.30 \pm 2.42$ & $24.73 \pm 4.03$ & 51.6 & $<0.001^{* *}$ & \\
TSL (rep) & GTRE $^{\mathrm{a}}$ & $12.50 \pm 2.00$ & $17.72 \pm 3.12$ & 41.4 & $<0.001^{* *}$ & 0.335 \\
& GTM $^{\text {a }}$ & $11.92 \pm 2.37$ & $16.50 \pm 2.51$ & 38.4 & $<0.001^{* *}$ & \\
8 FT UP \& & GTRE $^{\text {a }}$ & $6.32 \pm 0.85$ & $5.56 \pm 0.56$ & -11.99 & $<0.001^{* *}$ & \multirow{2}{*}{0.216} \\
GO \% (s) & GTM $^{\text {a }}$ & $6.57 \pm 0.91$ & $5.54 \pm 0.64$ & -15.74 & $<0.001^{* *}$ & \\
TAF (rep) & GTRE $^{\text {a }}$ & $37.63 \pm 4.19$ & $38.55 \pm 4.19$ & 2.44 & 0.297 & 0.350 \\
& GTM $^{\text {a }}$ & $36.23 \pm 4.37$ & $38.09 \pm 3.74$ & 5.15 & $0.004^{*}$ & \\
\hline
\end{tabular}

GTRE: grupo treinamento resistência elástica; GTM: grupo treinamento máquina ; TFC: teste de flexão de cotovelo; TSL: teste de sentar e levantar; TAF: teste de alcance funcional; ${ }^{*} \mathrm{p}<0.05 ;{ }^{*} \mathrm{p}<0.001$; ${ }^{\text {a }}$ Teste $t$ student independente; ${ }^{\mathrm{c}}$ Teste $U$ deMann-Whitney; †resultados inter-grupos da ANOVA

Em relação a capacidade funcional, o GTRE e o GTM, apresentaram aumento no número de repetições estatisticamente significativos ( $\mathrm{p}<0.001)$ para o TSL e TFC (Figuras 30 e 31). O teste de agilidade 8-foot up \& go apresentou uma diminuição no tempo de execução do teste, proporcionando assim, uma diferença estatisticamente significativa entre os momentos PRÉ e PÓS conforme pode ser visto na figura 32. O equilíbrio, realizado por meio do TAF, apresentou um pequeno aumento nos dois grupos, porém, sem significância estatística (Figura 33).

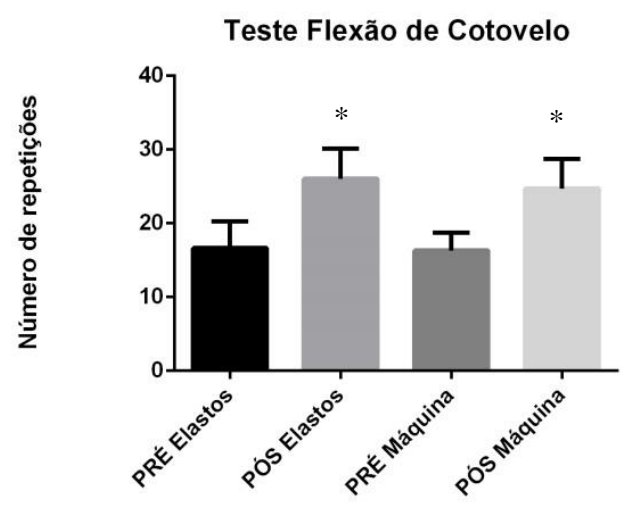

Figura 33 - Comparação do TFC para o GTRE e GTM nos momentos PRÉ e PÓS. *diferença intra-grupo, $\mathrm{p}<0,001$ 


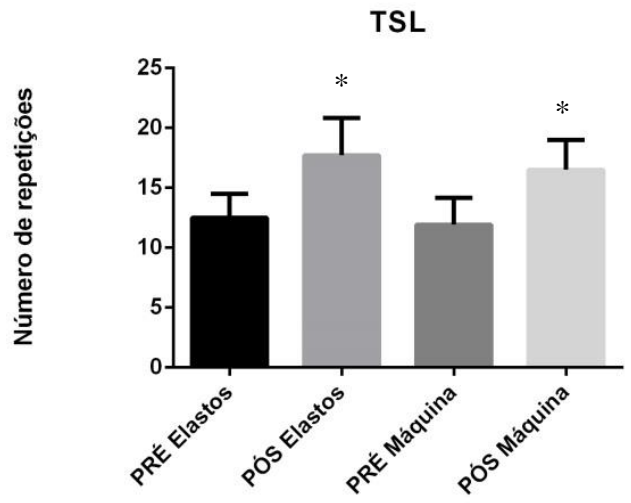

Figura 34 - Comparação do TSL para o GTRE e GTM nos momentos PRÉ e PÓS. *diferença intra-grupo, $\mathrm{p}<0,001$

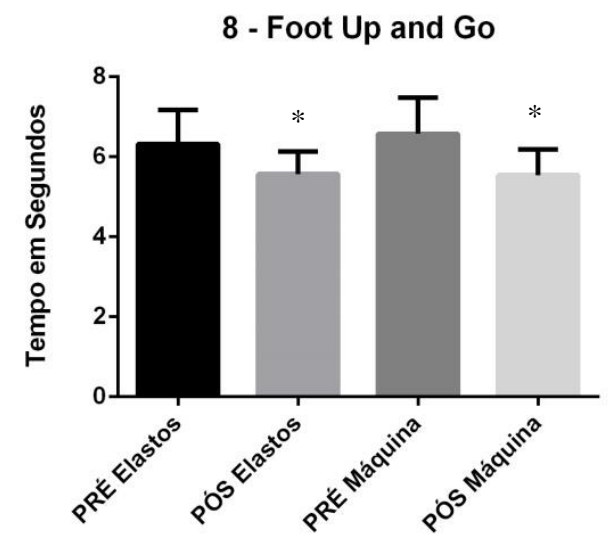

Figura 35 - Comparação do 8-foot up \& go para o GTRE e GTM nos momentos PRÉ e PÓS. *diferença intragrupo, $\mathrm{p}<0,001$

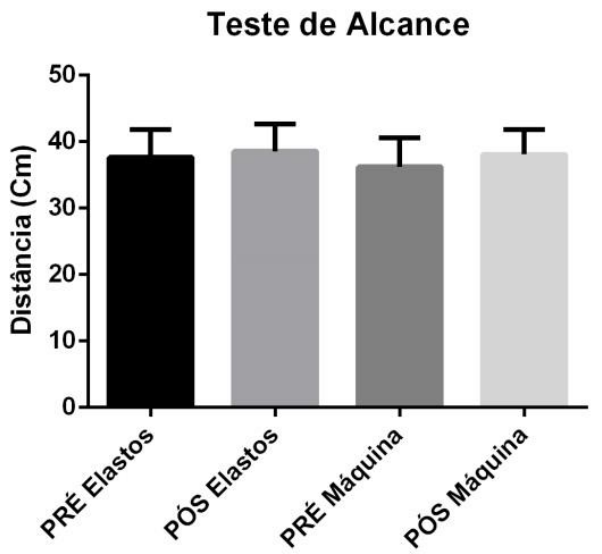

Figura 36 - Comparação do TAF para o GTRE e GTM nos momentos PRÉ e PÓS. 


\section{DISCUSSÃO}

O presente estudo teve como objetivo verificar e comparar os efeitos do TR com máquinas pneumáticas e resistência elástica na força, nas capacidades funcionais e equilíbrio de idosas. Os resultados dessa investigação sugere haver mudanças significativas na força e capacidade funcional, entretanto, o mesmo comportamento não foi visto para a variável de equilíbrio após doze semanas de TR com resistência elástica progressiva e máquinas pneumáticas. Para que uma melhor interpretação fosse feita na presente discussão, optou-se, por organizá-la em forma de tópicos.

\subsection{FORÇA MUSCULAR}

O TR é uma importante ferramenta para o ganho de força no idoso e é fundamental para que ele mantenha suas AVD de maneira independente. Ele pode ser realizado com diferentes tipos de equipamentos, dentre eles, resistência elástica progressiva ou máquinas pneumáticas apresentadas no presente estudo como métodos eficazes para ganho de força e aumento da capacidade funcional de idosas. Em uma revisão sistemática com meta-análise foi sugerido a existência de uma robusta associação entre o TR e o ganho de força em MMII e MMSS em idosos (Peterson, Rhea et al., 2010). Semelhantemente, Liu (2009) havia encontrado resultados que reforçaram a importância do TR para o aumento na força de extensores de joelho, grupamento muscular importante para desenvolver tarefas do cotidiano. No estudo de Liu 2009, objetivando diminuir a heterogeneidade de avaliações de diferentes grupos musculares, optou-se por analisar apenas os desfechos para força de extensores de joelho e foram encontrados efeitos moderados a altos para aumento de força de extensores de joelhos após o TR (SMD 0.84, 95\% CI 0.67 to 1.00, random-effects model; fixed-effect model: SMD $0.53,95 \%$ CI 0.46 to 0.61 ).

No presente estudo, doze semanas de treinamento resistido foram suficientes para aumentar o PT isocinético de maneira estatisticamente significativa $(\mathrm{p}<0,001)$ para as velocidades de $60 \%$ s e $180 \%$ s para o movimento de extensão de joelhos em ambos os grupos (GTM e GTRE). No movimento de flexão de cotovelo, o PT isocinético não foi significativo $(\mathrm{p}=0.136)$ apenas para a velocidade de 180 \% no GTRE, já para o GTM essa velocidade apresentou uma mudança estatisticamente significativa $(\mathrm{p}<0,001)$ quando comparamos os 
dados pré e pós intervenção e para a velocidade de $60 \%$, tanto o GTM quanto o GTRE, apresentaram melhoras significativas.

Em particular, observou-se também que não existiu diferença entre os resultados "Inter-grupos", ou seja, ganhos significativos de força muscular, ocasionados pelo TR com duração de 12 semanas nos PT no GTM e GTRE são equivalentes nos dois grupos. Colado e colaboradores (2010) em estudo que comparou os ganhos de força entre máquinas convencionais e resistência elástica obteve ganhos equivalentes nos dois grupos estudados também, porém, seu estudo foi conduzido com mulheres jovens durante 8 semanas de treinamento, sendo que, para avaliar a variável força foi utilizada a força máxima de contração isométrica. A equivalência nos ganhos de força “inter-grupos” pode ser explicada pelo fato de que os dois métodos, GTRE e GTM, realizarem as sessões de treino em intensidades semelhantes. Em 2005, um estudo com duração de 12 semanas, realizados três vezes por semana com homens e mulheres que não praticavam nenhum tipo de atividade física verificou que o ganho de força era influenciado pela intensidade de treinamento. O TR, realizado em moderadas e altas intensidades promoveu um aumento estatisticamente significativo $(\mathrm{p}<0.001)$ de força muscular para os dois grupos(moderado e alta intensidade), enquanto que o grupo controle não apresentou melhora para o ganho de força ao final das 12 semanas. Além disso, houve diferença significativa entre os grupos e aqueles que praticaram o TR em alta intensidade obtiveram ganhos significativos maiores que aqueles que realizaram o treinamento com moderada intensidade (Kalapotharakos, Michalopoulos et al., 2005).

Um ensaio clínico de 10 semanas com uso de bandas elásticas para o TR analisou o ganho de força isocinética em idosos frágeis (GTRE, $\mathrm{n}=50 ; \mathrm{GC}, \mathrm{n}=50$ ). O treinamento, realizado três vezes por semana, envolvia cinco exercícios de MMII com duas séries de dez repetições por exercício. Nele, a progressão da intensidade foi feita de acordo com o código de cores do material e o incremento de carga acontecia quando o indivíduo realizava facilmente duas séries de dez repetições do exercício com uma respectiva cor. No GTRE, o efeito do treinamento no PT isocinético de extensão do joelho a $60 \%$ foi estatisticamente maior que no GC. Foi observada uma mudança de 4.9 N.m (8\%) para o GTRE e uma diminuição de -0.7 N.m $(-1,4 \%)$ para o GC, isso indica que idosos frágeis podem ser beneficiados com o treinamento resistido (Chandler, Duncan et al., 1998). No presente estudo, a intensidade do GTRE foi realizada por meio da progressão de carga pela cor do componente elástico, a zona alvo de RM's e o percentual de estiramento do material e no 
GTM esse controle deu-se com o aumento de carga e a zona alvo de RM's. Os resultados indicam que o PT isocinético para extensão de joelho a $60 \%$ proporcionou uma mudança intra-grupo de 9,6\% para o GTRE e 14,4\% para o GTM, já no PT a 180\% esse ganho intragrupo foi de $11,4 \%$ para o GTRE e $14,1 \%$ para o GTM.

Jan e colaboradores (2008) conduziu um estudo em 98 idosos com osteoartite de joelho e realizou o TR com máquinas pneumáticas En-Dynamic durante 8 semanas. Os sujeitos foram alocados em três diferentes grupos, alta intensidade(60\% de 1RM), baixa intensidade $(10 \%$ de 1RM) e controle (nenhum tipo de treinamento). Mesmo com treinamentos em diferentes intensidades, os dois grupos que realizaram a intervenção, mantiveram um volume semelhante de treino. $\mathrm{O}$ volume foi adequado pela produto entre as variáveis RESISTÊNCIA X REPETIÇÕES X SÉRIES que foram distintas nos grupos e adequadas para que apresentassem volumes semelhantes. Foi medido o PT isocinético nas velocidades de $60 \%$ s, $120 \%$ e $180 \%$ s nos dois joelhos e os resultados obtidos demonstraram ganhos estatisticamente significativos $(\mathrm{p}<0.05)$ nos grupos de intervenção quando comparados com o GC. Entre os grupos de intervenção não houve diferença para os ganhos obtidos no PT nas três velocidades. O mesmo equipamento foi utilizado no presente estudo e também resultou em ganhos estatisticamente significativos já citados anteriormente.

Outros estudos comprovaram também a eficácia do treinamento resistido para o ganho de força em idosos e demonstraram que a hipertrofia e o aumento do recrutamento de unidades motoras podem explicar as adaptações neuromusculares oriundas desse tipo de treino, resultando em benefícios para a manutenção da qualidade de vida e independência desses idosos (Izquierdo, Hakkinen et al., 2001; Knight e Kamen, 2001; Kraemer, Adams et al., 2002; Bottaro, Machado et al., 2007).

Poucos são os estudos que avaliaram o decréscimo da força muscular em idosas por meio do PT isocinético em flexores de cotovelo. Frontera e colaboradores (1991) avaliou o PT isocinético nessa situação em velocidades de $60 \%$ s e $180 \%$ s para grupos de 45-54 anos e 65-78 anos e observou que havia uma diminuição de $17 \%$ e $21 \%$ para na força absoluta entre esses grupos etários. Um outro estudo, comparou que o PT isocinético para FC difere-se entre mulheres jovens e idosas em diferentes velocidades $60 \%$ s, $120 \%$ s, $180 \%$ e $240 \%$ de maneira estatisticamente significativa $(\mathrm{p}<0.05)$, sendo que, mulheres jovens apresentam um PT maior que mulheres idosas em todas as velocidades angulares testadas (Pousson, Lepers et al., 2001). 
No presente estudo, foi encontrado que o treinamento resistido promoveu um aumento na força no PT FC 60\% de 11,3\% e 18,9\% para o GTRE e GTM, respectivamente. Para o PT FC na velocidade de $180 \%$ foi verificado que o GTRE aumentou 9,2\% em relação ao momento pré e o GTM 19,6\%. Mesmo que os dois grupos tenham apresentado aumento de força, o GTRE apresentou uma menor diferença quando comparado o GTM, isto talvez possa ser explicado pelo fato de que o segundo grupo realizava os exercícios remada e puxada sentados e com suporte do equipamento, já o GTRE, precisava manter o controle e estabilidade do corpo além de realizar os mesmos movimentos sem suporte algum. Por isso, apesar de terem apresentados ganhos de força, o GTRE apresentou um ganho relativamente menor. Mesmo com esse comportamento os grupos não apresentaram diferenças inter-grupos.

Outra medida utilizada para avaliação da força muscular neste trabalho foi a força de preensão palmar (FPP). Essa medida tem sido largamente utilizada para avaliação clínica dessa variável e tem sido um importante indicador recomendado para o diagnóstico de sarcopenia. Por ser considerada como uma medida de força não apenas de MMSS, mas também, uma medida que designa a força total do corpo, a FPP tem sido determinante para associação entre diminuição da força muscular, quedas, dependência, diminuição da qualidade de vida em idosos e mortalidade (Ikemoto, Demura et al., 2007; Roberts, Denison et al., 2011).

Um dos desafios em relação a essa variável tem sido a padronização dos métodos de avaliação, pois, desde a escolha do tipo de dinamômetro de mão até mesmo o protocolo de coleta podem influenciar resultados. Diversos estudos utilizam o dinamômetro da marca Jamar, equipamento considerado padrão ouro para esse tipo de coleta, nesse estudo foi utilizado um dinamômetro semelhante da marca Saehan. Esse equipamento foi testado e apresentou confiabilidade excelente em relação ao Jamar ( $r=0.981$ e r=0.985) para mão direita e esquerda respectivamente. De acordo com esses resultados, os dados coletados com esse modelo de equipamento são equivalentes àqueles coletados com o Jamar (Mathiowetz, Kashman et al., 1985; Guerra e Amaral, 2009; Reis e Arantes, 2011).

Já é bem descrito na literatura que há uma tendência de diminuição de FPP com o avanço da idade. Em um estudo longitudinal com 307 idosos com idades entre 70-79 anos, foi verificada a relação da diminuição da FPP e da força de extensão de joelhos. Os resultados demonstraram que a diminuição na FPP ocorre de forma acelerada quando comparadas a força de membros inferiores (Xue, Beamer et al., 2010). 
Em relação à FPP não foram observadas diferenças estatisticamente significativas ( $>>0.05)$ para nenhum dos grupos. Esse achado corrobora com o estudo de Damush e colaboradores (1999), nele não foram encontradas diferenças estatísticas entre o grupo de treinamento em relação ao grupo controle para um programa de curta duração. Em um estudo recente, realizado com duração de 20 semanas de treinamento de potência, também não foram escontrados resultados estatisticamente significativos para a força de preensão palmar assim como no nosso estudo(Glenn, Gray et al., 2015).

\subsection{CAPACIDADE FUNCIONAL E EQUILÍBRIO}

Em 2012, Rikli \& Jones, propuseram pela primeira vez desenvolver critérios para padronizar valores que indicassem o grau de independência física e capacidade funcional em idosos. Independência física é definida como a capacidade de realizar AVD's sem qualquer tipo de assistência. Desde 1999 essas autoras desenvolveram estudos que respondessem à necessidade de uma ferramenta clínica, sem o elevado custo de equipamentos laboratoriais, e que avaliassem a aptidão física de idosos. Nesse sentido, foi desenvolvida uma bateria de testes e aplicados em 7.183 americanos com idade entre 60 e 94 anos. No presente estudo, adaptamos a bateria de testes propostos por Rikli \& Jones, e optamos por aqueles testes que atendessem as questões relacionadas à força, agilidade e equilíbrio.

O TR tem sido proposto como meio para promover e melhorar a capacidade funcional e o equilíbrio em idosos. Em um estudo de revisão sistemática foram analisados 121 ensaios clínicos com um total de 6700 participantes para o desfecho da influência do treinamento resistido nas capacidades funcionais em idosos. A maioria dos ensaios clínicos realizavam o treinamento de duas a três vezes por semana em altas intensidades. Aqueles que possuíam algum tipo de limitação funcional obtiveram uma melhora com um efeito de moderado a alto na em situações para levantar-se da cadeira (SMD 0.94, 95\%) e um largo efeito na força muscular (SMD 0.84, 95\%).

Neste cenário, nossos resultados apresentaram melhora estatisticamente significativa ( $<<0.001$ ) para o GTRE e GTM com 41,4\% e 38,4\% respectivamente para o TSL; aumento de $56,3 \%$ e 51,6\% para o TFC para os mesmos grupos respectivamente; uma diminuição do tempo para realização do teste de agilidade em $-11,99 \%$ e $-15,74 \%$ para o GTRE e GTM; porém, o nosso estudo mostrou não haver uma melhora estatisticamente significativa $(\mathrm{p}>0.05)$ 
para o equilíbrio no teste de alcance funcional nos dois grupos, apresentando uma mudança de apenas $2,44 \%$ no GTRE e $5.15 \%$ no GTM.

No que diz respeito à capacidade funcional, nossos resultados foram compatíveis com autores que realizaram o treinamento resistido a fim de promover melhora nas capacidades funcionais. Um estudo piloto recente verificou a eficácia do TRP com tubos elásticos em idosos durante 12 semanas. A força indireta foi medida pelo teste de sentar e levantar(5 repetições), o equilíbrio pelo teste de alcance e a agilidade pelo Timed up and go. Em todas as variáveis foi verificado aumento estatisticamente significativo $(\mathrm{p}<0.001)$ e um ganho percentual de 30,3\% no TSL; 27,1\% no TUG e 15,3\% no TAF (Motalebi e Loke, 2014). Esses resultados diferem-se do presente estudo, pois, nossos achados foram semelhantes apenas nas variáveis relacionadas à força indireta de MMII em que o TSL também resultou em um aumento estatisticamente significativo $(\mathrm{p}<0.001)$ e na diminuição do tempo para realização do teste de agilidade com $\mathrm{p}<0.001$. Já para o teste de equilíbrio, os achados diferem-se entre si, pois, nosso estudo demonstrou não haver uma melhora estatisticamente significativa $(\mathrm{p}>0.05)$ para os dois grupos no TAF enquanto que os autores do estudo piloto encontraram diferença estatisticamente significativa $(\mathrm{p}<0.001)$ para essa variável. Sousa e colaboradores $(2005)$ também encontraram diferença estatisticamente significativa $(\mathrm{p}<0.05)$ para o TAF com $13 \%$ de aumento na distância alcançada no teste nas medidas pré e pós em seu estudo. Semelhantemente, Granacher e colaboradores, conseguiram obter um resultado positivo para o TAF após treze semanas de TR em alta intensidade, nessa ocasião, houve um aumento de $11 \%$ entre as médias das avaliações pré e pós e isso foi suficiente para uma melhora estatisticamente significativa no equilíbrio(Granacher, Gruber et al., 2009).

De acordo com uma revisão sistemática com meta-análise da base de dados Cochrane que incluiu 66 artigos com 3783 participantes, o TRP, não apresenta de forma clara benefícios e efeitos significativos no equilíbrio de idosos(Latham, Anderson et al., 2003). O tema ainda é um tanto controverso, pois, alguns autores encontraram uma melhora de equilíbrio após o treinamento resistido enquanto que outros reportam que o TR não promove melhora estatisticamentessignificativa o equilíbrio em idosos. Um dos problemas acerca do tema se diz respeito a heterogeneidade dos métodos de avaliação de equilíbrio podendo ser um dos motivos pelo qual exista tanta divergência na literatura acerca do assunto. 


\subsection{APLICAÇÕES PRÁTICAS}

A partir dos resultados apresentados, o presente estudo identificou que o treinamento resistido realizados com máquinas pneumáticas ou resistência elástica progressiva geram benefícios semelhantes na força muscular de membros inferiores e superiores, além de promover uma melhora das capacidades funcionais em mulheres idosas. Conforme já mencionado, foi possível verificar que os ganhos promovidos pelos dois tipos de treinamento não foram diferentes entre si. Vale lembrar que o custo dos equipamentos de resistência elástica é menor que o custo dos equipamentos pneumáticos. Em termos práticos, isto se faz relevante no âmbito científico, clínico, e até mesmo em questões sociais, pois, os efeitos deletérios do processo de envelhecimento é um problema de saúde pública e programas preventivos podem ser implantados de maneira segura e com baixo custo.

Neste sentido, o TRP com uso de materiais com RE deveria ser contemplado em programas de atividade física para idosos, pois, o fortalecimento muscular pode alterar favoravelmente a condição do idoso em aspectos relacionados à manutenção da qualidade de vida e independência. 


\section{CONCLUSÃO}

Os resultados encontrados na presente pesquisa permitem concluir que o TR aplicado por um período de 12 semanas com o uso de resistência elástica progressiva ou máquinas pneumáticas produzem melhorias na força e capacidade funcionais de mulheres idosas. Especificamente, o protocolo de treinamento adotado promoveu aumentos significativos no PT isocinético em extensores de joelhos e flexores de cotovelo, aumento na capacidade funcional no que diz respeito à força muscular indireta pelo TFC e TSL e redução significativa no tempo de execução do teste de agilidade 8-foot up \& go.

Diante disso, o TR com uso desses equipamentos constituem uma importante intervenção para atenuar os efeitos deletérios associado ao envelhecimento, sendo que, o uso de REP para realização do TR deveria ser incentivado por se tratar de um recurso que apresentou ganhos na força e capacidade funcional, além de ser um equipamento que apresenta um custo reduzido quando comparado à MP e que possibilita a prática em diversos ambientes (resisdência, parques, clubes, academias, consultórios). Ademais, novos estudos com esse tema de pesquisa são necessários com diferentes desenhos metodológicos ou com um período de duração maior para verificar os possíveis efeitos nessa população. 


\section{REFERÊNCIAS BIBLOIGRÁFICAS}

ALLEY, D. E. et al. Grip strength cutpoints for the identification of clinically relevant weakness. J Gerontol A Biol Sci Med Sci, v. 69, n. 5, p. 559-66, May 2014. ISSN 10795006.

BARNETT, A. et al. Community-based group exercise improves balance and reduces falls in at-risk older people: a randomised controlled trial. Age Ageing, v. 32, n. 4, p. 407-14, Jul 2003. ISSN 0002-0729 (Print)

0002-0729.

BAUMGARTNER, R. N. et al. Epidemiology of sarcopenia among the elderly in New Mexico. Am J Epidemiol, v. 147, n. 8, p. 755-63, Apr 15 1998. ISSN 0002-9262 (Print) 0002-9262 (Linking). Disponível em: < http://www.ncbi.nlm.nih.gov/pubmed/9554417 >.

BERTOLDO BENEDETTI, T. R. et al. Normative values of functional fitness in 70-to-79 year-old women. 2007, v. 9, n. 1, p. 9, 2007-03-30 2007. ISSN 1980-0037. Disponível em: < https://periodicos.ufsc.br/index.php/rbcdh/article/view/4026/16721 >.

BOHANNON, R. W. et al. Average grip strength: a meta-analysis of data obtained with a Jamar dynamometer from individuals 75 years or more of age. J Geriatr Phys Ther, v. 30, n. 1, p. 28-30, 2007. ISSN 1539-8412 (Print) $1539-8412$.

BOTTARO, M. et al. Effects of age and rest interval on strength recovery. Int J Sports Med, v. 31, n. 1, p. 22-5, 2010.

BOTTARO, M. et al. Effect of high versus low-velocity resistance training on muscular fitness and functional performance in older men. European journal of applied physiology, v. 99, n. 3, p. 257-264, 2007. ISSN 1439-6319.

BOTTARO, M.; RUSSO AÉ, F.; DE OLIVEIRA, R. The Effects of Rest Interval on Quadriceps Torque During an Isokinetic Testing Protocol in Elderly. J Sports Sci Med, v. 4, n. 3, p. 285-90, Sep 2005.

BUCHNER, D. M. et al. The effect of strength and endurance training on gait, balance, fall risk, and health services use in community-living older adults. J Gerontol A Biol Sci Med Sci, v. 52, n. 4, p. M218-24, Jul 1997. ISSN 1079-5006 (Print) 
1079-5006.

BURTON, L. A.; SUMUKADAS, D. Optimal management of sarcopenia. Clinical Interventions in Aging, v. 5, p. 217-228, 09/07

08/04/received 2010. ISSN 1176-9092

1178-1998. Disponível em: < http://www.ncbi.nlm.nih.gov/pmc/articles/PMC2938029/ >.

CAMARA, F. M. et al. Capacidade funcional do idoso: formas de avaliação e tendências Elderly functional capacity: types of assessment and trends. CEP, v. 13035, p. 610, 2008.

CAPODAGLIO, P. et al. Muscle function and functional ability improves more in community-dwelling older women with a mixed-strength training programme. Age Ageing, v. 34, n. 2, p. 141-7, Mar 2005. ISSN 0002-0729 (Print)

0002-0729.

CARUSO, J. F.; BROWN, L. E.; TUFANO, J. J. The reproducibility of isokinetic dynamometry data. Isokinetics and Exercise Science, v. 20, n. 4, p. 239, 2012. ISSN 09593020 .

CEDERHOLM, T. E. et al. Toward a definition of sarcopenia. Clin Geriatr Med, v. 27, n. 3, p. 341-53, Aug 2011. ISSN 0749-0690.

CHANDLER, J. M. et al. Is lower extremity strength gain associated with improvement in physical performance and disability in frail, community-dwelling elders? Arch Phys Med Rehabil, v. 79, n. 1, p. 24-30, Jan 1998. ISSN 0003-9993 (Print) 0003-9993.

CHODZKO-ZAJKO, W. J. et al. American College of Sports Medicine position stand. Exercise and physical activity for older adults. Med Sci Sports Exerc, v. 41, n. 7, p. 1510-30, Jul 2009. ISSN 0195-9131.

CHRISTMAS, C.; ANDERSEN, R. A. Exercise and Older Patients: Guidelines for the Clinician. Journal of the American Geriatrics Society, v. 48, n. 3, p. 318-324, 2000. ISSN 1532-5415. Disponível em: < http://dx.doi.org/10.1111/j.1532-5415.2000.tb02654.x http://onlinelibrary.wiley.com/doi/10.1111/j.1532-5415.2000.tb02654.x/abstract $>$.

CLOSS, V. E.; SCHWANKE, C. H. A. A evolução do índice de envelhecimento no Brasil, nas suas regiões e unidades federativas no período de 1970 a 2010. Revista Brasileira de Geriatria e Gerontologia, v. 15, p. 443-458, 2012. ISSN 1809-9823. Disponível em: < http://www.scielo.br/scielo.php?script=sci_arttext\&pid=S1809$\underline{98232012000300006 \& n r m=\text { iso }}>$.

COLADO, J. et al. A comparison of elastic tubing and isotonic resistance exercises.

International journal of sports medicine, v. 31, n. 11, p. 810, 2010. ISSN 0172-4622.

CRUZ-JENTOFT, A. J. et al. Sarcopenia: European consensus on definition and diagnosis: Report of the European Working Group on Sarcopenia in Older People. n. 1468-2834 (Electronic), 20100617 DCOM- 201009302010. 
DA COSTA ROSAA, T. E.; BENÍCIOB, M. H. D. A.; DO ROSÁRIO DIAS, M. Fatores determinantes da capacidade funcional entre idosos. Rev saúde pública, v. 37, n. 1, p. 40-8, 2003.

DAMUSH, T. M.; DAMUSH, J. G., JR. The effects of strength training on strength and health-related quality of life in older adult women. Gerontologist, v. 39, n. 6, p. 705-10, Dec 1999. ISSN 0016-9013 (Print)

0016-9013.

DE VOS, N. J. et al. Optimal load for increasing muscle power during explosive resistance training in older adults. J Gerontol A Biol Sci Med Sci, v. 60, n. 5, p. 638-47, May 2005. ISSN 1079-5006 (Print) 1079-5006.

DOHERTy, T. J. Invited review: Aging and sarcopenia. J Appl Physiol (1985), v. 95, n. 4, p. 1717-27, Oct 2003. ISSN 8750-7587 (Print) 0161-7567.

DUNCAN, P. W. et al. Functional reach: a new clinical measure of balance. Journal of gerontology, v. 45, n. 6, p. M192-M197, 1990. ISSN 0022-1422.

EL DIB, R. P. Como praticar a medicina baseada em evidências. J Vasc Bras, v. 6, n. 01, 2007.

ENSRUD, K. E. et al. Correlates of impaired function in older women. J Am Geriatr Soc, 1994. ISSN 1532-5415.

FARINATTI, P. D. T. Envelhecimento, promoção da saúde e exercício: vases teóricas e metodológicas Barueri, SP Manole, 2008.

FEIGENBAUM, M. S.; POLLOCK, M. L. Prescription of resistance training for health and disease. Med Sci Sports Exerc, v. 31, n. 1, p. 38-45, Jan 1999. ISSN 0195-9131 (Print) 0195-9131.

FIELD, A. Descobrindo a estatística usando o SPSS. Bookman, 2009. ISBN 8536320184.

FIELDING, R. A. et al. High-velocity resistance training increases skeletal muscle peak power in older women. Journal of the American Geriatrics Society, v. 50, n. 4, p. 655-662, 2002. ISSN 1532-5415.

FLECK, S. J. Periodized Strength Training: A Critical Review. The Journal of Strength \& Conditioning Research, v. 13, n. 1, p. 82-89, 1999. ISSN 1064-8011.

FRONTERA, W. R.; BIGARD, X. The benefits of strength training in the elderly. Science \& sports, v. 17, n. 3, p. 109-116, 2002. ISSN 0765-1597. 
FRONTERA, W. R. et al. A cross-sectional study of muscle strength and mass in 45-to 78yr-old men and women. Journal of applied physiology, v. 71, n. 2, p. 644-650, 1991. ISSN 8750-7587.

FROST, D. M.; CRONIN, J.; NEWTON, R. U. A biomechanical evaluation of resistance. Sports medicine, v. 40, n. 4, p. 303-326, 2010. ISSN 0112-1642.

GARCIA, M. R., M.; BOREGA, R. O envelhecimento e a saúde. Journal Of Medical Sciences, Campinas, v. 11, n. 3, 2002. ISSN 2318-0897

GARDNER, M. M.; ROBERTSON, M. C.; CAMPBELL, A. J. Exercise in preventing falls and fall related injuries in older people: a review of randomised controlled trials. Br J Sports Med, v. 34, n. 1, p. 7-17, Feb 2000. ISSN 0306-3674 (Print)

0306-3674.

GLENN, J. M.; GRAY, M.; BINNS, A. The effects of loaded and unloaded high-velocity resistance training on functional fitness among community-dwelling older adults. Age Ageing, Jul 11 2015. ISSN 0002-0729.

GRANACHER, U.; GRUBER, M.; GOLLHOFER, A. Resistance training and neuromuscular performance in seniors. Int J Sports Med, v. 30, n. 9, p. 652-7, Sep 2009. ISSN 0172-4622.

GUERRA, R.; AMARAL, T. F. Comparison of hand dynamometers in elderly people. The journal of nutrition, health \& aging, v. 13, n. 10, p. 907-912, 2009. ISSN 1279-7707.

GUIMARÃES, L. et al. Comparação da propensão de quedas entre idosos que praticam atividade física e idosos sedentários. Rev Neurocienc, v. 12, n. 2, p. 68-72, 2004.

HARMAN, E. Resistance Training Modes: A Biomechanical Perspective. Strength \& Conditioning Journal, v. 16, n. 2, p. 59-65, 1994. ISSN 1524-1602. Disponível em: < http://journals.lww.com/nscascj/Fulltext/1994/04000/Resistance_Training_Modes_A_Biomechanical.15.aspx $>$.

HARTMANN, A. et al. Reproducibility of an isokinetic strength-testing protocol of the knee and ankle in older adults. Gerontology, v. 55, n. 3, p. 259-268, 2009. ISSN 1423-0003.

HERMAN, S. et al. Upper and lower limb muscle power relationships in mobility-limited older adults. The Journals of Gerontology Series A: Biological Sciences and Medical Sciences, v. 60, n. 4, p. 476-480, 2005. ISSN 1079-5006.

HOLVIALA, J. H. et al. Effects of strength training on muscle strength characteristics, functional capabilities, and balance in middle-aged and older women. The Journal of Strength \& Conditioning Research, v. 20, n. 2, p. 336-344, 2006. ISSN 1064-8011.

HOSTLER, D. et al. Skeletal muscle adaptations in elastic resistance-trained young men and women. Eur J Appl Physiol, v. 86, n. 2, p. 112-8, Dec 2001. ISSN 1439-6319 (Print) 1439-6319. 
HRUDA, K. V. Training for muscle power in older adults: effects on functional abilities. $\mathrm{n}$. 1066-7814 (Print), 20030626 DCOM- 200307282006.

HUGHES, V. A. et al. Longitudinal Muscle Strength Changes in Older Adults: Influence of Muscle Mass, Physical Activity, and Health. The Journals of Gerontology Series A:

Biological Sciences and Medical Sciences, v. 56, n. 5, p. B209-B217, May 1, 20012001. Disponível em: < http://biomedgerontology.oxfordjournals.org/content/56/5/B209.abstract >.

IKEMOTO, Y. et al. Force-time parameters during explosive isometric grip correlate with muscle power. Sport Sciences for Health, v. 2, n. 2, p. 64-70, 2007/12/01 2007. ISSN 18247490. Disponível em: < http://dx.doi.org/10.1007/s11332-007-0041-3 http://link.springer.com/article/10.1007\%2Fs11332-007-0041-3 >.

IZQUIERDO, M. et al. Maximal strength and power, endurance performance, and serum hormones in middle-aged and elderly men. Med Sci Sports Exerc, v. 33, n. 9, p. 1577-87, Sep 2001. ISSN 0195-9131 (Print)

0195-9131.

JAN, M. H. et al. Investigation of clinical effects of high- and low-resistance training for patients with knee osteoarthritis: a randomized controlled trial. Phys Ther, v. 88, n. 4, p. 42736, Apr 2008. ISSN 0031-9023.

JOZSI, A. et al. Changes in power with resistance training in older and younger men and women. The Journals of Gerontology Series A: Biological Sciences and Medical Sciences, v. 54, n. 11, p. M591-M596, 1999. ISSN 1079-5006.

KALAPOTHARAKOS, V. I. et al. Effects of a heavy and a moderate resistance training on functional performance in older adults. J Strength Cond Res, v. 19, n. 3, p. 652-7, Aug 2005. ISSN 1064-8011 (Print)

1064-8011.

KING, M. B. et al. The performance enhancement project: Improving physical performance in older persons. Archives of Physical Medicine and Rehabilitation, v. 83, n. 8, p. 10601069, 8// 2002. ISSN 0003-9993. Disponível em: < http://www.sciencedirect.com/science/article/pii/S000399930200028X >.

KNIGHT, C. A.; KAMEN, G. Adaptations in muscular activation of the knee extensor muscles with strength training in young and older adults. J Electromyogr Kinesiol, v. 11, n. 6, p. 405-12, Dec 2001. ISSN 1050-6411 (Print) $1050-6411$.

KOWAL, P. et al. Data resource profile: the World Health Organization Study on global AGEing and adult health (SAGE). International journal of epidemiology, v. 41, n. 6, p. 1639-1649, 2012. ISSN 0300-5771. 
KRAEMER, W. J. et al. American College of Sports Medicine position stand. Progression models in resistance training for healthy adults. Med Sci Sports Exerc, v. 34, n. 2, p. 364-80, Feb 2002. ISSN 0195-9131 (Print)

0195-9131.

KRAEMER, W. J. et al. Influence of resistance training volume and periodization on physiological and performance adaptations in collegiate women tennis players. Am J Sports Med, v. 28, n. 5, p. 626-33, Sep-Oct 2000. ISSN 0363-5465 (Print) 0363-5465.

KRAEMER, W. J.; RATAMESS, N. A. Fundamentals of resistance training: progression and exercise prescription. Med Sci Sports Exerc, v. 36, n. 4, p. 674-88, Apr 2004. ISSN 01959131 (Print)

0195-9131.

LANZA, I. R. et al. Effects of age on human muscle torque, velocity, and power in two muscle groups. J Appl Physiol (1985), v. 95, n. 6, p. 2361-9, Dec 2003. ISSN 8750-7587 (Print)

0161-7567.

LARSSON, L.; GRIMBY, G.; KARLSSON, J. Muscle strength and speed of movement in relation to age and muscle morphology. J Appl Physiol Respir Environ Exerc Physiol, v. 46, n. 3, p. 451-6, Mar 1979. ISSN 0161-7567 (Print)

0161-7567.

LATHAM, N. et al. Progressive resistance strength training for physical disability in older people. Cochrane Database Syst Rev, n. 2, p. Cd002759, 2003. ISSN 1361-6137.

LEBRÃO, M. L. O envelhecimento no Brasil: aspectos da transição demográfica e epidemiológica. Saúde Coletiva, v. 4, n. 17, p. 135-40, 2007.

LIU-AMBROSE, T. et al. Resistance and agility training reduce fall risk in women aged 75 to 85 with low bone mass: a 6-month randomized, controlled trial. J Am Geriatr Soc, v. 52, n. 5, p. 657-65, May 2004. ISSN 0002-8614 (Print)

$0002-8614$.

LIU, C.; LATHAM, N. K. Progressive resistance strength training for improving physical function in older adults. Cochrane Database Syst Rev, n. 3, p. Cd002759, 2009.

LUSTOSA, L. P. et al. Tradução e adaptação transcultural do Minnesota Leisure Time Activities Questionnaire em idosos. Geriatria \& Gerontologia, v. 5, n. 2, p. 57-65, 2011.

MACALUSO, A.; DE VITO, G. Muscle strength, power and adaptations to resistance training in older people. Eur J Appl Physiol, v. 91, n. 4, p. 450-72, Apr 2004. ISSN 1439-6319 (Print) 1439-6319. 
MARTINS, W. R. et al. Mechanical evaluation of elastic tubes used in physical therapy. Physiother Theory Pract, v. 30, n. 3, p. 218-22, Apr 2014. ISSN 0959-3985.

MATHIOWETZ, V. et al. Grip and pinch strength: normative data for adults. Arch Phys Med Rehabil, v. 66, n. 2, p. 69-74, 1985. ISSN 0003-9993.

MATSUDO, S. M.; MATSUDO, V. K. R.; BARROS NETO, T. L. Atividade física e envelhecimento: aspectos epidemiológicos. Revista Brasileira de Medicina do Esporte, v. 7, p. 2-13, 2001. ISSN 1517-8692. Disponível em: < http://www.scielo.br/scielo.php?script=sci_arttext\&pid=S1517$\underline{86922001000100002 \& n r m=i s o}>$.

MCLEAN, R. R. et al. Criteria for clinically relevant weakness and low lean mass and their longitudinal association with incident mobility impairment and mortality: the foundation for the National Institutes of Health (FNIH) sarcopenia project. J Gerontol A Biol Sci Med Sci, v. 69, n. 5, p. 576-83, May 2014. ISSN 1079-5006.

MCMASTER, D. T.; CRONIN, J.; MCGUIGAN, M. Forms of Variable Resistance Training. Strength \& Conditioning Journal, v. 31, n. 1, p. 50-64, 2009. ISSN 1524-1602. Disponível em: < http://journals.lww.com/nscascj/Fulltext/2009/02000/Forms_of_Variable_Resistance_Training.10.aspx $>$.

MEROM, D. et al. Prevalence and correlates of participation in fall prevention exercise/physical activity by older adults. Prev Med, v. 55, n. 6, p. 613-7, Dec 2012. ISSN 0091-7435.

MILJKOVIC, N. et al. Aging of skeletal muscle fibers. Ann Rehabil Med, v. 39, n. 2, p. 155-62, Apr 2015. ISSN 2234-0645 (Print)

2234-0645.

MITSIONIS, G. et al. Normative data on hand grip strength in a Greek adult population. International orthopaedics, v. 33, n. 3, p. 713-717, 2009. ISSN 0341-2695.

MOHER, D. et al. CONSORT 2010 Explanation and Elaboration: Updated guidelines for reporting parallel group randomised trials. J Clin Epidemiol, v. 63, n. 8, p. e1-37, Aug 2010. ISSN 0895-4356.

MOTALEBI, S. A.; LOKE, S. C. Efficacy of Progressive Resistance Tube Training in Community Dwelling Older Adults: A Pilot Study. International Journal of Gerontology, v. 8, n. 4, p. 213-218, 12// 2014. ISSN 1873-9598. Disponível em: < http://www.sciencedirect.com/science/article/pii/S1873959814001008 >.

NÓBREGA, A. C. L. D. et al. Posicionamento oficial da Sociedade Brasileira de Medicina do Esporte e da Sociedade Brasileira de Geriatria e Gerontologia: atividade física e saúde no idoso. Revista Brasileira de Medicina do Esporte, v. 5, p. 207-211, 1999. ISSN 1517-8692. Disponível em: < http://www.scielo.br/scielo.php?script=sci_arttext\&pid=S1517$\underline{86921999000600002 \& n r m=i s o}>$. 
ORR, R. et al. Power training improves balance in healthy older adults. The Journals of Gerontology Series A: Biological Sciences and Medical Sciences, v. 61, n. 1, p. 78-85, 2006. ISSN 1079-5006.

PAULUS, D. C.; REISER, R. F., 2ND; TROXELL, W. O. Pneumatic strength assessment device: design and isometric measurement. Biomed Sci Instrum, v. 40, p. 277-82, 2004. ISSN 0067-8856 (Print)

0067-8856.

PENDERGAST, D. R.; FISHER, N. M.; CALKINS, E. 9 Cardiovascular, Neuromuscular, and Metabolic Alterations With Age Leading to Frailty. Journal of Gerontology, v. 48, n. Special Issue, p. 61-67, 1993. ISSN 0022-1422.

PETERSON, M. D. et al. Resistance exercise for muscular strength in older adults: a metaanalysis. Ageing research reviews, v. 9, n. 3, p. 226-237, 2010. ISSN 1568-1637.

PETERSON, M. D.; SEN, A.; GORDON, P. M. Influence of resistance exercise on lean body mass in aging adults: a meta-analysis. Medicine and science in sports and exercise, v. 43, n. 2, p. 249, 2011.

POLLOCK, M. L. et al. ACSM position stand: the recommended quantity and quality of exercise for developing and maintaining cardiorespiratory and muscular fitness, and flexibility in healthy adults. Med Sci Sports Exerc, v. 30, n. 6, p. 975-991, 1998.

PORTER, M. M.; VANDERVOORT, A. A.; LEXELL, J. Aging of human muscle: structure, function and adaptability. Scand J Med Sci Sports, v. 5, n. 3, p. 129-42, Jun 1995. ISSN 0905-7188 (Print)

0905-7188.

POUSSON, M.; LEPERS, R.; VAN HOECKE, J. Changes in isokinetic torque and muscular activity of elbow flexors muscles with age. Experimental gerontology, v. 36, n. 10, p. 16871698, 2001. ISSN 0531-5565.

RAJ, I. S.; BIRD, S. R.; SHIELD, A. J. Aging and the force-velocity relationship of muscles. Exp Gerontol, v. 45, n. 2, p. 81-90, Feb 2010. ISSN 0531-5565.

RANTANEN, T. et al. Association of muscle strength with maximum walking speed in disabled older women. Am J Phys Med Rehabil, v. 77, n. 4, p. 299-305, Jul-Aug 1998. ISSN 0894-9115 (Print)

0894-9115.

REIS, M. M.; ARANTES, P. M. M. Medida da força de preensão manual- validade e confiabilidade do dinamômetro saehan. Fisioterapia e Pesquisa, v. 18, p. 176-181, 2011. ISSN 1809-2950. Disponível em: < http://www.scielo.br/scielo.php?script=sci_arttext\&pid=S1809$\underline{29502011000200013 \& n r m=i s o}>$. 
RHEA, M. R. et al. A meta-analysis to determine the dose response for strength development. Med Sci Sports Exerc, v. 35, n. 3, p. 456-64, Mar 2003. ISSN 0195-9131 (Print)

0195-9131.

RICHENS, B.; CLEATHER, D. J. The relationship between the number of repetitions performed at given intensities is different in endurance and strength trained athletes. Biol Sport, v. 31, n. 2, p. 157-61, Jun 2014. ISSN 0860-021X (Print) 0860-021x.

RIKLI, R. E. Teste de Aptidão Física para Idosos. São Paulo: Manole Biomedicina, 2008. ISBN 978-85-2041-921-2.

RIKLI, R. E.; EDWARDS, D. J. Effects of a three-year exercise program on motor function and cognitive processing speed in older women. Res Q Exerc Sport, v. 62, n. 1, p. 61-7, Mar 1991. ISSN 0270-1367 (Print)

0270-1367.

RIKLI, R. E.; JONES, C. J. Development and validation of a functional fitness test for community-residing older adults. Journal of aging and physical activity, v. 7, p. 129-161, 1999. ISSN 1063-8652.

ROBERTS, H. C. et al. A review of the measurement of grip strength in clinical and epidemiological studies: towards a standardised approach. Age and ageing, p. afr051, 2011. ISSN 0002-0729.

ROLLAND, Y. et al. Sarcopenia: its assessment, etiology, pathogenesis, consequences and future perspectives. J Nutr Health Aging, v. 12, n. 7, p. 433-50, Aug-Sep 2008. ISSN 12797707 (Print) 1279-7707.

ROSENBERG, I. H. Epidemiologic and methodologic problems in determining nutritional status of older persons. Proceedings of a conference. Albuquerque, New Mexico, October 1921, 1988. Am J Clin Nutr, v. 50, n. 5 Suppl, p. 1121-235, Nov 1989. ISSN 0002-9165 (Print) 0002-9165 (Linking). Disponível em: < http://www.ncbi.nlm.nih.gov/pubmed/2816807 >.

Sarcopenia: origins and clinical relevance. Clin Geriatr Med, v. 27, n. 3, p. 337-9, Aug 2011. ISSN 0749-0690.

RUBENSTEIN, L. Z.; JOSEPHSON, K. R. Falls and their prevention in elderly people: what does the evidence show? Med Clin North Am, v. 90, n. 5, p. 807-24, Sep 2006. ISSN 00257125 (Print)

$0025-7125$.

SAKANOUE, N.; KATAYAMA, K. The Resistance Quantity in Knee Extension Movement of Exercise Bands (Thera-Band). Journal of Physical Therapy Science, v. 19, n. 4, p. 287291, 2007. ISSN 0915-5287. 
SAYER, A. A. et al. Falls, sarcopenia, and growth in early life: findings from the Hertfordshire cohort study. Am J Epidemiol, v. 164, n. 7, p. 665-71, Oct 1 2006. ISSN 00029262 (Print)

0002-9262.

SCOTT, D. et al. The epidemiology of sarcopenia in community living older adults: what role does lifestyle play? J Cachexia Sarcopenia Muscle, v. 2, n. 3, p. 125-34, Sep 2011. ISSN 2190-5991 (Print).

SHUMWAY-COOK, A.; HORAK, F. B. Assessing the influence of sensory interaction of balance. Suggestion from the field. Phys Ther, v. 66, n. 10, p. 1548-50, Oct 1986. ISSN 0031-9023 (Print)

0031-9023.

SIQUEIRA, F. V. et al. Prevalência de quedas em idosos e fatores associados. Revista de Saúde Pública, v. 41, p. 749-756, 2007. ISSN 0034-8910. Disponível em: < http://www.scielo.br/scielo.php?script=sci_arttext\&pid=S0034$\underline{89102007000500009 \& n r m=i s o}$ >.

SKELTON, D. A. et al. Strength, power and related functional ability of healthy people aged 65-89 years. Age Ageing, v. 23, n. 5, p. 371-7, Sep 1994. ISSN 0002-0729 (Print) 0002-0729.

SOUSA, N.; SAMPAIO, J. Effects of progressive strength training on the performance of the Functional Reach Test and the Timed Get-Up-and-Go Test in an elderly population from the rural north of Portugal. American Journal of Human Biology, v. 17, n. 6, p. 746-751, 2005. ISSN 1520-6300.

SPIRDUSO, W. W. Dimensões físicas do envelhcimento. Editora Manole Ltda, 2005. ISBN 8520413412.

STEIB, S.; SCHOENE, D.; PFEIFER, K. Dose-response relationship of resistance training in older adults: a meta-analysis. Medicine and science in sports and exercise, v. 42, n. 5, p. 902-914, 2010. ISSN 0195-9131.

STONE, M.; PLISK, S.; COLLINS, D. Training principles: evaluation of modes and methods of resistance training--a coaching perspective. Sports Biomech, v. 1, n. 1, p. 79-103, Jan 2002. ISSN 1476-3141 (Print) $1476-3141$.

STUDENSKI, S. A. et al. The FNIH sarcopenia project: rationale, study description, conference recommendations, and final estimates. J Gerontol A Biol Sci Med Sci, v. 69, n. 5, p. 547-58, May 2014. ISSN 1079-5006.

THERAPISTS, A. S. O. H. Clinical Assessment Recommendations. American Society of Hand Therapists, 1992. Disponível em: <

https://books.google.com.br/books?id=JI_bHAAACAAJ >. 
TORAMAN, A.; YILDIRIM, N. U. The falling risk and physical fitness in older people. Arch Gerontol Geriatr, v. 51, n. 2, p. 222-6, Sep-Oct 2010. ISSN 1872-6976 (Electronic) 0167-4943 (Linking). Disponível em: < http://www.ncbi.nlm.nih.gov/pubmed/19939475 >.

TOSCANO, J. J. D. O.; OLIVEIRA, A. C. C. D. Qualidade de vida em idosos com distintos níveis de atividade física. Revista Brasileira de Medicina do Esporte, v. 15, p. 169-173, 2009. ISSN 1517-8692. Disponível em: < http://www.scielo.br/scielo.php?script=sci_arttext\&pid=S1517$\underline{86922009000300001 \& \text { nrm }=\text { iso }}>$.

VANDERVOORT, A. A.; MCCOMAS, A. J. Contractile changes in opposing muscles of the human ankle joint with aging. J Appl Physiol (1985), v. 61, n. 1, p. 361-7, Jul 1986. ISSN 8750-7587 (Print)

0161-7567.

VERAS, R. P.; RAMOS, L. R.; KALACHE, A. Crescimento da população idosa no Brasil: transformações e consequiências na sociedade. Revista de Saúde Pública, v. 21, p. 225-233, 1987. ISSN 0034-8910. Disponível em: <

http://www.scielo.br/scielo.php?script=sci_arttext\&pid=S0034$\underline{89101987000300007 \& n r m=i s o}$ >.

VIITASALO, J. T. et al. Muscular strength profiles and anthropometry in random samples of men aged 31-35, 51-55 and 71-75 years. Ergonomics, v. 28, n. 11, p. 1563-1574, 1985/11/01 1985. ISSN 0014-0139. Disponível em: < http://dx.doi.org/10.1080/00140138508963288 >. Acesso em: 2015/07/22.

VILLAREAL, D. T. et al. Regular multi-component exercise increases physical fitness and muscle protein anabolism in frail, obese, older adults. Obesity (Silver Spring, Md.), v. 19, n. 2, p. 312-318, 05/20 2011. ISSN 1930-7381. Disponível em: < http://www.ncbi.nlm.nih.gov/pmc/articles/PMC3069710/ >.

VISSER, M. et al. Muscle mass, muscle strength, and muscle fat infiltration as predictors of incident mobility limitations in well-functioning older persons. The Journals of Gerontology Series A: Biological Sciences and Medical Sciences, v. 60, n. 3, p. 324-333, 2005. ISSN 1079-5006.

VON HAEHLING, S.; MORLEY, J. E.; ANKER, S. D. An overview of sarcopenia: facts and numbers on prevalence and clinical impact. J Cachexia Sarcopenia Muscle, v. 1, n. 2, p. 129-133, Dec 2010. ISSN 2190-5991 (Print) 2190-5991.

WHO. Good health adds life to years: Global brief for World Health Day 2012. World Health Organization

2012.

WILSON, J.; KRITZ, M. Practical Guidelines and Considerations for the Use of Elastic Bands in Strength and Conditioning. Strength \& Conditioning Journal, v. 36, n. 5, p. 1-9, 
2014. ISSN 1524-1602. Disponível em: < http://journals.lww.com/nscascj/Fulltext/2014/10000/Practical_Guidelines_and_Considerations_for_the.1.aspx $>$.

XUE, Q. L. et al. Heterogeneity in rate of decline in grip, hip, and knee strength and the risk of all-cause mortality: the Women's Health and Aging Study II. J Am Geriatr Soc, v. 58, n. 11, p. 2076-84, Nov 2010. ISSN 0002-8614.

\section{ANEXOS E APÊNDICES}

\section{APÊNDICE A - QUESTIONÁRIO PARA IDENTIFICAÇÃO INICIAL DOS CRITÉRIOS DE SELEÇÃO DA AMOSTRA}

Nome: Data:

Telefone: Idade:

Código para preenchimento das perguntas: $\mathrm{S}=\operatorname{sim}$ ou $\mathrm{N}=$ Não.

Critérios de inclusão:

O Sr.(a),

( ) Reside no distrito federal? Bairro?

( ) Tem idade igual ou superior a 60 anos?

( ) Tem atestado médico de liberação para exercícios resistidos?

Critérios de exclusão:

O Sr. (a)

( ) Possui algum problema de saúde (doença)?

Qual(s):

( ) Tem hipertensão arterial (>150/90 mmHg)? 
Medicamento em uso:

Algum outro medicamento?

( ) Sofreu infarto do miocárdio nos últimos 6 meses?

( ) Tem marcapasso no coração?

( ) Já fez alguma cirurgia para colocação de prótese?

Local:

( ) Tem fez alguma cirurgia para colocação de placa e/ou parafuso?

Local:

( ) Fez alguma cirurgia nos últimos 6 meses?

Tipo/região:

( ) Sofreu fratura óssea ou lesão muscular nos últimos 6 meses?

Local:

( ) Faz algum tipo de treinamento resistido nos últimos 06 meses?

Qual(s):

( ) Faz uso de terapia hormonal (mulheres apenas)?

( ) Sofreu fratura óssea ou lesão muscular nos últimos 6 meses?

Local:

( ) Faz algum tipo de treinamento resistido nos últimos 06 meses?

Qual(s):

( ) Faz uso de terapia hormonal (mulheres apenas)? 


\section{APÊNDICE B - TCLE}

\section{TERMO DE CONSENTIMENTO LIVRE E ESCLARECIDO}

Caro participante, você está sendo convidado a participar voluntariamente de uma pesquisa na Universidade de Brasília intitulada de "Efeitos do treinamento com resistência elástica progressiva na força, massa muscular e desempenho funcional de idosos sedentários".

Por favor, leia com atenção as informações contidas neste termo antes de tomar qualquer decisão sobre sua participação como voluntário. Todos os esclarecimentos que julgar necessário antes e durante a pesquisa poderão ser feitos diretamente para o pesquisador responsável. A sua participação é voluntária e você terá plena e total liberdade para desistir do estudo a qualquer momento, sem que isso acarrete em qualquer prejuízo para você. Da mesma forma, você terá direito de recusar a responder questões que lhe tragam constrangimentos. Todas as informações relacionadas a pesquisa são confidenciais e qualquer informação divulgada em relatório ou publicação será feita sob forma codificada, para que seu sigilo seja mantido. Os pesquisadores garantem que seu nome não será divulgado sob hipótese alguma em qualquer publicação.

O objetivo desta pesquisa é verificar se exercícios com dispositivos de resistência elástica podem aumentar a força e massa muscular em idosos sedentários. Espera-se que os exercícios elásticos possam aumentar a força e massa muscular dos membros superiores, inferiores e coluna de idosos, como ocorre nos exercícios com máquinas de musculação. Para prevenir possíveis dores musculares decorrente do início do treinamento, todos os 
voluntários realizarão 02 (duas) semanas de exercícios leves, em um período chamado de familiarização, com total de 04 dias de exercícios.

Em relação aos procedimentos da pesquisa, caso você não tenha um atestado médico próprio para a prática de exercícios resistidos, você deverá passar por uma consulta médica para avaliar sua saúde hoje e no passado. Caso seja necessário, podemos indicar um médico para tal avaliação, o qual poderá de acordo com a necessidade recomendar exames complementares para o coração com intuito de atestar sua aptidão física para participar de exercícios. No entanto, se for do seu interesse, essa avaliação poderá ser feita com seu cardiologista particular, que deverá Ihe fornecer um atestado médico. A próxima etapa da pesquisa envolve a realização de 03 (três) testes: (1ํ) avaliação do nível de atividade física, (2) avaliação da força muscular dos membros e coluna e (3ํ) avaliação da composição corporal. Essa etapa poderá durar de 01 (um) a 02 (dois) dias. Com o término dessa etapa de avaliação tem início a fase de exercícios com o chamado período de familiarização, que consistirá de duas semanas de exercícios leves. Depois dessas 02 (duas) semanas, você realizará mais 48 (quarenta e oito) semanas de exercícios com nível de esforço progressivo. A fase de exercícios será realizada sempre as segundas e quartas feiras, ou terças e quintas, no período matutino. A avaliação da força muscular dos membros e a avaliação da composição corporal serão novamente repetidas na 12a , 24ạ , 36a e $48 \underline{a}$ semana de exercícios. É importante ressaltar que os voluntários precisam ter no mínimo 75\% (setenta e cinco por cento) de presença para um resultado significativo. Considerando o total de 96 (noventa e seis) dias de exercícios (48 semanas efetivas após familiarização), você necessitará comparecer no mínimo em 72 (setenta e duas) sessões de exercício, podendo assim ter no máximo 24 (vinte e quatro) faltas. Toda a pesquisa será realizada na Faculdade de Educação Física da Universidade de Brasília, localizada no Campus Universitário Darcy Ribeiro, Brasília, DF - CEP 70910-900.

Os resultados do presente estudo serão divulgados em eventos e revistas científicas nacionais ou internacionais Esse termo de consentimento encontra-se redigido em duas vias, sendo uma para o participante e outra para o pesquisador.

Em caso de dúvidas utilize os contatos abaixo: 
- Contatos do pesquisador responsável: (62) 9242-8111 (comercial). Email: gersonjunior1984@hotmail.com

- Contatos do Comitê de Ética em Pesquisa da Faculdade de Ciências da Saúde da Universidade de Brasília: (61) 3107-1947. Email: cepfs@unb.br

Diante do exposto acima eu, declaro que li e discuti com o pesquisador responsável pelo presente estudo os detalhes descritos neste documento e fui esclarecido(a) sobre os objetivos e procedimentos do presente estudo. Participo de livre e espontânea vontade do estudo em questão. Foi-me assegurado o direito de abandonar o estudo a qualquer momento, se eu assim o desejar. Eu entendi as informações apresentadas neste termo de consentimento e recebi uma cópia assinada e datada deste documento de consentimento informado.

Brasília, de de 
ANEXO A - PARECER DO COMITÊ DE ÉTICA 


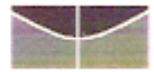

Universidade de Brasilia

Faculdade de Ciências da Saúde

Comitê de Fitica em Pesquisa - CIP/FS

\section{PROCESSO DE ANÁLISE DE PROJETO DE PESQUISA}

Repistro do Projeto no CEP: 081/11

Titulo do Projcto: "Efeitos do treinamento resistido com máquinas de peso versus

dispositivos elasticos sobre a força muscular de idosos".

I'esquisadora Responsável: Wagner Rodrigues Martins

1)ata de Fntrada: 10/05/11

Com hase na Resoluçăo 196/96. do CNS/MS. que regulamenta a ćlica cm pespuisa com seres humanos, o Comitê de Ética em Pesquisa com Seres llumanos da Faculdade de ('iências da Saúde da Universidade de Brasilia. após análise dos aspectos éticos e do contexto técnico-cientilico, resolveu APROVAR o projeto 081/11 com o título: "Efeitos do treinamento resistido com máquinas de peso versus dispositives clásticos sobre a força muscular de idosos". analisado na $1^{3}$ reuniào extraordinária realizadia no dia 28 de junho de 2011

O pesquisador responsável fica. desde já, notificado da obrigatoriedade da apresentação de um relatório semestral e relatório final sucinto e objetivo subre o tesenvolvimento do Projeto, no prazo de 1 (um) ano a contar da presente data (item VII.13 da Resolução 196/96).

ANEXO B - Questionário adaptado utilizado para medidas de atividade física a partir da versão Brasileira do Minessota Leisure Time Activity Questionaire. 


\section{Bloco 1 - Itens referentes à prática de exercícios físicos e esportes ativos}

Agora eu vou lhe dizer os nomes de várias atividades físicas que as pessoas realizam por prazer, para se exercitarem, para se divertirem, porque fazem bem para a saúde ou porque precisam.

$\rightarrow$ Em primeiro lugar eu vou perguntar sobre caminhadas, ciclismo, dança, exercícios físicos, atividades feitas na água e esportes. Gostaria de saber quais dessas atividades o/a senhor/a vem praticando nos últimos 12 meses.

\begin{tabular}{|c|c|c|c|c|}
\hline Perguntar para homens e mulheres: & Resposta & $\begin{array}{l}\text { Quantos } \\
\text { meses no } \\
\text { ano? }\end{array}$ & $\begin{array}{l}\text { Quantos } \\
\text { dias na } \\
\text { semana? }\end{array}$ & $\begin{array}{l}\text { Quanto } \\
\text { minutos } \\
\text { por dia? }\end{array}$ \\
\hline $\begin{array}{l}\text { 3. Faz caminhadas sem esforço, de maneira } \\
\text { confortável, em parques, jardins, praças e ruas, na } \\
\text { praia ou à beira-rio, para passear ou para se exercitar } \\
\text { porque é bom para a saúde? }\end{array}$ & $\begin{array}{l}\text { 1.Sim } \\
\text { 2.Não } \\
\text { 99.NR }\end{array}$ & & & \\
\hline $\begin{array}{l}\text { 4. Sobe escadas porque quer, mesmo podendo tomar } \\
\text { o elevador (pelo menos um lance ou andar)? }\end{array}$ & $\begin{array}{l}\text { 1.Sim } \\
\text { 2.Não } \\
\text { 99.NR }\end{array}$ & & & \\
\hline $\begin{array}{l}\text { 5. Pratica ciclismo por prazer ou vai trabalhar de } \\
\text { bicicleta? }\end{array}$ & $\begin{array}{l}\text { 1.Sim } \\
\text { 2.Não } \\
\text { 99.NR }\end{array}$ & & & \\
\hline 6. Faz dança de salão? & $\begin{array}{l}\text { 1.Sim } \\
\text { 2.Não } \\
\text { 99.NR }\end{array}$ & & & \\
\hline $\begin{array}{l}\text { 7. Faz ginástica, alongamento, yoga, tai-chi-chuan ou } \\
\text { outra atividade desse tipo, dentro da sua casa? }\end{array}$ & $\begin{array}{l}\text { 1.Sim } \\
\text { 2.Não } \\
\text { 99.NR }\end{array}$ & & & \\
\hline $\begin{array}{l}\text { 8. Faz ginástica, alongamento, yoga, tai-chi-chuan ou } \\
\text { outra atividade desse tipo, numa academia, num } \\
\text { clube, centro de convivência ou SESC? }\end{array}$ & $\begin{array}{l}\text { 1.Sim } \\
\text { 2.Não } \\
\text { 99.NR }\end{array}$ & & & \\
\hline $\begin{array}{l}\text { 9. Faz hidroginástica na academia, num clube, centro } \\
\text { de convivência ou SESC? }\end{array}$ & $\begin{array}{l}\text { 1.Sim } \\
\text { 2.Não } \\
\text { 99.NR }\end{array}$ & & & \\
\hline 10. Pratica corrida leve ou caminhada mais vigorosa? & $\begin{array}{l}\text { 1.Sim } \\
\text { 2.Não } \\
\text { 99.NR }\end{array}$ & & & \\
\hline $\begin{array}{l}\text { 11. Pratica corrida vigorosa e contínua por períodos } \\
\text { mais longos, pelo menos } 10 \text { minutos de cada vez? }\end{array}$ & $\begin{array}{l}\text { 1.Sim } \\
\text { 2.Não } \\
\text { 99.NR }\end{array}$ & & & \\
\hline 12. Faz musculação? (não importa o tipo). & $\begin{array}{l}\text { 1.Sim } \\
\text { 2.Não } \\
\text { 99.NR }\end{array}$ & & & \\
\hline $\begin{array}{l}\text { 13. Pratica natação em piscinas grandes, dessas } \\
\text { localizadas em clubes ou academias? }\end{array}$ & $\begin{array}{l}\text { 1.Sim } \\
\text { 2.Não } \\
\text { 99.NR }\end{array}$ & & & \\
\hline $\begin{array}{l}\text { 14. Pratica natação em praia ou lago, indo até o } \\
\text { fundo, até um lugar onde não dá pé? }\end{array}$ & $\begin{array}{l}\text { 1.Sim } \\
\text { 2.Não }\end{array}$ & & & \\
\hline
\end{tabular}




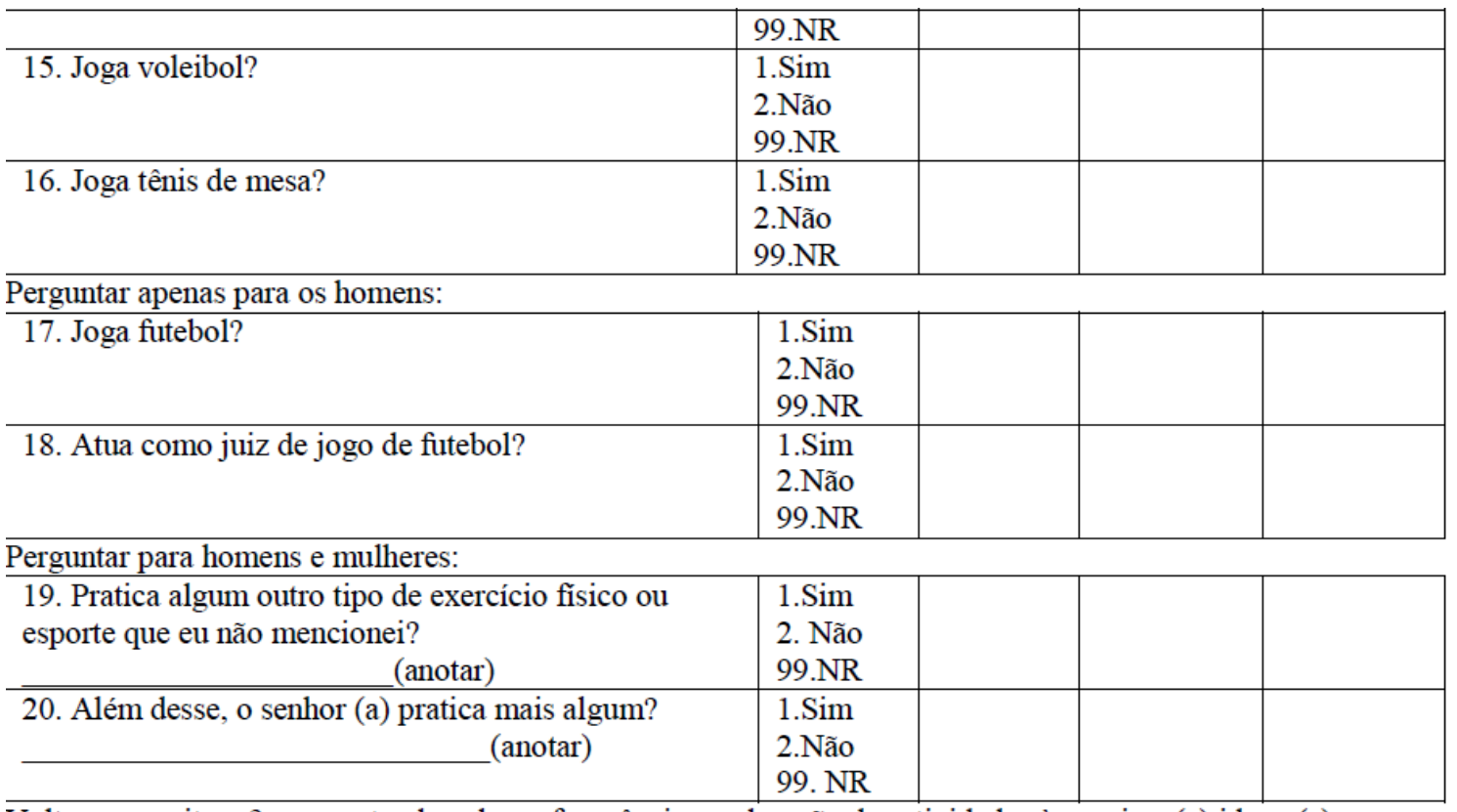

Voltar para o item 3, perguntando sobre a frequência e a duração das atividades às quais o (a) idoso (a) respondeu sim.

\section{Bloco 2- Itens referentes a tarefas domésticas}

Agora eu vou lhe perguntar sobre atividades domésticas que o senhor vem praticando nos últimos 12 meses. O (a) senhor(a) vai respondendo somente sim ou não.

\begin{tabular}{|c|c|c|c|c|}
\hline Perguntar para homens e mulheres: & Resposta & $\begin{array}{l}\text { Quantos } \\
\text { meses no } \\
\text { ano? }\end{array}$ & $\begin{array}{l}\text { Quantos } \\
\text { dias na } \\
\text { semana? }\end{array}$ & $\begin{array}{l}\text { Quanto } \\
\text { tempo por } \\
\text { dia? }\end{array}$ \\
\hline $\begin{array}{l}\text { 21. Realiza trabalhos domésticos leves? (tais como } \\
\text { tirar o pó, lavar a louça, varrer, passar aspirador, } \\
\text { consertar roupas)? }\end{array}$ & $\begin{array}{l}\text { 1.Sim } \\
\text { 2.Não } \\
\text { 99.NR }\end{array}$ & & & \\
\hline $\begin{array}{l}\text { 22. Realiza trabalhos domésticos pesados? (tais como } \\
\text { lavar e esfregar pisos e janelas, fazer faxina pesada, } \\
\text { carregar sacos de lixo)? }\end{array}$ & $\begin{array}{l}\text { 1.Sim } \\
\text { 2.Não } \\
\text { 99.NR }\end{array}$ & & & \\
\hline 23. Cozinha ou ajuda no preparo da comida? & $\begin{array}{l}\text { 1.Sim } \\
\text { 2.Não } \\
\text { 99.NR }\end{array}$ & & & \\
\hline 24. Corta grama com cortador elétrico? & $\begin{array}{l}\text { 1.Sim } \\
\text { 2.Não } \\
\text { 99.NR }\end{array}$ & & & \\
\hline 25. Corta grama com cortador manual? & $\begin{array}{l}\text { 1.Sim } \\
\text { 2.Não } \\
\text { 99.NR }\end{array}$ & & & \\
\hline $\begin{array}{l}\text { 26. Tira o mato e mantém um jardim ou uma horta } \\
\text { que já estavam formados? }\end{array}$ & $\begin{array}{l}\text { 1.Sim } \\
\text { 2.Não } \\
\text { 99.NR }\end{array}$ & & & \\
\hline $\begin{array}{l}\text { 27. Capina, afofa a terra, aduba, cava, planta ou } \\
\text { semeia para formar um jardim ou uma horta? }\end{array}$ & $\begin{array}{l}\text { 1.Sim } \\
\text { 2.Não } \\
\text { 99.NR }\end{array}$ & & & \\
\hline $\begin{array}{l}\text { 28. Constrói ou conserta móveis ou outros utensílios } \\
\text { domésticos, dentro de sua casa, usando martelo, serra } \\
\text { e outras ferramentas? }\end{array}$ & $\begin{array}{l}\text { 1.Sim } \\
\text { 2.Não } \\
\text { 99.NR }\end{array}$ & & & \\
\hline 29. Pinta a casa por dentro, faz ou conserta & 1.Sim & & & \\
\hline
\end{tabular}




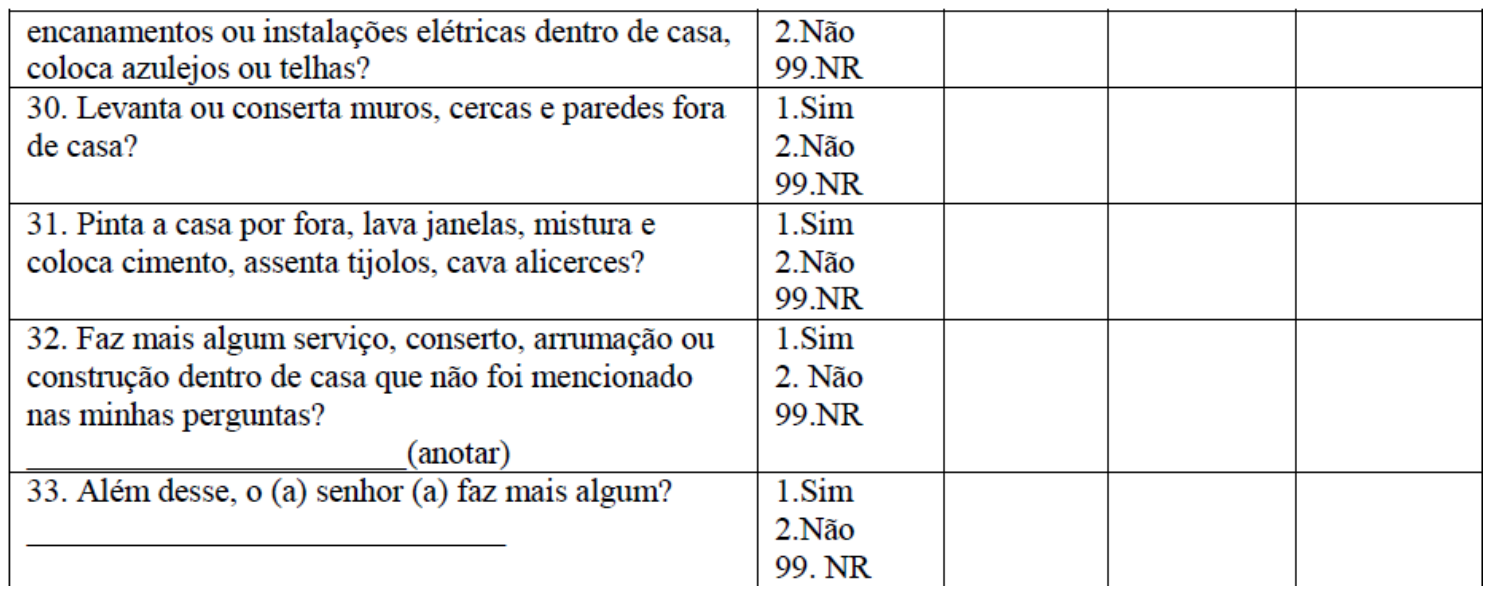

